\title{
Ag-Based Catalysts in Heterogeneous Selective Oxidation of Alcohols: A Review
}

\author{
Viktoriia V. Torbina ${ }^{1}$, Andrei A. Vodyankin ${ }^{1}$, Sergey Ten ${ }^{1}$, Grigory V. Mamontov ${ }^{1}$, \\ Mikhail A. Salaev ${ }^{1}$, Vladimir I. Sobolev ${ }^{2}$ and Olga V. Vodyankina ${ }^{1, *}$ \\ 1 Laboratory of catalytic research, Tomsk State University, 36, Lenin Ave., Tomsk 634050, Russia; \\ ms.itory@mail.ru (V.V.T.); orzie@mail.ru (A.A.V.); rip_richard@mail.ru (S.T.); \\ grigoriymamontov@mail.ru (G.V.M.); mihan555@yandex.ru (M.A.S.) \\ 2 Boreskov Institute of Catalysis, Russian Academy of Sciences, Pr. Akademika Lavrentieva, 5, \\ Novosibirsk 630090, Russia; visobo@catalysis.ru \\ * Correspondence: vodyankina_o@mail.ru; Tel.: +7-905-990-44-53
}

Received: 16 September 2018; Accepted: 8 October 2018; Published: 11 October 2018

check for updates

\begin{abstract}
Alcohols (bioalcohols) is a class of chemicals that are used as a feedstock for the manufacturing of a large number of valuable intermediates in industrially important processes. Currently, sustainable technologies for selective conversion of alcohols utilize "green" oxidants, mainly, ambient air or oxygen. Due to the high affinity of oxygen towards silver, the latter serves as an active component of supported heterogeneous catalysts. In this review, we consider Ag-based catalysts that participate in gas- or liquid-phase oxidation of alcohols. Oxidation of methanol, ethanol, ethylene glycol, propylene glycol, glycerol, benzyl and allyl alcohols is mostly considered. A particular attention is paid to selective photooxidation of alcohols over Ag-based catalysts. We discuss the catalyst composition in terms of (1) the state of the active component, (2) the nature of the substrate, (3) support nature, and (4) the strength of the metal-support interactions.
\end{abstract}

Keywords: heterogeneous catalysis; selective oxidation of alcohols; mono- and polyalcohols; silver catalyst; Ag nanoparticles; gas-phase and liquid-phase oxidation of alcohols; photooxidation

\section{Introduction}

Mono- and polyalcohols (including such important bioalcohols as ethanol, glycerol, etc.) are important platform molecules for industrial manufacturing of a large number of value-added products, including but not limited to aldehydes, ketones, ethers, molecular hydrogen, etc. Catalytic oxidation with ambient oxygen or "green" oxidants $\left(\mathrm{H}_{2} \mathrm{O}_{2}\right.$, tert-butyl hydroperoxide) through gas- or liquid-phase processes is considered the most promising, sustainable and economically feasible way to convert the alcohols. For the last 10 years, a stable interest in alcohol oxidation is observed (Figure 1).

Many effective catalytic composites were proposed for selective oxidation of alcohols [1-4], including those based on individual noble metals ( $\mathrm{Au}$ [5-7], Pd [7], Pt [8], Ru [9], Cu [9], Ir [9], etc.) and bimetallic compositions (e.g., [7]). The nature of the support, a concentration of surface functional groups, the distribution of the active component along the support surface, the presence of impurities, thermal conductivity and stability, physical-mechanical properties, etc. are considered important challenges in developing a new generation of highly effective catalysts for alcohol oxidation.

Silver-based catalysts bring about a special interest [10-14] due to a number of valuable features of the metal. These include its ability to activate molecular oxygen, homogeneous distribution of metal particles/clusters over various supports [e.g., $\mathrm{SiO}_{2}, \mathrm{CeO}_{2}, \mathrm{Mn}_{\mathrm{x}} \mathrm{O}_{\mathrm{y}}, \mathrm{Si}_{3} \mathrm{~N}_{4}, \mathrm{TiO}_{2}$, etc.] and a synergistic action with a large number of promoters and modifiers (noble metals, transition metal oxides, halogen-containing compounds, $\mathrm{P}_{2} \mathrm{O}_{5}$, etc.). These features became a ground for the application 
of the Ag-based catalysts in the industrial gas-phase oxidation of methanol to formaldehyde and ethylene glycol to glyoxal.

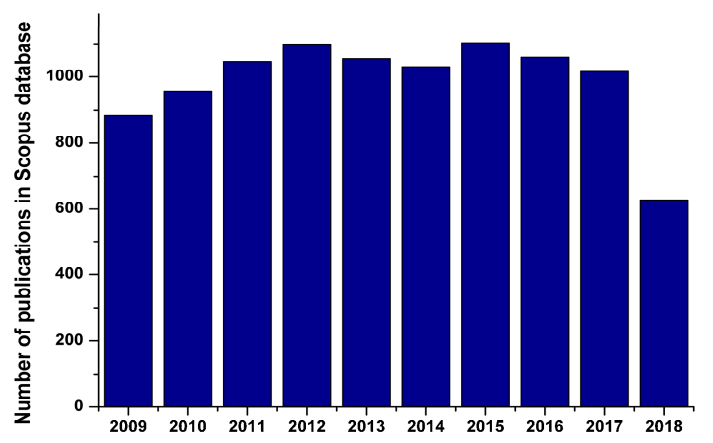

Figure 1. The number of publications in Scopus database (keywords "alcohol oxidation", as of September 2018).

In this review, we survey a current state of the Ag-based heterogeneous catalysts for gas- and liquid-phase heterogeneous selective oxidation of alcohols. The processes are discussed in terms of (1) catalyst composition, including the state of the active component, (2) nature of the substrate, (3) support nature, and (4) strength of the metal-support interactions.

\section{Heterogeneous Gas-Phase Selective Oxidation}

In this chapter, we elucidate the reactions of heterogeneous gas-phase selective oxidation of alcohols. The catalysts and reactions of monoalcohols (methanol, ethanol, benzyl alcohol (BA)), polyols (ethylene glycol (EG), propylene glycol (PG), glycerol (GLY)), and unsaturated alcohols (allylic alcohol) are considered. The gas-phase oxidation of alcohols is usually realized in a wide temperature range (from $150{ }^{\circ} \mathrm{C}$ for ethanol and other $\mathrm{C}_{2+}$ monoatomic alcohols to up to $550-650{ }^{\circ} \mathrm{C}$ for methanol and EG). Water is usually used to prepare the alcohol-water mixtures (especially for EG and GLY) and lightens the evaporation of the alcohol. In a number of cases, high catalyst selectivity is achieved by applying the dilution of the reaction mixture with inert gas (usually, nitrogen).

\subsection{Monoalcohols}

\subsubsection{Methanol}

Methanol is known as an intermediate in the production of a number of value-added products, including, but not limited to formaldehyde [10], methyl formate (MF) [15], hydrogen [16,17], etc. Gas-phase methanol oxidation is one of the most important industrial processes to manufacture formaldehyde, and is carried out over polycrystalline or supported Ag [18] (under alcohol-rich conditions and adiabatic mode) or Fe-Mo-O $[19,20]$ (under alcohol-lean conditions) catalysts. For Ag-based catalysts, the process is carried out over bulk $\left(550-600{ }^{\circ} \mathrm{C}\right)$ and supported $\left(650-700{ }^{\circ} \mathrm{C}\right)$ materials in adiabatic mode at alcohol/oxygen molar ratio of $0.35-0.42$. For supported catalyst up to $30 \%$ of water is added to prepare an initial methanol solution. An incomplete methanol conversion occurs. The selectivity $(85-90 \%)$ is usually higher for polycrystalline catalysts than for supported materials. In comparison with Fe-Mo oxide catalysts, the Ag catalyst productivity is higher, while contact times are lower. Despite thorough investigation of the process mechanism [21-25], surface chemistry $[26,27]$ as well as the process modeling [28,29], the selective methanol oxidation over Ag-based catalysts still attracts a vivid research interest. Table 1 summarizes the most recent experimental findings.

In case selective oxidation of methanol to formaldehyde, the researchers explore the opportunities to develop new catalytic systems utilizing those supports that are not traditionally used in the process. Thus, Aouat et al. proposed a hybrid catalyst representing thermally activated Congo-red 
(CR) nanoparticles (NPs) entrapped within Ag deposited on titania nanofibers (nf) [30] (Table 1). $\mathrm{TiO}_{2}$ nanofibers were shown to boost the catalyst performance in comparison with unsupported CR@Ag powder and supported undoped $\mathrm{Ag} / \mathrm{TiO}_{2}$-nf catalysts. This was assumed to be caused by structural-morphological benefits provided by titania. The same group showed earlier [31] that the role of organic dopant molecules in such systems is to prevent the formation of large aggregates, which result in a higher specific surface and porous morphology. The CR residues are located within the silver agglomerates and serve as a barrier for Ag sintering.

Halperin et al. tested the uniform Ag fiber mats and composite $\mathrm{Ag} / \mathrm{C}$ fibers synthesized by electrospinning in the selective oxidation of methanol to formaldehyde [32] (Table 1). The results obtained show better catalyst performance for the $\mathrm{Ag} / \mathrm{C}$ composite fibers as compared to $\mathrm{Ag}$ fibers and powder analogues. The carbon near the silver grains was assumed to participate in the process under consideration via the "adsorb and shuttle" of "spillover" mechanisms.

Sobczak and Dembowiak used mesostructured cellular foams (MCF) and NbMCF as supports for Au-Ag bimetallic catalysts [33] (Table 1). The samples were prepared by loading of the metals $(\mathrm{Au} / \mathrm{Ag}$ atomic ratios were 0.5 and 2$)$ on 3-aminopropyl-trimethoxysilane grafted supports followed by reduction by $\mathrm{NaBH}_{4}$ prior to calcination at $773 \mathrm{~K}$. An Au-Ag alloy was shown to form on the surface of AuAg-MCF and AuAg-NbMCF samples. The pretreatment conditions determined the composition of the Au-Ag alloy that was enriched in silver partially by treatment with Ar flow and substantially by a reduction in $\mathrm{H}_{2}$ flow as well as the alloy particle size. The presence of $\mathrm{Au}-\mathrm{Ag}$ alloy on the MCF surface caused a synergistic effect between metal species and was responsible for high activity of the catalysts. $\mathrm{Nb}$ species in the MCF support were assumed to influence on both the catalytic activity and the selectivity towards formaldehyde.

Wisniewska et al. [34] used MCF, NbMCF and TaMCF as supports for Ag and/or Pt catalysts. The bimetallic catalysts were prepared by grafting of metal species on the supports functionalized with APTMS and MPTMS, and the functionalizing agents influenced significantly on the dispersion of metals, the nature of the bimetallic species formed and the strength of $\mathrm{Nb} / \mathrm{Ta}$ interaction with $\mathrm{Pt} / \mathrm{Ag}$. The promoting effects of $\mathrm{Nb}$ and Ta were connected with the changing of the oxidation state of silver due to silver- $\mathrm{Nb} / \mathrm{Ta}$ interaction. This determined the observed catalytic activity. Wisniewska and Ziolek pointed out that MCFs help to preserve the Pt-Ag alloy (and the active phases formed) after activation under argon [35]. For bimetallic samples, the partial segregation of $\mathrm{Ag}$ and $\mathrm{Pt}$ in the alloy occurred.

The most recent theoretical findings show [36] that under process relevant conditions, oxygen on the silver surface is present in low concentrations, while playing an important role by promoting the activation of $\mathrm{OH}$ bond in methanol, which results in methoxy species further yielding formaldehyde. Earlier work [37] showed that surface oxygen may promote the formaldehyde destruction through the formation of $\mathrm{CH}_{2} \mathrm{O}_{2}$ further decomposing to $\mathrm{CHO}_{2}$ and then to carbon dioxide and hydrogen. Montoya and Haynes [38] found that a subsurface oxygen stabilizes the adsorbed phases by increasing the binding energy of $\mathrm{Ag}(111)$ and has less dramatic impact on the scission of $\mathrm{O}-\mathrm{H}$ and $\mathrm{C}-\mathrm{H}$ bonds as compared to surface-bound oxygen species.

Shirman et al. prepared bimetallic Ag-Au NPs with controlled bimetallic nanoparticle size and composition as well as well-defined structural hierarchy embedded in a porous silica matrix $\left(\mathrm{SiO}_{2}-\mathrm{Ag}_{\mathrm{x}} \mathrm{Au}_{\mathrm{y}}\right)$ [39]. The composites were synthesized by a decoration of polymeric colloids with the bimetallic NPs followed by an assembly into a colloidal crystal backfilled with the matrix precursor and a subsequent removal of the polymeric template. The performance of these catalysts in selective oxidation of both methanol and ethanol to esters was superior to nanoporous dilute $\mathrm{Ag}_{3} \mathrm{Au}_{97}$ alloy catalysts. The proposed approach was assumed to provide the fine control over the composition, morphology, size, distribution, and availability of the supported NPs. 
Table 1. Catalysts for selective oxidation of methanol.

\begin{tabular}{|c|c|c|c|c|c|c|c|c|}
\hline Catalyst Composition & Product & Reaction Conditions & $\mathrm{S}, \%$ & $x, \%$ & Ag, \%wt. & $\mathrm{S}_{\mathrm{BET}}, \mathrm{m}^{2} / \mathrm{g}$ & Mean Particle Size, nm & Ref. \\
\hline $\begin{array}{l}\text { CR@Ag/TiO }{ }_{2} \text {-nf (thermally } \\
\text { activated Congo-red (CR) } \\
\text { entrapped within silver } \\
\text { deposited on } \mathrm{TiO}_{2} \text { nanofibers) }\end{array}$ & \multirow[t]{2}{*}{ formaldehyde } & \multirow{2}{*}{$\begin{array}{c}550-200{ }^{\circ} \mathrm{C}, \text {, "methanol ballast process", } \\
\text { WHSV }=140-335 \text { gmeth }^{*} \mathrm{gAg}^{-1 *} \mathrm{~h}^{-1}, \text { methanol } \\
\text { volume concentration }=0.5 \mathrm{~g} / \mathrm{L}\end{array}$} & $65\left(550^{\circ} \mathrm{C}\right)$ & $94\left(550^{\circ} \mathrm{C}\right)$ & - & - & $\begin{array}{l}\text { Ag: Initial: } 9.4 \text {; after } \\
\text { oxidation: } 44.9\end{array}$ & \multirow[t]{2}{*}[30]{} \\
\hline $\mathrm{Ag} / \mathrm{TiO}_{2}-\mathrm{nf}$ & & & $60\left(550^{\circ} \mathrm{C}\right)$ & $74\left(550^{\circ} \mathrm{C}\right)$ & - & - & $\begin{array}{l}\text { Initial: } 5.2 ; \text { after } \\
\text { oxidation: } 58.8\end{array}$ & \\
\hline Metallic Ag fibers & \multirow{2}{*}{ formaldehyde } & \multirow{2}{*}{$\begin{array}{c}\text { temperature range: } 550 \text { to } 150{ }^{\circ} \mathrm{C} \text {, methanol ballast } \\
\text { process, weight of } \mathrm{Ag} \text { fiber mats }=45-70 \mathrm{~g}, \mathrm{CH}_{3} \mathrm{OH} \\
\text { concentration }=500 \mathrm{mg} / \mathrm{L} \text {, total pressure }=1.5 \mathrm{bar} \text {, } \\
\text { feed gas mixture flow rate }=8.35 \mathrm{~L} / \mathrm{h}, \\
\text { WHSV in the range of } 60-90 \mathrm{~h}^{-1},\end{array}$} & 82.4 & 94.2 & 100 & - & $\begin{array}{l}\text { Uniform mats, containing } \\
\text { fibres with } 300-600 \mathrm{~nm}\end{array}$ & \multirow{2}{*}{ [32] } \\
\hline $\mathrm{Ag} / \mathrm{C}$ & & & 84.1 & 95.8 & $\begin{array}{l}70 \text { in the "green" } \\
\text { Electrospun } \\
\text { fibers }\end{array}$ & - & $\sim 50$ & \\
\hline $\mathrm{AuAg}(0.5)-\mathrm{NbMCF}$ & formaldehyde & $\begin{array}{l}0.02 \mathrm{~g} \text { of the catalyst of the size diameter of } \\
0.5<\mathrm{d}<1 \mathrm{~mm} \\
\text { Supply rate of } 40 \mathrm{~cm}^{3} \mathrm{~min}^{-1}\end{array}$ & 99 & 42 & 0.5 & 393 & 6.7 & [33] \\
\hline
\end{tabular}


Thus, despite a long history of the development of new generations of the Ag-based catalysts for selective oxidation of methanol to formaldehyde, the studies are in progress. The main reasons for the increased attention of the researchers are connected with the process realization at elevated temperatures that causes a number of serious challenges (e.g., catalyst deactivation due to sintering, the loss of active component, etc.). Recent trends are connected with (1) the transition to the hierarchical porous composite fibrous materials having high hydrodynamic permeability [34], (2) the use of the nanosized Ag particles fixed on the surface of MCFs modified by $\mathrm{Nb}$ or $\mathrm{Ta}$ [31]. In the latter case the effect of methanol interaction with the reduced sites of $\mathrm{Nb}$ having their own activity is also discussed.

It is noteworthy that a significant reduction of the process temperature for Ag catalysts without the addition of the second metal (e.g., $\mathrm{Pt}$ ) was not yet achieved, which is connected with a weak adsorption of methanol over the silver surface and difficulties in the $\mathrm{C}-\mathrm{H}$ bond cleavage in the methanol molecule as compared to other alcohols. Addition of Pt into the composition of PtAg/NbMCF-M catalyst provided the highest selectivity towards formaldehyde (53\%) at $85 \%$ methanol conversion $\left(200{ }^{\circ} \mathrm{C}\right)$, i.e., the impact of total oxidation of alcohol is high [31,32].

The use of $\mathrm{Au}-\mathrm{Ag}$ alloy as NPs supported on the MCF with and without addition of $\mathrm{Nb}$ under mild conditions changes the direction of methanol transformation towards formation of methyl formate. At an $\mathrm{Au} / \mathrm{Ag}$ ratio of 2 in the presence of $\mathrm{NbMCF}$, formaldehyde is formed with a $48 \%$ selectivity at $250{ }^{\circ} \mathrm{C}$. However, the selectivity towards $\mathrm{CO}_{2}$ is also high (45\%) [35]. The role of $\mathrm{Nb}$ lies in the significant changing of the selectivity towards formaldehyde that opens wide prospects for further development of such materials.

\subsubsection{Ethanol}

A catalytic conversion of ethanol is of high importance for the synthesis of acetaldehyde [40], butadiene [41,42], acetone [43] and other compounds. A growing interest in ethanol conversion is mainly attributed to the application of bioethanol, which is a cheap raw compound for organic synthesis [44]. The application of different catalysts is widely discussed in the literature for ethanol oxidation: $\mathrm{Ag}$ and $\mathrm{Au}$ supported on ceria [45,46], $\mathrm{Au}-\mathrm{Ir}$ catalysts [47], vanadium oxides [48], etc. The main challenge is connected with the controlling of the activity at relatively low temperatures with maintaining of the selectivity towards the desired products. Among the catalytic compositions, the catalysts based on group 11 metals deserve special attention due to a high selectivity in the oxidation of alcohols into carbonyls.

Thus, Silbaugh et al. [49] carried out a comparison of $\mathrm{Ag}, \mathrm{Cu}$ and $\mathrm{Au}$ supported on $\mathrm{Li}_{2} \mathrm{O} / \gamma-\mathrm{Al}_{2} \mathrm{O}_{3}$ in ethanol oxidation. Ethanol dehydration into diethyl ether was found to take place over the $\gamma-\mathrm{Al}_{2} \mathrm{O}_{3}$ support. The formation of acetaldehyde $(\mathrm{S} \approx 85 \%)$ and diethyl ether and ethyl acetate $(\mathrm{S} \approx 10 \%)$ occurred over the $\mathrm{Li}_{2} \mathrm{O} / \gamma-\mathrm{Al}_{2} \mathrm{O}_{3}$ support with the ethanol conversion of $45 \%$ at $400{ }^{\circ} \mathrm{C}$. This indicated a surface coverage of alumina support by $\mathrm{Li}_{2} \mathrm{O}$ accompanied by the blocking of strong acid sites. The highest activity in ethanol oxidation was achieved over the $\mathrm{Ag}-\mathrm{Li}_{2} \mathrm{O} / \gamma-\mathrm{Al}_{2} \mathrm{O}_{3}$ catalyst: $100 \%$ conversion of ethanol at $350{ }^{\circ} \mathrm{C}$ with the selectivity towards acetaldehyde up to $100 \%$ at $100-300{ }^{\circ} \mathrm{C}$ and $88-95 \%$ at $325-400{ }^{\circ} \mathrm{C}$. The $\mathrm{Ag}$ catalysts were more active and selective in ethanol oxidation into acetaldehyde as compared to $\mathrm{Au}$ - or $\mathrm{Cu}$-based catalysts. Ethylene oxide did not form for all catalysts as opposed to results by Lippits et al. who observed the ethylene oxide formation in ethanol oxidation over $\mathrm{Au} / \mathrm{Al}_{2} \mathrm{O}_{3}[50]$ and $\mathrm{Ag} / \mathrm{Al}_{2} \mathrm{O}_{3}$ [51] catalysts doped with $\mathrm{CeO}_{\mathrm{x}}$ and $\mathrm{Li}_{2} \mathrm{O}$.

Janlamool and Jongsomjit studied ethanol oxidative dehydrogenation over $\mathrm{Ag} / \mathrm{Li}-\mathrm{Al}_{2} \mathrm{O}_{3}$ catalysts [52]. The authors studied the role of a phase of alumina support, and a pure $\gamma$, pure $\chi$ and equally mixed phases of alumina were used as supports. The highest activity of Ag-Li catalyst supported on the mixed $\gamma-\chi$ alumina support was found. The increased amounts of weak basic sites $\left(\mathrm{CO}_{2}-\mathrm{TPD}\right)$ and $\mathrm{Ag}_{\mathrm{n}}{ }^{\delta+}$ clusters (UV-Vis spectroscopy) enhanced the catalytic activity. The TPR data showed that the phase of alumina support affected the interaction with $\mathrm{Ag}^{+}$species, and a weaker interaction led to a facilitated reduction of $\mathrm{Ag}^{+}$species into $\mathrm{Ag}_{\mathrm{n}}{ }^{\delta+}$ clusters that according to authors' opinion are more active in dehydrogenation in comparison with $\mathrm{Ag}^{+}$and $\mathrm{Ag}^{0}$ species. 
Shimizu and Satsuma studied oxidant-free dehydrogenation of alcohol over small silver clusters supported on $\mathrm{Al}_{2} \mathrm{O}_{3}$ [53]. The authors emphasize an important role of basic and acid sites of the support in the cooperative dehydrogenation of alcohols into carbonyl compounds (Figure 2). The active basic and acidic sites of the support participate in both stabilization of silver clusters [54] and alcohol activation.

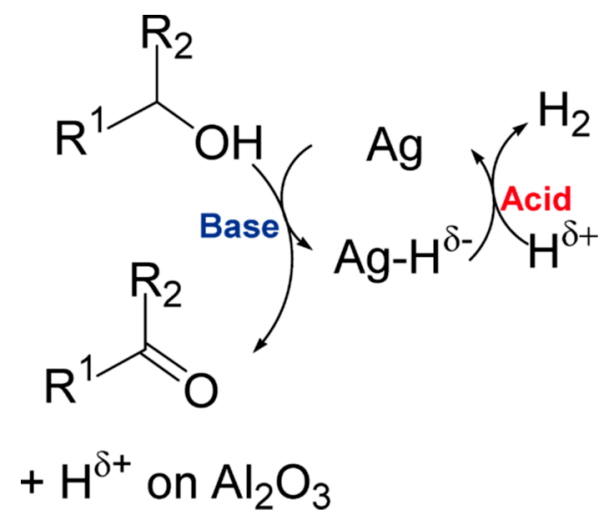

Figure 2. Proposed mechanism for oxidant-free dehydrogenation of alcohol. Reprinted with permission from reference [53]. Copyright 2011 Japan Petroleum Institute.

$\mathrm{Xu}$ et al. [55] studied the oxidative dehydrogenation of ethanol into acetaldehyde over $\mathrm{Ag} /$ hydroxyapatite. A high activity (a turnover frequency $(\mathrm{TOF})=1.38 \mathrm{~s}^{-1}$ ) was achieved over the hydroxyapatite-supported highly dispersed Ag NPs. The selectivity of $\sim 100 \%$ was observed at ethanol conversion of $\sim 17 \%$ at $277{ }^{\circ} \mathrm{C}$. The high selectivity was attributed to a low activation energy of acetaldehyde formation $(38.6 \mathrm{~kJ} / \mathrm{mol}$ ) over the $\mathrm{Ag}(111)$ (density functional theory (DFT) calculations) in comparison with the $\mathrm{CO}_{2}$ formation $(126.4 \mathrm{~kJ} / \mathrm{mol})$. The DFT calculations and results of temperature-programmed surface reaction (TPSR) allowed concluding that the ethanol oxidation predominantly occurred on a terrace surface of silver. The role of hydroxyapatite support consisted in stabilization of the highly dispersed Ag particles, while the authors did not discuss the possibility of ethanol adsorption over the support.

The nature of the materials used as supports for the preparation of the supported Ag catalysts as well as their properties play an important role during both the preparation stage and catalytic process. Taking into account that the oxidation processes are exothermal, a heat exchange between the reagent flow and the catalyst surface as well as between the active species (Ag NPs) and the support influences significantly on the state of active surface and the ratio between selective and nonselective stages. Blokhina et al. [56] studied the ethanol oxidation over the $\mathrm{Si}_{3} \mathrm{~N}_{4}$-supported silver catalyst with a low specific surface area and unique thermal conductivity. The Ag NPs with sizes below $30 \mathrm{~nm}$ were uniformly distributed over the surface of $\mathrm{Si}_{3} \mathrm{~N}_{4}$ after calcination of the catalysts at $500{ }^{\circ} \mathrm{C}$ in air. The silver particles were formed due to decomposition of silver trifluoroacetate and were mostly located in hollows and in places of contact between the coalesced support particles. The supported Ag NPs in the catalytic process show high stability that was attributed to the epitaxial bonding of silver with the support.

Moreover, a chemical composition of the support surface including functional groups of different nature (acid-base or redox) can also influence on the state of active component. In our previous work [57] we showed that the impurities of $\mathrm{Fe}$ in the $\mathrm{Si}_{3} \mathrm{~N}_{4}$ support, which was prepared by self-propagating high-temperature synthesis from Fe-Si alloy, influence on the surface redox properties of $\mathrm{Ag} / \mathrm{Si}_{3} \mathrm{~N}_{4}$ and are a part of bifunctional active species in selective oxidation of ethanol. Thus, both redox and acid-base properties of the support affect the catalytic properties of the supported silver NPs.

Dutov et al. [58] studied silver supported on manganese oxides (OMS-2) with pronounced acid (Lewis acid sites) and redox (transition $\mathrm{Mn}^{4+} \leftrightarrow \mathrm{Mn}^{3+} \leftrightarrow \mathrm{Mn}^{2+}$ ) properties. It was shown that 
a modification of OMS-2 by silver improved the redox properties of the catalysts and increased their activity in ethanol oxidation. However, a high activity of the active sites in $\mathrm{Ag} / \mathrm{MnO}_{\mathrm{x}}$ catalysts promotes the non-selective reactions, mainly, deep oxidation of ethanol into carbon oxides. The authors also compared the synthesized $\mathrm{Ag} / \mathrm{MnO}_{\mathrm{x}}$ with other $\mathrm{Ag}$ catalysts (Table 2).

Table 2. Comparison of various Ag-containing catalysts for gas-phase ethanol oxidation. Reprinted with permission from reference [58]. Copyright 2016 Elsevier.

\begin{tabular}{|c|c|c|c|c|c|c|c|c|c|}
\hline \multirow{2}{*}{ Catalyst } & \multirow{2}{*}{ Ag, wt. \% } & \multirow{2}{*}{$\begin{array}{l}\text { Activity } \times 10^{-2}, \\
\text { mol-Et/g-kat*h }\end{array}$} & \multirow{2}{*}{$\mathrm{TOF}^{\mathrm{a}}, \mathrm{h}^{-1}$} & \multicolumn{3}{|c|}{ Reaction Conditions } & \multirow{2}{*}{$\mathrm{S}_{\mathrm{Ac}} \%$} & \multirow{2}{*}{$\operatorname{STY}^{b}, h^{-1}$} & \multirow{2}{*}{ Ref. } \\
\hline & & & & GHSV, $\mathrm{ml} / \mathrm{g}^{*} \mathrm{~h}$ & $\mathrm{~T},{ }^{\circ} \mathrm{C}$ & $\mathrm{Et} / \mathrm{O}_{2}{ }^{\mathrm{c}}$ & & & \\
\hline $\mathrm{Ag} / \mathrm{Fe}-\mathrm{Si}_{3} \mathrm{~N}_{4}$ & 4.9 & 0.58 & 12.7 & 7200 & 283 & $1 / 9$ & 96 & 4.9 & [57] \\
\hline OMS-2 & - & 0.43 & - & & & \multirow{7}{*}{$1 / 9$} & 98 & - & [58] \\
\hline Ag/OMS-2-CP & 3.7 & 0.66 & 19.3 & 7200 & 170 & & 97 & 7.7 & [58] \\
\hline $\mathrm{Ag} / \mathrm{OMS}-2-\mathrm{Impr}$ & 5 & 0.64 & 13.8 & & & & 96 & 5.3 & [58] \\
\hline Ag/OMS-2-CP & 3.7 & 1.41 & 41.3 & \multirow{2}{*}{36,000} & 200 & & 58 & 9.8 & {$[58]$} \\
\hline $\mathrm{Ag} / \mathrm{OMS}-2 / \mathrm{SiO}_{2}-\mathrm{CP}$ & 0.95 & 1.91 & 217.6 & & 230 & & 85 & 75.4 & [58] \\
\hline OMS- $2 / \mathrm{SiO}_{2}$ & - & 0.15 & - & \multirow{2}{*}{7200} & \multirow{2}{*}{170} & & 98 & - & {$[58]$} \\
\hline $\mathrm{Ag} / \mathrm{OMS}-2 / \mathrm{SiO}_{2}-\mathrm{CI}$ & 5.39 & 0.23 & 4.6 & & & & 98 & 1.81 & [58] \\
\hline $\mathrm{Ag} / \mathrm{OMS}-2 / \mathrm{SiO}_{2}-\mathrm{CP}$ & 0.95 & 0.28 & 32.1 & & & & 98 & 12.8 & [58] \\
\hline $\mathrm{Ag} / \mathrm{OMS}-2$ & - & 1.25 & - & 36,000 & 190 & $1 / 2$ & 98 & - & [59] \\
\hline Ag/OMS-2 & - & 5.52 & - & 36,000 & 230 & $1 / 2$ & 95 & 26 & [60] \\
\hline rous $\mathrm{Ag}$ & 100 & 46.3 & 50 & 133,333 & 250 & $2 / 1$ & 95 & 21 & [61] \\
\hline $\mathrm{Ag} / \mathrm{MgCuCr}_{2} \mathrm{O}_{4}$ & 0.89 & 1.23 & 149.2 & 100,000 & 225 & $1 / 3$ & 99 & 65 & [62] \\
\hline
\end{tabular}

Mamontov et al. [63] studied the dehydrogenation and oxidative dehydrogenation of ethanol over $\mathrm{Ag} / \mathrm{SiO}_{2}$ catalyst doped with $\mathrm{CeO}_{2}$. It was shown that a high activity and selectivity towards acetaldehyde in a wide temperature range can be achieved over the $\mathrm{Ag} / \mathrm{SiO}_{2}$ catalyst as compared to $\mathrm{Au} / \mathrm{SiO}_{2}$ counterpart (where $\mathrm{SiO}_{2}$ is MCM-41, SBA-15 and unordered mesoporous silica) [64] in both oxidative and non-oxidative dehydrogenation of ethanol. The addition of $\mathrm{CeO}_{2}$ in the $\mathrm{Ag} / \mathrm{SiO}_{2}$ catalysts was shown to promote the activity in ethanol oxidation (Figure 3). It was proposed that the growth of the activity in oxidative dehydrogenation of ethanol was associated with a spillover of active oxygen from ceria to silver NPs increasing the total amount of the oxidative sites. The growth of the activity in non-oxidative dehydrogenation of ethanol may be a result of a cooperation of active $\mathrm{Ag}$ species and ceria on the $\mathrm{Ag}-\mathrm{CeO}_{2}$ interface. To reveal an influence of the $\mathrm{Ag}-\mathrm{CeO}_{2}$ interfacial interaction on the activity of $\mathrm{Ag}-\mathrm{CeO}_{2} / \mathrm{SiO}_{2}$ catalysts, the series of catalysts with a controllable distribution of silver and ceria were synthesized [65]. It was shown that an increasing $\mathrm{Ag}-\mathrm{CeO}_{2}$ interfacial interaction in the catalyst prepared by the impregnation of the pre-reduced $\mathrm{CeO}_{2} / \mathrm{SiO}_{2}$ support with $\mathrm{AgNO}_{3}$ aqueous solution led to the growth of activity in oxidative dehydrogenation of ethanol into acetaldehyde with maintaining of high selectivity towards acetaldehyde.

Grabchenko et al. [66] studied the oxidative dehydrogenation of ethanol into acetaldehyde over $\mathrm{Ag} / \mathrm{CeO}_{2}$ catalysts. At $85-130{ }^{\circ} \mathrm{C}$ ethanol predominantly converted into acetaldehyde, and $\mathrm{CO}_{2}$ formation as the major by-product was observed at temperatures above $130^{\circ} \mathrm{C}$. The process conditions (temperature, contact time, features of the oxidant (water or ethanol) and oxidant/substrate ratio) determined the routes of ethanol conversion over $\mathrm{Ag} / \mathrm{CeO}_{2}$. Acetaldehyde may be obtained over the $\mathrm{Ag} / \mathrm{CeO}_{2}$ as the first intermediate of ethanol conversion only in a narrow range of conditions. A total oxidation of ethanol into $\mathrm{CO}_{2}$ is observed over the $\mathrm{Ag} / \mathrm{CeO}_{2}$ catalyst at relatively low temperatures of $130-200^{\circ} \mathrm{C}$, when oxygen is used as an oxidant. 


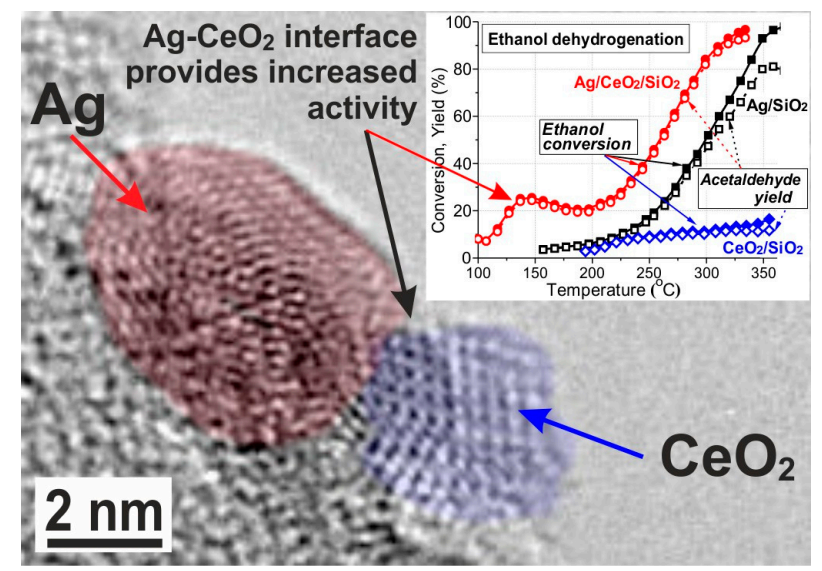

Figure 3. The contact of $\mathrm{Ag}$ and $\mathrm{CeO}_{2}$ on the surface of $\mathrm{SiO}_{2}$ and corresponding growth of activity in ethanol dehydrogenation. Reprinted with permission from reference [63]. Copyright 2018 Elsevier.

Acetone is another valuable product for organic synthesis, which is generally produced by dehydrogenation of isopropanol, while Rodrigues et al. [67] carried out an acetone synthesis from ethanol. The authors also showed the opportunity to carry out the ethanol conversion with water vapor into acetone (ethanol/water molar ratio was 1/8) without oxygen over $\mathrm{Ag} / \mathrm{CeO}_{2}$ catalysts [68]. Acetone formation was also observed at $400{ }^{\circ} \mathrm{C}$ in our previous work [66], when water was used as a mild oxidant. The role of silver was attributed to an increase of the reducibility of $\mathrm{CeO}_{2}$ that led to higher selectivity towards acetone (up to $66 \%$ at $400{ }^{\circ} \mathrm{C}$ ) and a lower selectivity towards ethylene $(\sim 5 \%)$. According to the mechanism proposed by Rodrigues et al. [67] the ethanol conversion into acetaldehyde takes place over the oxidative species of ceria. The main role of silver is to promote the oxidation of acetaldehyde into acetate species increasing the selectivity towards acetone.

Thus, the selective oxidation of ethanol is an important process for the manufacturing of valuable organic compounds. The Ag-containing materials are promising catalysts for selective oxidation of ethanol into acetaldehyde, acetone and other compounds due to higher selectivity in comparison with $\mathrm{Au}, \mathrm{Cu}$ and other catalysts. The activity of silver catalysts significantly depends on the redox and acid-base properties of the support due to a cooperation of the active silver sites and the support at the Ag-support/modifier interfaces $[57,63]$. The control of this interfacial interaction can be used to enhance the catalyst performance.

Thus, the recent progress in the field of development of highly effective Ag catalysts for selective oxidation of ethanol is mainly connected with the use of $\mathrm{Ag}$ as isolated ions, in cluster state and in the form of small nanosized particles [52,54,55]. The acid-base properties of the support surface play an important role. The controlling of the acid-base properties of $\gamma-\mathrm{Al}_{2} \mathrm{O}_{3}$ by introduction of $\mathrm{Li}_{2} \mathrm{O}$ allowed achieving a $100 \%$ conversion of ethanol at $350{ }^{\circ} \mathrm{C}$ with the selectivity towards acetaldehyde of up to $100 \%$ [49,51]. Gold and copper-containing catalysts cedes the Ag composites in terms of activity. The main reason is the formation of $\mathrm{Ag}_{\mathrm{n}}$ clusters on the surface of Li-modified alumina. The use of hydroxyapatite as a support for Ag NPs leads to significant decrease of the conversion (below $20 \%$ at $277^{\circ} \mathrm{C}$ ) with maintaining of a $100 \%$ selectivity towards acetaldehyde. Thus, it is necessary to optimize the acid-base properties of the support to achieve the maximal effectiveness.

The next important approach to increase the effectiveness of Ag-based catalysts is the use of transition metal oxides $\left(\mathrm{CeO}_{2}, \mathrm{MnO}_{2}, \mathrm{Fe}_{2} \mathrm{O}_{3}\right.$, etc.) as supports, modifiers and/or matrixes for distribution of isolated $\mathrm{Ag}^{+}$cations [58]. The strong metal-support interaction plays a crucial role in the growth of the catalyst activity in oxidative dehydrogenation of ethanol into acetaldehyde at high selectivity [63]. Thus, to create the highly effective catalysts a balance is required between redox and acid-base properties. This provides the distribution of active component as nanosized clusters and/or isolated ions in the close contact with the oxide modifier possessing redox properties. 


\subsubsection{Benzyl Alcohol}

Gas-phase selective oxidation of benzyl alcohol (BA) over Ag-based catalysts is extensively studied. Different supports are used in the BA partial oxidation over Ag-based catalysts (Table 3) including materials based on $\mathrm{SiO}_{2}$ with amorphous [69] and mesoporous ordered structure such as HMS [70], SBA-15 [71], Na-ZSMs [69], alkali-earth metal oxide $\mathrm{CaO}$ and $\mathrm{MgO}$ [69], $\mathrm{Al}_{2} \mathrm{O}_{3}$ [72], and heat conductivity materials Ni-fibers [73] and $\mathrm{SiC}[74,75]$.

Ordered mesoporous $\mathrm{SiO}_{2}$ materials are also actively studied as supports for silver catalysts in the gas-phase selective oxidation of BA to benzaldehyde (BAld). Jia et al. [70] synthesized silver-containing hexagonal mesoporous silica (Ag-HMS) catalysts with different $\mathrm{Si} / \mathrm{Ag}$ ratios using a one-pot hydrothermal method. The Ag-HMS catalysts with different Ag loadings (0.55-3.50 wt.\%) and Ag particle sizes (5-32 nm) showed similar catalyst performance due to close Ag surface area. These catalysts exhibited the catalytic properties superior to those of other M-HMS catalysts $(\mathrm{M}=\mathrm{Co}$, $\mathrm{Ce}, \mathrm{La}, \mathrm{Cu}, \mathrm{Sr}, \mathrm{Cd}, \mathrm{Ni}, \mathrm{Mn}, \mathrm{V}$, and $\mathrm{Fe}$ ) and the enhanced catalytic activity was assumed to be caused by the oxygen spillover yielding Ag surface oxygen species (Figure 4).

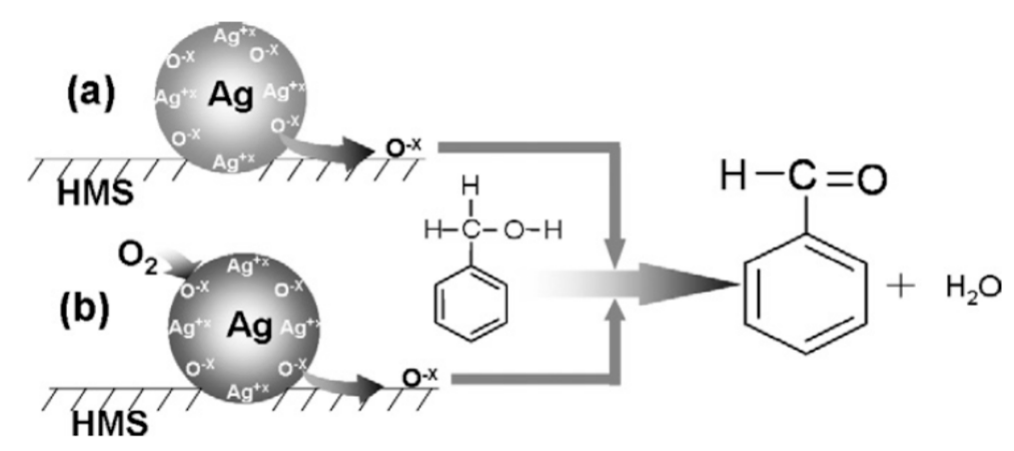

Figure 4. Catalytic mechanism illustration for selective oxidation of benzyl alcohol to benzaldehyde on Ag-HMS catalyst. Reproduced from Ref. with permission from the Elsevier. Reprinted with permission from reference [70]. Copyright 2012 Elsevier.

Ma et al. [71] prepared the Ag/SBA-15 catalysts with different Ag content by an impregnation method. A nano-confinement effect caused silver incorporation into the channels of the mesoporous SBA-15 structure as well as Ag dispersion over the support surface. This increased the specific surface area and provided a uniform pore size. Oxygen spillover of nucleophilic oxygen species from the silver NPs to the support enhanced the catalytic activity. The developed composites also showed high thermal gradient stability. 
Table 3. Comparison of various Ag-containing catalysts for gas-phase BA oxidation.

\begin{tabular}{|c|c|c|c|c|c|c|c|c|}
\hline Catalyst Composition & Reaction Conditions & $\mathrm{T},{ }^{\circ} \mathrm{C}$ & $\mathrm{S}, \%$ & $\mathbf{Y}, \%$ & Ag Loading, \%wt. & $\mathrm{S}_{\mathrm{BET}}, \mathrm{m}^{2} / \mathrm{g}$ & Mean Particle Size, nm & Ref. \\
\hline $\mathrm{Ag}(1.0) / \mathrm{SiO}_{2}$ & & \multirow{7}{*}{240} & \multirow{7}{*}{ Close to $100 \%$} & 49.9 & 1.0 & 190 & $76(\mathrm{Ag})$ & \multirow{7}{*}{ [69] } \\
\hline $\mathrm{CaO}$ & $\begin{array}{l}\text { continuouss-flow } \\
\text { fixed-bed reactor (Pyrex, } 15 \mathrm{~mm} \text { i.d. }\end{array}$ & & & 22.0 & 1.0 & - & - & \\
\hline $\mathrm{MgO}$ & $\begin{array}{l}\text { fixed-bed reactor (Pyrex, } 15 \mathrm{~mm} \text { 1.d. } \\
0.2 \mathrm{~g} \text { of catalyst }\end{array}$ & & & 14.0 & 1.0 & - & - & \\
\hline $\mathrm{SiO}_{2}$ & total flow rate $=0.023 \mathrm{~mol} / \mathrm{min}$ & & & 3.6 & 1.0 & - & - & \\
\hline NaZSM-5 & $\mathrm{N}_{2}: \mathrm{O}_{2}: \mathrm{BA}=32: 3: 1$ & & & 2.3 & 1.0 & - & - & \\
\hline MCM-41 & Temperature range: $227-377 \mathrm{~K}$ & & & 0.36 & 1.0 & - & - & \\
\hline $\mathrm{NaY}$ & & & & 0.27 & 1.0 & - & - & \\
\hline Ag-HMS-25 & $\begin{array}{c}0.5 \mathrm{~g} \text { catalyst purified } \mathrm{N}_{2}\left(38 \mathrm{~mL} \mathrm{~min}^{-1}\right), \\
\text { purified } \mathrm{O}_{2}\left(13 \mathrm{~mL} \mathrm{~min}^{-1}\right) \text { BA }\left(0.10 \mathrm{~mL} \mathrm{~min}^{-1}\right)\end{array}$ & 575 & 96.0 & 96.0 & Si $/$ Ag ratio $=25: 1$ & 605 & 23 & \\
\hline HMS & $\begin{array}{c}\text { total flow rate of } 3.24 \mathrm{mmol} \mathrm{min}^{-1} \\
\mathrm{O}_{2} / \text { alcohol molar ratio }=0.6\end{array}$ & 724 & 85 & 9.0 & - & - & - & [70] \\
\hline SBA-15 & catalyst $(0.8 \mathrm{~g})$ was sieved to $40-60$ mesh powders and & \multirow{5}{*}{240} & 60.5 & 1.21 & - & 676 & - & \multirow{5}{*}{ [71] } \\
\hline 4.1\%Ag/SBA- 15 & pretreated $\left(\mathrm{O}_{2}: \mathrm{N}_{2}\right.$ volume ratio of $3: 7$, flow rate was 50 & & 85.2 & 63.7 & 4.1 & 541 & 5.5 & \\
\hline $5.3 \% A g / S B A-15$ & $\mathrm{~mL} / \mathrm{min}$ ) at $550^{\circ} \mathrm{C}$ for $2 \mathrm{~h}$ before testing & & 96.9 & 91.0 & 5.3 & 546 & 6.4 & \\
\hline $8.1 \% \mathrm{Ag} / \mathrm{SBA}-15$ & purified $\mathrm{N}_{2}(35 \mathrm{~mL} / \mathrm{min})$, purified $\mathrm{O}_{2}$ & & 96.0 & 90.4 & 8.1 & 476 & 10.2 & \\
\hline $16.5 \% \mathrm{Ag} / \mathrm{SBA}-15$ & WHSV $=4.7-12.5 \mathrm{~h}^{-1}$ vaporized at $220^{\circ} \mathrm{C}$ & & 91.5 & 88.4 & 16.5 & 411 & 17.4 & \\
\hline $\mathrm{Ag} / \mathrm{Ni}$-fiber & $\begin{array}{c}0.3 \mathrm{~g} \text { for the } \mathrm{Ag} / \mathrm{Ni} \text {-fiber, } 1.0 \mathrm{~g} \text { for both the electrolytic silver } \\
\text { and } \mathrm{Ag} / \alpha-\mathrm{Al}_{2} \mathrm{O}_{3} \\
\text { Calcination temperature: } 400-700^{\circ} \mathrm{C} \\
\mathrm{O}_{2} / \mathrm{ol}=0.6, \mathrm{WHSV}=25 \mathrm{~h}^{-1} \text { for } \mathrm{Ag} / \mathrm{Ni} \text {-fiber, } \mathrm{O}_{2} / \mathrm{ol}=0.6\end{array}$ & \multirow[t]{3}{*}{380} & 90 & 80.1 & 10.2 & $\sim 2.0$ & - & \multirow[t]{3}{*}{ [72] } \\
\hline Electrolytic silver & $\mathrm{T}=500^{\circ} \mathrm{C}$ and WHSV $=8 \mathrm{~h}^{-1}$ for the electrolytic silver and & & 79 & 44.2 & 100 & - & - & \\
\hline $\mathrm{Ag} / \alpha-\mathrm{Al}_{2} \mathrm{O}_{3}$ & $\mathrm{Ag} / \alpha-\mathrm{Al}_{2} \mathrm{O}_{3}$ & & 74 & 60.7 & - & - & - & \\
\hline $\mathrm{Ag} / \mathrm{Ni}$-fiber-M & \multirow{2}{*}{$\begin{array}{l}\text { WHSV }=20 \mathrm{~h}^{-1} \\
\text { Calcination temperature: } 300-600^{\circ} \mathrm{C}\end{array}$} & 300 & 97.0 & 94.1 & 9.9 & - & $\sim 10 \mathrm{~nm}$ thick by & \multirow{2}{*}{ [73] } \\
\hline $\mathrm{Ag} / \mathrm{Ni}$-fiber & & 380 & 87.0 & 80 & 9.7 & - & $200-300$ & \\
\hline $\mathrm{Ag}_{2.5} / \mathrm{SiC}$ & \multirow{4}{*}{$\begin{array}{c}\text { reaction temperature }=280^{\circ} \mathrm{CO}_{2} / \text { hydroxyl }=0.6 \\
W H S V=10 \mathrm{~h}^{-1}\end{array}$} & \multirow{4}{*}{280} & 99.9 & 1.9 & - & 0.8 & $30-70$ & \multirow{4}{*}{ [74] } \\
\hline $\mathrm{Ag}_{2.5} \mathrm{Cu}_{5} / \mathrm{SiC}$ & & & 99.6 & 98.9 & - & 0.20 & - & \\
\hline $\mathrm{Ag}_{2.5} / \mathrm{SiC} \& \mathrm{Cu}_{5} / \mathrm{SiC}$ & & & 98.9 & 62.1 & - & - & - & \\
\hline $\mathrm{Ag}_{2.5} \mathrm{Fe}_{5} / \mathrm{SiC}$ & & & 99.8 & 55.7 & - & - & - & \\
\hline $\mathrm{SiC}$ & \multirow{12}{*}{$\begin{array}{c}0.3 \mathrm{~g}(200-300 \mathrm{mesh}) \\
\text { WHSV }=2 \mathrm{~h}^{-1} \\
\text { alcohol } / \mathrm{O}_{2} / \mathrm{N}_{2} \text { is } 1 / 0.6 / 2.4\end{array}$} & \multirow{12}{*}{280} & 97 & 2.9 & - & 0.15 & - & \multirow{12}{*}[75]{} \\
\hline $\mathrm{Ag}_{1} / \mathrm{SiC}$ & & & 98 & 10.8 & 0.96 & - & - & \\
\hline $\mathrm{Ag}_{2} / \mathrm{SiC}$ & & & 99 & 14.9 & 1.88 & - & 36 & \\
\hline $\mathrm{Ag}_{3} / \mathrm{SiC}$ & & & 98 & 29.4 & 2.78 & - & - & \\
\hline $\mathrm{Mn}_{5} / \mathrm{SiC}$ & & & 98 & 7.8 & - & - & - & \\
\hline $\mathrm{Ag}_{1} \mathrm{Mn}_{5} / \mathrm{SiC}$ & & & 98 & 80.4 & 0.82 & - & - & \\
\hline $\mathrm{Ag}_{2} \mathrm{Mn}_{5} / \mathrm{SiC}$ & & & 98 & 92.1 & 1.93 & - & 34 & \\
\hline $\mathrm{Ag}_{3} \mathrm{Mn}_{5} / \mathrm{SiC}$ & & & 97 & 93.1 & 2.90 & - & - & \\
\hline $\mathrm{Ag}_{4} \mathrm{Mn}_{5} / \mathrm{SiC}$ & & & 98 & 93.1 & 3.65 & - & - & \\
\hline $\mathrm{Ag}_{5} \mathrm{Mn}_{5} / \mathrm{SiC}$ & & & 96 & 93.1 & 4.66 & - & - & \\
\hline $\begin{array}{l}\mathrm{Ag}_{2} / \mathrm{SiC} \& \\
\mathrm{Mn}_{5} / \mathrm{SiC}\end{array}$ & & & 97 & 24.3 & - & - & - & \\
\hline Nanoporous Ag & & & 99 & 97 & - & - & - & \\
\hline $\mathrm{Ag} / \mathrm{SiO}_{2}$ & continuous-flow fixed-bed reactor (Pyrex, $15 \mathrm{~mm}$ i.d.), $0.2 \mathrm{~g}$ & \multirow[b]{3}{*}{240} & 97.4 & 1.5 & 1.0 & \multirow[b]{3}{*}{$160-260$} & - & \multirow{3}{*}{ [76] } \\
\hline $\mathrm{Ag} / \mathrm{SiO}_{2}+\mathrm{Ca} / \mathrm{SiO}_{2}$ & of catalyst & & 96.5 & 4.6 & 1.0 & & - & \\
\hline $\mathrm{Ca}-\mathrm{Ag} / \mathrm{SiO}_{2}$ & $\begin{array}{c}\text { total flow rate }=0.023 \mathrm{~mol} / \mathrm{min} \\
\mathrm{N}_{2}: \mathrm{O}_{2}: \mathrm{BA}=32: 3: 1 \\
\text { Temperanture range: } 500-650 \mathrm{~K}\end{array}$ & & 99.6 & 66.7 & 1.0 & & - & \\
\hline
\end{tabular}


The promotion of Ag-based catalysts by alkali or alkali earth metal compounds is also studied. Thus, Yamamoto et al. [69] used the unpromoted and K-promoted silica-supported Ag catalysts for BAld production as well as $\mathrm{CaO}$-supported samples. The promotion by $\mathrm{K}$ was shown to enhance the $\mathrm{Ag} / \mathrm{SiO}_{2}$ performance. The highest BAld yield was observed in the range of 553-593 K. An increase of the calcination temperature influenced positively on the selective oxidation activity. A combination of high calcination temperature, a basic support, and the alkali promotion lightened the reduction of supported oxidized Ag species to metallic ones. Sawayama et al. [76] considered the alkaline earth metal-promoted $\mathrm{Ag} / \mathrm{SiO}_{2}$ catalysts for BA oxidation into BAld. $\mathrm{Ca}$, $\mathrm{Sr}$ and Ba promoters were used. The alkaline earth metals promoted the catalytic activity, inhibited the formation of carbonaceous materials and facilitated the dispersion of metallic Ag and oxygen adsorption over the silver surface to yield the oxygenated Ag surface species active in the BA partial oxidation (Figure 5).

\section{(a) $\mathrm{Ag} / \mathrm{SiO}_{2}$ catalyst}

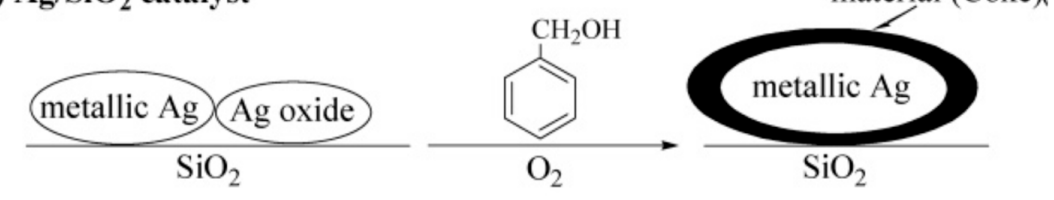

(b) $\mathrm{Ca}-\mathrm{Ag} / \mathrm{SiO}_{2}$ catalyst

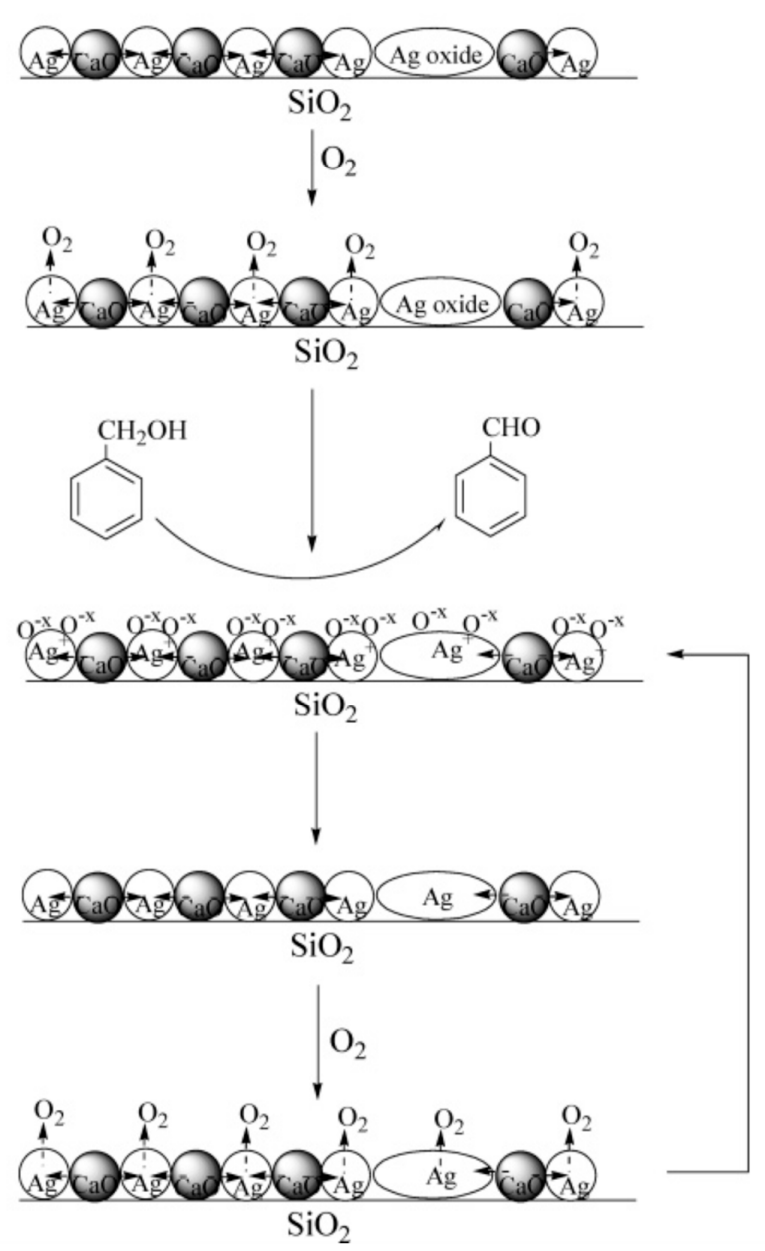

Figure 5. Reprinted with permission from reference [76]. Copyright 2006 Elsevier.

Recently, Ni fiber-based supports attracted a growing interest. Mao et al. [72] prepared a non-woven microfibrous thin-sheet support with 5 vol $\% 8 \mu \mathrm{m}$ diameter nickel fibers using a wet-lay 
papermaking and sintering processes. Incipient wetness impregnation allowed supporting of silver. The fresh Ag/Ni-fiber catalysts exhibited an enhanced catalytic activity in BAld production and showed an increased steady-state volumetric reaction rate at a relatively low Ag content as compared to pure electrolytic silver and $\mathrm{Ag} / \alpha-\mathrm{Al}_{2} \mathrm{O}_{3}$ catalysts. Deng et al. [73] showed that water pre-wetting and overnight drying treatment processes significantly improved the wettability of the Ni-fiber support. As a result, higher amount of $\mathrm{Ag}$ cations and oxygen species were formed (Ag/Ni-fiber-M) as compared to the catalyst prepared over the untreated support (Ag/Ni-fiber). The differences in morphology and particle size of silver resulted in higher activity/selectivity for the $\mathrm{Ag} / \mathrm{Ni}$-fiber-M catalyst at a lower temperature. Both direct oxygen activation route and a spillover of oxygen of $\mathrm{NiO}_{\mathrm{x}}$ were the main routes of $\mathrm{BA}$ selective oxidation. $\mathrm{A} \mathrm{Ni}_{\mathrm{x}} \mathrm{C}$ phase was shown to be formed and hamper the latter reaction route leading to partial catalyst deactivation (Figure 6). A restoration of the spent catalyst activity was achieved at $400{ }^{\circ} \mathrm{C}$.

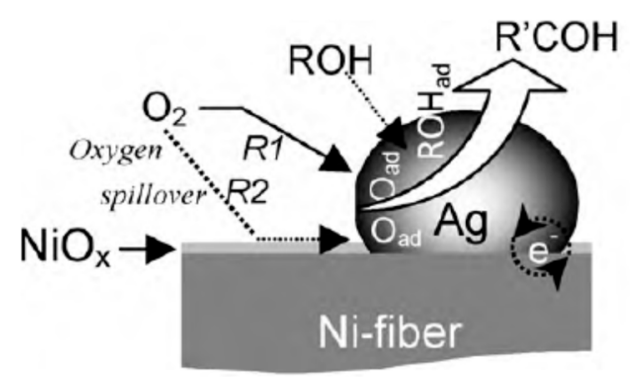

Reaction

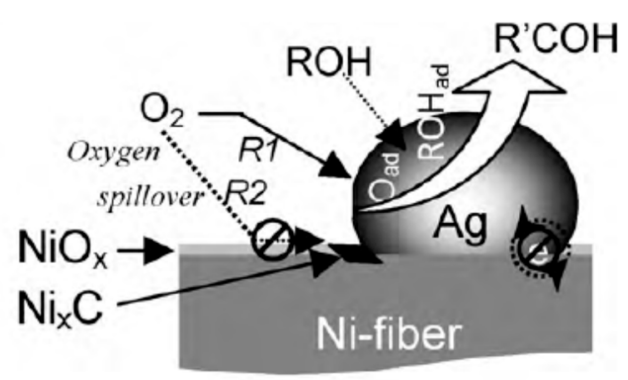

Partial Deactivation

Figure 6. Possible reaction and partial deactivation schemes for the gas-phase selective oxidation of benzyl alcohol over the Ni-microfibrous-structure supported silver catalysts. Note: R1, direct $\mathrm{O}_{2}$ activation route; $\mathrm{R}_{2}, \mathrm{NiO}_{\mathrm{x}}$-participating $\mathrm{O}_{2}$ spillover route. Reprinted with permission from reference [73]. Copyright 2010 Elsevier.

Silicon carbide is also used as a support for the Ag-based catalysts for selective oxidation of BA and other alcohols (e.g., 1-phenylethanol, 2-octanol, cyclohexanol, PG). Zhao et al. [74] synthesized the bimetallic $\mathrm{AgCu} / \mathrm{SiC}$-powder catalysts with prolonged catalytic activity. A formation of $\mathrm{Ag}-\mathrm{Cu}_{2} \mathrm{O}$ ensembles after the pre-activation process caused high activity and stability, with $\mathrm{Cu}_{2} \mathrm{O}$ species playing a crucial role in the selective oxidation of BA (Figure 7).

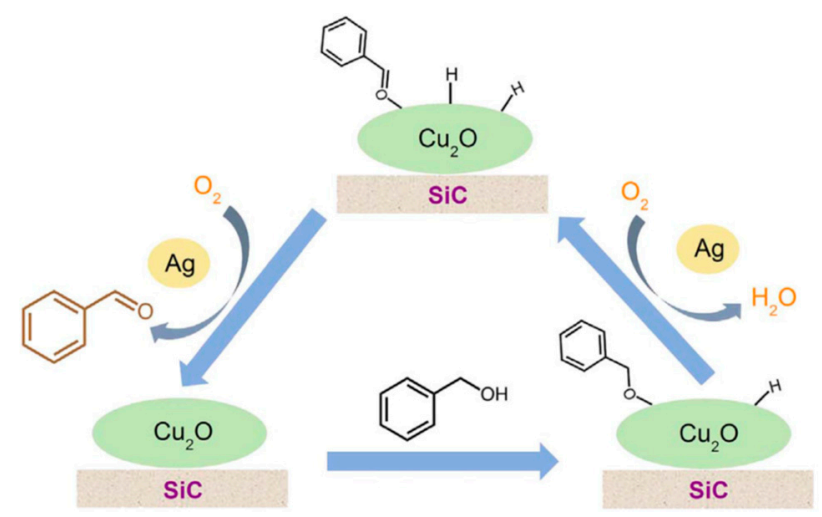

Figure 7. The catalytic mechanism of pre-activated $\mathrm{Ag}_{2.5} \mathrm{Cu}_{5} / \mathrm{SiC}$ for the gas-phase selective oxidation of benzyl alcohol. Reprinted with permission from reference [74]. Copyright 2017 Elsevier.

Liu et al. [75] proposed $\mathrm{Ag}-\mathrm{Mn} / \mathrm{SiC}$ catalyst. The formation of highly active $\mathrm{Ag}^{0}-\mathrm{Mn}_{3} \mathrm{O}_{4}$ species formed from $\mathrm{Ag}_{2} \mathrm{O}$ and $\mathrm{MnO}_{2}$ under the process conditions was assumed to cause an enhanced catalytic activity of the samples. The $34 \mathrm{~nm} \mathrm{Ag}$ and $5.5 \mathrm{~nm} \mathrm{Mn} \mathrm{O}_{4} \mathrm{NPs}$ provided a synergistic effect. 
Thus, the attempts are made to use the highly heat-conducting materials as supports (Ni fibers or $\mathrm{SiC}$ ). However, it seems that the surface of such materials lacks of functional sites. This requires, for instance, partial oxidation of the surface of metallic Ni fibers. To increase the functional properties of silicon carbide, the additives based on transition metal oxides (e.g., manganese) are used. At the same time, the use of mesoporous ordered silicates as supports for Ag NPs allows achieving quite high performance of the catalysts in BA selective oxidation even without application of modified additives. It is noteworthy that for such catalysts the oxidation is carried out at elevated temperatures.

Thus, in the field of development of highly effective catalysts for BA selective oxidation the main advantages are connected with the use of highly heat-conducting supports $[73,74]$, such as Ni fibers, $\mathrm{SiC}$ that are characterized by low specific surface area and practically complete absence of functional groups. A synergistic effect between the particles of $\mathrm{Ag}^{0}$ and $\mathrm{Mn}_{2} \mathrm{O}_{3}$ allowed a significant increasing of the effectiveness of the composites as compared to individual components and their mechanical mixtures [75]. The results for $\mathrm{Ag}_{2} \mathrm{Mn}_{5}$ composite showed that the heat conductivity of the supports is a key factor to provide the high efficiency of the catalyst with time. Nevertheless, a long-time test for the $\mathrm{Ag}_{2} \mathrm{Mn}_{5} / \mathrm{SiC}$ catalyst showed that a periodic regeneration of the catalyst is required, which is connected with accumulation of carbon-containing products in time as well as with reoxidation of $\mathrm{MnO}$ particles into $\mathrm{Mn}_{2} \mathrm{O}_{3}$. Hence, under the chosen process conditions $\left(\mathrm{T}=280^{\circ} \mathrm{C}, \mathrm{O}_{2} /\right.$ alcohol $\left.=0.6\right)$ a reoxidation of the catalyst surface is complicated, i.e., it is necessary to increase the partial pressure of $\mathrm{O}_{2}$ in the mixture that can result in a significant reduction of selectivity.

For $5.3 \mathrm{Ag} / \mathrm{SBA}-15$ catalyst that contains $\mathrm{Ag}$ distributed inside the channels of the ordered mesoporous silicate a periodic regeneration in air at $550{ }^{\circ} \mathrm{C}$ is also required. The productivity of the catalyst decreases after $40 \mathrm{~h}$ run at $240{ }^{\circ} \mathrm{C}$ in the reaction mixture (WHSV $=8 \mathrm{~h}^{-1}$ ) as a result of agglomeration of Ag NPs to up to plugging of the channels in the support. One can conclude that further development of catalytic systems for gas-phase selective oxidation of BA will be connected with a search for the composites that allow balancing the processes of oxidation-reduction of active phases distributed on the surfaces of highly heat-conducting supports.

\subsubsection{Allyl Alcohol}

The bulk alloyed and supported Ag catalysts were used in oxidative dehydrogenation of allyl alcohol to acrolein [77]. High activity and selectivity towards acrolein were achieved in the range of 340-380 ${ }^{\circ} \mathrm{C}$. Alloying of silver with $\mathrm{Au}$ or $\mathrm{Cu}$ was shown to improve the catalyst activity, but reduced its selectivity leading to low acrolein yields. The supports comprising $\mathrm{LaPO}_{4}$, carbon nanotubes, $\mathrm{TiO}_{2}$, $\mathrm{Al}_{2} \mathrm{O}_{3}$ and $\mathrm{SiO}_{2}$ were prepared by the impregnation method. $\mathrm{Ag} / \mathrm{SiO}_{2}$ composite showed the highest acrolein yield at $360^{\circ} \mathrm{C}$ (alcohol conversion reached $89.2 \%$ at $96 \%$ selectivity towards acrolein; Ag mass was $3.1 \mathrm{mg}$, alcohol flow was $0.0214 \mathrm{~mol} / \mathrm{h}$; air flow was $20 \mathrm{ml} / \mathrm{min}$, alcohol/oxygen ratio was 2.0).

\subsection{Polyalcohols}

\subsubsection{Ethylene Glycol}

Selective vapor-phase oxidation of ethylene glycol (EG) into glyoxal (GO) over the Ag catalysts in the alcohol-rich adiabatic mode at $500-650{ }^{\circ} \mathrm{C}$ is one of the most important industrial processes to produce GO [78]. Bulk and supported Ag catalysts are usually considered. Polycrystalline silver is used as a catalyst for GO production $[79,80]$. However, the high-temperature conditions of the process lead to sintering of an active surface of $\mathrm{Ag}$ crystals as well as a deposition of the carbon-containing products [81], and the GO yield is reduced in time. An introduction of volatile promoters to the reaction mixture and/or addition of modifying components on the catalyst surface allows decreasing the negative effects preventing the formation of carbon deposits on the catalyst surface and sintering. Two main approaches are widely used to address these challenges with a keeping of high activity and selectivity towards GO. The first approach is an introduction of phosphorous-containing volatile organic compounds such as mono-, di-, and trialcyl phosphate 
into the reaction mixture [82]. The second approach is connected with the addition of phosphoric acid onto the Ag crystal surface [83,84]. The authors [84] found that the phosphate-containing compounds were distributed on the Ag catalyst surface forming the phosphorous-containing promoter layer with a thickness of about $35-45 \AA$ (Figure 8 ).

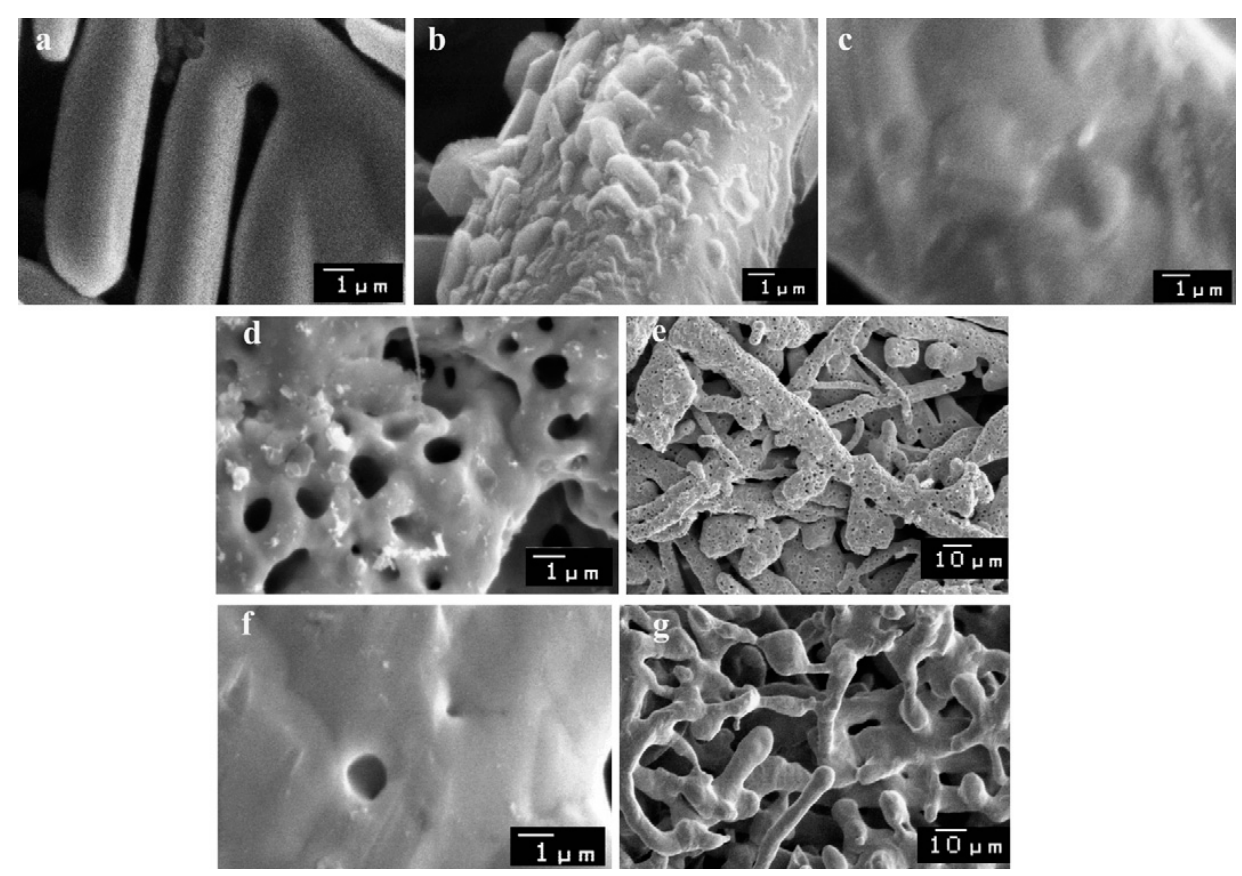

Figure 8. SEM images of the electrolytic silver catalysts before $(\mathbf{a}-\mathbf{c})$ and after $(\mathbf{d}-\mathbf{f})$ the catalytic experiments (at $550{ }^{\circ} \mathrm{C}$ for $60 \mathrm{~min}$ ): (a) unpromoted $\mathrm{Ag}$ catalyst; (b) after promoting by phosphoric acid; (c) P-containing catalyst after annealing at $\mathrm{T}=650^{\circ} \mathrm{C}$ for $3 \mathrm{~h}$ in the air; (d,e) unpromoted $\mathrm{Ag}$ catalyst after catalytic reaction; $(\mathbf{f}, \mathbf{g})$ P-containing Ag catalyst after catalytic reaction. Reprinted with permission from reference [84]. Copyright 2008 Elsevier.

Metallic silver can be dissolved in this layer and distributed along the subsurface region as isolated ions and metal clusters under the action of oxygen at high temperature. According to Auger-spectroscopy data, the reverse transformation of the metal-ionic Ag states depending on the oxygen and temperature treatments was observed. The formation of the $\mathrm{Ag}_{\mathrm{x}} \mathrm{O}_{\mathrm{y}}$ oxidized particles inside the polyphosphate layer occurred during the interaction with the gas-phase oxygen. A destruction of these oxidized $\mathrm{Ag}_{\mathrm{x}} \mathrm{O}_{\mathrm{y}}$ species led to an oxygen release as a single TPD peak at temperatures above $500{ }^{\circ} \mathrm{C}$ (Figure 9) that indicated an increase of strengths of oxygen-silver bond.

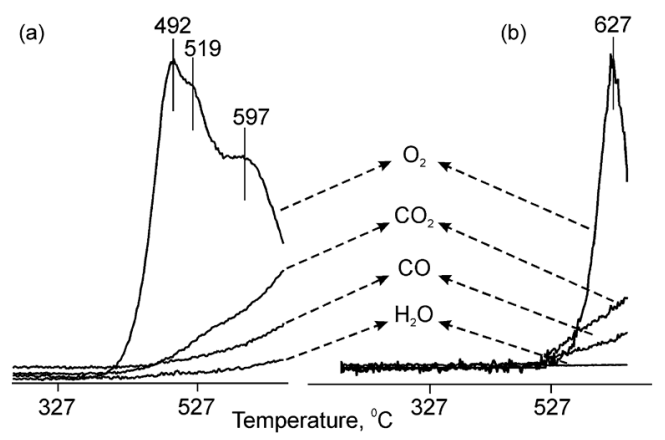

Figure 9. TPD spectra of oxygen taken from the surface of (a) the unpromoted $\mathrm{Ag}$ foil $\left(\mathrm{Po}_{2}=400 \mathrm{~Pa}\right.$ at $400{ }^{\circ} \mathrm{C}$ for $\left.30 \mathrm{~min}\right)$ and (b) P-containing $\mathrm{Ag}$ foil $\left(\mathrm{Po}_{2}=400 \mathrm{~Pa}\right.$ at $400{ }^{\circ} \mathrm{C}$ for $\left.10 \mathrm{~h}\right)$. Reprinted with permission from reference [84]. Copyright 2008 Elsevier. 
Thus, the introduction of the phosphate-containing compounds onto polycrystalline Ag catalyst allowed increasing the GO yield by $15-20 \%$ due to the selectivity growth. The authors concluded that the oxygen-containing clusters distributed in the promoter layer were the active surface species on the P-containing polycrystalline Ag catalyst.

The next generation of the catalysts for the selective EG oxidation is connected with the development of the idea about the application of Ag clusters/NPs as active species able to adsorb oxygen in a strongly bounded form. Such an approach was implemented in our previous works [85-89], where the Ag-containing materials $(5 \mathrm{wt} \%)$ were applied as catalysts instead of polycrystalline Ag. The active component in the form of Ag NPs was distributed in the mesoporous space of the silica matrix (Figure 10) together with the polyphosphate modifier. The sizes of Ag NPs were below $30 \mathrm{~nm}$ with a maximum of particle size distribution at $4-8 \mathrm{~nm}$ that was in a good correlation with the XRD data.
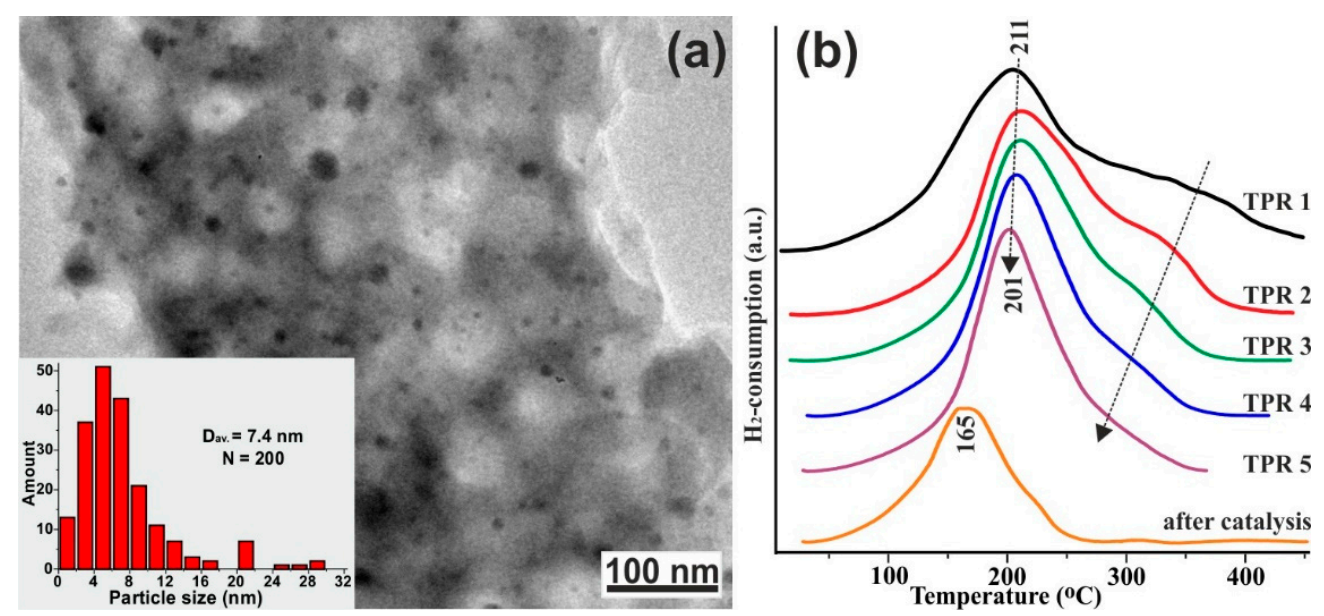

Figure 10. TEM image and silver particle size distribution of as-prepared $\mathrm{Ag} / \mathrm{P}_{2} \mathrm{O}_{5} / \mathrm{SiO}_{2}$ catalyst (a) and TPR profiles of the catalyst during a series of cyclic TPO/TPR treatments and after catalysis (b). Reprinted with permission from reference [89]. Copyright 2015 Trans. Tech. Publications.

We studied a dynamic behavior of the Ag NPs under the cyclic action of redox TPR/TPO treatment (Figure 10b). During the five cycles of reversible oxidation-reduction, the TPR peak of $\mathrm{H}_{2}$ consumption insignificantly shifted to a low-temperature region and became more intensive and narrow. Thus, under the action of redox treatment, the redistribution of the Ag NPs occurred from the bulk to the subsurface region. Similar TPR profile was obtained during the long operation under the catalytic conditions.

Interactions between the silica surface, polyphosphate modifier and Ag was studied in our previous works $[87,90,91]$. Based on the TPR, UV-vis DRS, and IR spectroscopy data, we suggested a mechanism for active species organization (highly dispersed silver particles) on the surface of the investigated Ag-containing materials. An introducing of phosphorous acid into silica at the stage of synthesis was shown to result in the formation of a phosphate-containing layer on the walls of pores of the silica matrix. Under the temperature treatment, a formation of chemical $\mathrm{P}-\mathrm{O}-\mathrm{Si}$ bonds between the phosphate and silicate components along with the free (unbound) polyphosphate acids were observed [91]. It was established [90] that silver was distributed in the pores of amorphous silica in metallic NPs/clusters/ions, which were able to adsorb oxygen to yield several types of oxygen-containing species. An introduction of the polyphosphate to the $\mathrm{Ag} / \mathrm{SiO}_{2}$ catalyst led to changing of the silver state due to the predominant coordination of the Ag ions by phosphate groups. An increase of the phosphate content to up to $50 \% \mathrm{wt}$. in the catalyst composition allowed transforming all silver into ionic state participating in the reversible redox process. It is noteworthy that silver coordinated by the polyphosphate was not able to participate in the deep oxidation of EG [87]. In Figure 11 the TPR profiles for $\mathrm{Ag} / \mathrm{SiO}_{2}$ and $\mathrm{Ag} / \mathrm{P}_{2} \mathrm{O}_{5} / \mathrm{SiO}_{2}$ catalysts in $\mathrm{CO} / \mathrm{He}$ mixture are presented. 

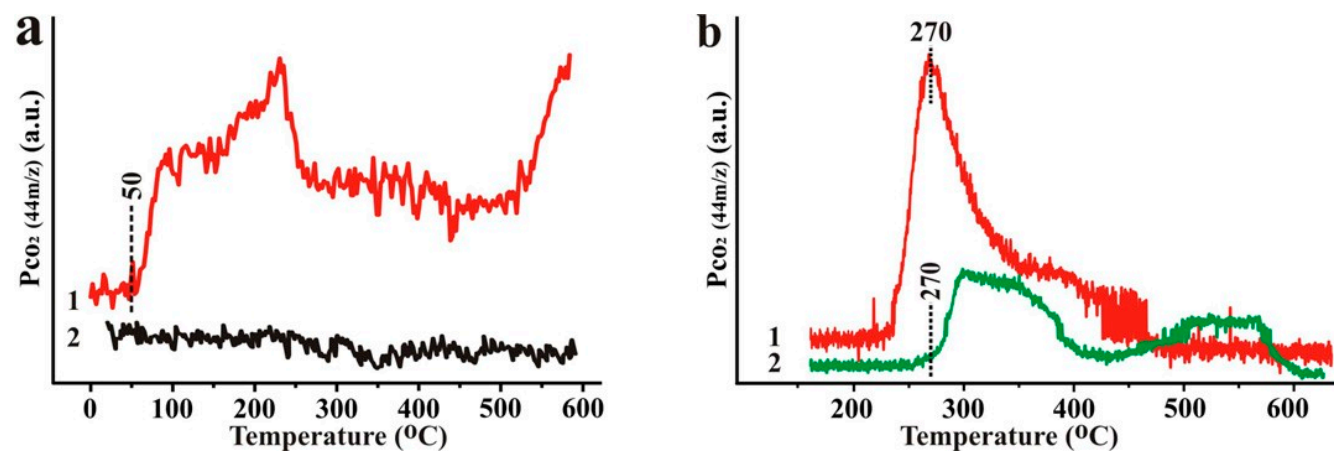

Figure 11. $\mathrm{CO}$ TPR profiles for the Ag- (a) $\left(1-\mathrm{Ag} / \mathrm{SiO}_{2}, 2-\mathrm{Ag} / 5 \_\mathrm{P}_{2} \mathrm{O}_{5} / \mathrm{SiO}_{2}\right)$ and Cu-containing (b) $\left(1-\mathrm{Cu} / \mathrm{SiO}_{2}, 2-\mathrm{Cu} / 30 \_\mathrm{P}_{2} \mathrm{O}_{5} / \mathrm{SiO}_{2}\right)$ model systems. Reprinted with permission from reference [87]. Copyright 2013 Elsevier.

$\mathrm{No} \mathrm{CO}_{2}$ formation occurred in the whole temperature range for the $\mathrm{Ag} / 5-\mathrm{P}_{2} \mathrm{O}_{5} / \mathrm{SiO}_{2}$ catalyst, while for the $\mathrm{Ag} / \mathrm{SiO}_{2}$ sample the $\mathrm{CO}_{2}$ formation was observed starting from $50{ }^{\circ} \mathrm{C}$. Moreover, during the subsequent TPR- $\mathrm{H}_{2}$ experiment for the $\mathrm{Ag} / 5-\mathrm{P}_{2} \mathrm{O}_{5} / \mathrm{SiO}_{2}$ catalyst, the $\mathrm{CO}$ evolution from 280 to up to $340{ }^{\circ} \mathrm{C}$ was observed along with the $\mathrm{H}_{2}$ consumption. This indicated a $\mathrm{CO}$ adsorption on the $\mathrm{Ag}^{+}$species without further oxidation. Thus, the introduction of the phosphate modifier prevented the participation of the Ag-containing active species in $\mathrm{CO}$ oxidation. For $\mathrm{Cu} / 30 \mathrm{P}_{2} \mathrm{O}_{5} / \mathrm{SiO}_{2}$ catalyst, a similar experiment showed $\mathrm{CO}_{2}$ release during the $\mathrm{CO}$ TPR (Figure 11b). It was pointed out that the ability to $\mathrm{CO}$ oxidation into $\mathrm{CO}_{2}$ retained in the presence of polyphosphate (30 wt.\%) in the catalyst composition. A comparison of $\mathrm{Ag}$ - and $\mathrm{Cu}$-containing catalysts showed that under oxidative conditions the $\mathrm{Ag}_{2} \mathrm{O}$ forming upon the interaction with oxygen instantly transforms into silver phosphate without further participation in the total oxidation, while $\mathrm{CuO}$ is presented on the surface. Thus, the catalytic activity of the $\mathrm{Cu} / \mathrm{P}_{2} \mathrm{O}_{5} / \mathrm{SiO}_{2}$ catalysts was lower than that of Ag-containing catalysts due to the formation of the copper oxide on the catalyst surface.

One of the widely used approaches in the field of Ag-containing catalysts for selective oxidation of alcohols is a distribution of the active component along the support surface. Challenges related to support are connected with nature and concentration of functional groups, presence of impurities, thermal conductivity and stability, mechanical strength, etc. For the process of selective EG oxidation, a number of materials was studied as supports, including SiC [82], alumosilicate [79], silicon nitride [57], zirconium phosphate [92,93].

The advantages of the ceramic materials based on silicon nitride $\left(\mathrm{Si}_{3} \mathrm{~N}_{4}\right)$ are high thermal conductivity, enhanced hardness and strength compared to traditional oxide supports such as silica, alumina and their mixtures. Silicon nitride is also a chemically inert material with low specific surface are and practically unfunctionalized surface. All these features are useful for catalysts used in the high-temperature adiabatic conditions. We proposed the $\mathrm{Si}_{3} \mathrm{~N}_{4}$-supported Ag catalysts (unmodified and modified with $\mathrm{Al}$ and $\mathrm{Zr}$ compounds) [57] and prepared them by deposition method from toluene solution using $\mathrm{CF}_{3} \mathrm{COOAg}$ as a precursor. An application of deposition from organic solution allowed distributing the Ag particles uniformly with a maximum of Ag particle sizes of $65-85 \mathrm{~nm}$. A selectivity towards GO exceeded $50 \%$ at $87 \%$ EG conversion. Glycolic aldehyde (GlyAld) was obtained as the main by-product and glycolic (GlycA) and glyoxalic (GOA) acids were detected in the reaction product mixture. It was proposed that the presence of Fe-containing impurities on the silicon nitride surface was the main reason for the decreasing of the selectivity towards GO. The appearance of the Fe-containing impurities was connected with the method of preparation of $\mathrm{Si}_{3} \mathrm{~N}_{4}$ grains, when the nitriding of $\mathrm{Fe}-\mathrm{Si}$ alloy was carried out by a self-propagating high-temperature synthesis (SHS). The final product of the SHS contained the metallic Fe particles surrounded by small $\mathrm{Si}_{3} \mathrm{~N}_{4}$ crystals.

The use of the support able to facilitate the formation of highly dispersed Ag particles on its surface allows increasing the conversion of alcohols and selectivity towards the corresponding carbonyl compounds. Brik et al. [94] and Arsalane et al. [95] studied the catalytic activity of 
silver- and copper-containing phosphates of elements of group 4 in 2-butanol transformations. The advantageous feature of the double phosphate of the element of group 4 is an ion conductivity for $\mathrm{ns}^{1}$ metal cations. A specific ionic conductivity of the double phosphates allows forming the $\mathrm{Ag}$ (or $\mathrm{Cu}$ ) particles with small sizes on the matrix surface and providing their stability in the catalytic process. Dorofeeva et al. [92] studied the selective oxidation of EG over zirconium and silver-zirconium phosphate catalysts. The Ag-containing zirconium phosphate catalysts were prepared by co-precipitation method (CP), sol-gel method (SG) and method of ion-exchange of $\mathrm{Na}^{+}$cations to $\mathrm{Ag}^{+}$(IE). It was established that the using of CP method led to maximal Ag loss in the mother solution due to the formation of impurity $\mathrm{ZrP}_{2} \mathrm{O}_{7}$ and $\mathrm{Zr}_{2.25}\left(\mathrm{PO}_{4}\right)_{3}$ phases along with $\mathrm{AgZr}_{2}\left(\mathrm{PO}_{4}\right)_{3}$ phase. The catalytic properties of silver-containing zirconium phosphates prereduced in $\mathrm{H}_{2}$ flow were studied in EG oxidation into GO. The EG conversion for Ag-containing catalysts increased simultaneously with oxygen content in the feed and at $\mathrm{O}_{2} / \mathrm{EG}=1$ it achieved $95 \%$. However, $\mathrm{CO}$ and $\mathrm{CO}_{2}$ yields also increased. The maximal selectivity towards $\mathrm{GO}$ for $\mathrm{CP}$ and SG catalysts were $53 \%$ and $41 \%$, respectively, at a lower molar ratio of $\mathrm{O}_{2} / \mathrm{EG}=0.6$. The maximal selectivity towards GO for IE sample (53\%) at $93 \%$ EG conversion was observed at $\mathrm{O}_{2} / \mathrm{EG}=1.0$. The main reason for a relatively low selectivity of Ag-containing zirconium phosphate catalysts was associated with the irreversible destruction of $\mathrm{AgZr} 2\left(\mathrm{PO}_{4}\right)_{3}$ phase to yield $\mathrm{ZrP}_{2} \mathrm{O}_{7}$ and $\mathrm{Zr}_{3}\left(\mathrm{PO}_{4}\right)_{4}$ phases under the action of reducing agent $\left(\mathrm{H}_{2}\right)$ accumulating in the reaction mixture. Thus, in its turn, the formation of the oxide-like Ag-containing species occurred, and the selectivity towards $\mathrm{CO}_{x}$ product increased.

The mechanism of selective EG oxidation was actively studied $[88,96,97]$. To determine the role of phosphate and silicate functional groups in the composition of the Ag-containing catalyst of new generation, Mamontov et al. [88] compared the EG adsorption on the surfaces of $\mathrm{Ag} / \mathrm{SiO}_{2}$ and $\mathrm{Ag} / \mathrm{P}_{2} \mathrm{O}_{5} / \mathrm{SiO}_{2}$ catalysts before and after oxygen treatment using in-situ IR-spectroscopy. The nature and a concentration of the active species on the catalyst surface were determined by the low-temperature $\mathrm{CO}$ adsorption. According to the spectra for the oxidized $\mathrm{Ag} / \mathrm{P}_{2} \mathrm{O}_{5} / \mathrm{SiO}_{2}$ and $\mathrm{Ag} / \mathrm{SiO}_{2}$ catalysts, the absorption bands at $2172-2175 \mathrm{~cm}^{-1}$ identified as acid sites were represented as $\mathrm{Ag}^{+}$in the concentrations of $115 \mu \mathrm{mol} / \mathrm{g}\left(4.11 \mu \mathrm{mol} / \mathrm{m}^{2}\right)$ and $77 \mu \mathrm{mol} / \mathrm{g}\left(0.82 \mu \mathrm{mol} / \mathrm{m}^{2}\right)$, respectively. The isolated $\mathrm{OH}$ groups $\left(\nu \mathrm{CO}=2150 \mathrm{~cm}^{-1}\right)$ were obtained on the surface of reduced $\mathrm{Ag} / \mathrm{P}_{2} \mathrm{O}_{5} / \mathrm{SiO}_{2}$ catalyst. A concentration of the isolated $\mathrm{OH}$ groups on the reduced $\mathrm{Ag} / \mathrm{SiO}_{2}$ catalyst was greater as compared to the one on the oxidized catalyst that confirmed their participation in coordination of the charged silver species. An incomplete reduction of silver on the surface of the reduced $\mathrm{Ag} / \mathrm{P}_{2} \mathrm{O}_{5} / \mathrm{SiO}_{2}$ was observed. Based on the data on the temperature dependence of EG adsorption it was shown that EG is predominantly adsorbed on the catalyst surface with the participation of the phosphate groups (Figure 12).

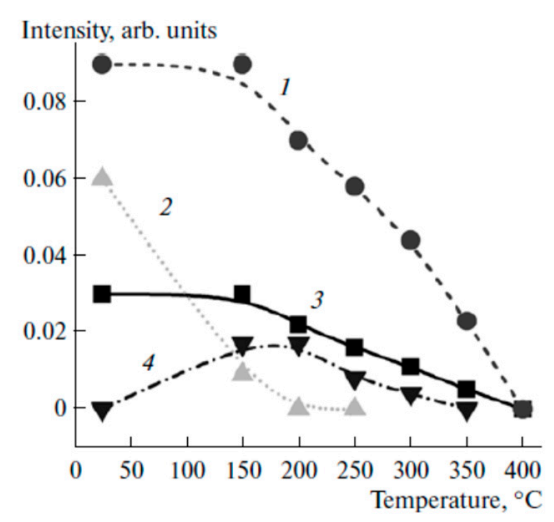

Figure 12. The temperature dependence of the stability of ethylene glycol complexes adsorbed on the reduced $\mathrm{Ag} / \mathrm{P}_{2} \mathrm{O}_{5} / \mathrm{SiO}_{2}$ : (1) catalyst: (1) $\mathrm{H}$-bonded $\mathrm{POH}$ groups $\left(3500-3600 \mathrm{~cm}^{-1}\right.$ ), (2) $\mathrm{H}$-bonded $\mathrm{OH}$ groups of ethylene glycol $\left(3220 \mathrm{~cm}^{-1}\right)$, (3) CH groups of ethylene glycol $\left(2960 \mathrm{~cm}^{-1}\right)$, and (4) free $\mathrm{OH}$ groups $\left(3735 \mathrm{~cm}^{-1}\right)$. Reprinted with permission from reference [88]. Copyright 2013 Springer. 
The kinetics of EG interaction with oxygen was investigated at $300{ }^{\circ} \mathrm{C}$ [88]. The adsorbed complexes of EG with silver ions and $\mathrm{H}$-bonded complexes slowly decomposed in the presence of oxygen (for $5 \mathrm{~min}$ ) on the oxidized $\mathrm{Ag} / \mathrm{P}_{2} \mathrm{O}_{5} / \mathrm{SiO}_{2}$ catalyst. However, carbon dioxide was detected in the products. On the reduced $\mathrm{Ag} / \mathrm{P}_{2} \mathrm{O}_{5} / \mathrm{SiO}_{2}$ samples, $\mathrm{CO}_{2}$ and water were also formed, while weak absorption bands due to vibrations of $\mathrm{C}=\mathrm{O}\left(1690 \mathrm{~cm}^{-1}\right)$ and carboxyl $-\mathrm{COOH}\left(1825-1850 \mathrm{~cm}^{-1}\right)$ groups were detected in the spectra.

Based on the experimental kinetic data, a scheme of EG transformation steps was proposed (Figure 13).

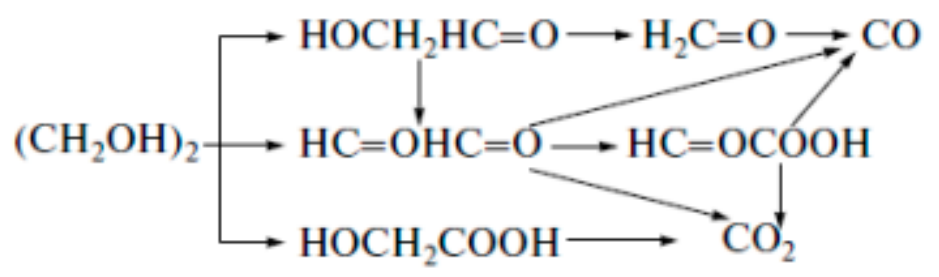

Figure 13. Base directions of EG transformation. Reprinted with permission from reference [88].

Copyright 2013 Springer.

EG was able to adsorb reversibly on the reduced surface of Ag yielding a bidentately bound intermediate compound [97]. After the preliminary adsorption of oxygen on the surface of silver a 1,2-ethanedioxide cyclic intermediate was formed. Then two $\beta-\mathrm{C}-\mathrm{H}$ bonds in the intermediate were destroyed to form GO. An increase of the surface coverage of adsorbed oxygen led to the $\mathrm{C}-\mathrm{C}$ bond scission in a bidentately bonded intermediate to yield formaldehyde and $\mathrm{CO}_{2}$. The formation of a monodentately bound intermediate compound with its subsequent transformation into GlyAld under the testing conditions did not occur. An increase in the contact time and/or temperature led to the appearance of GO, which was formed as a result of a simultaneous scission of two $\beta-\mathrm{C}-\mathrm{H}$ bonds in the cyclic intermediate. The formation of cyclic intermediate occurred only with an increasing of the temperature to up to $450-500{ }^{\circ} \mathrm{C}$, when a parallel reaction route made a significant contribution (to up to $30 \%)$.

A detailed investigation of the mechanism of EG oxidation over $\mathrm{Ag}_{4}$ silver cluster was carried out at B3LYP/DGDZVP level of theory in our previous work [96]. The results were obtained for all species involved within a common approach. The reaction profiles reflecting the processes of EG partial oxidation to $\mathrm{GO}$ and its deep oxidation to $\mathrm{CO}_{2}$ were generated. Bridge sites were preferable for atomic oxygen adsorption and participated in EG activation. Hollow sites were involved in deep oxidation processes. This correlated well with known assumptions on different forms of oxygen on the surface of Ag-containing catalysts and their roles in oxidation processes over Ag-containing catalysts. Ethylenedioxy and 2-oxyethoxy species were revealed as the most important reaction intermediates transforming into major reaction products.

\subsubsection{Propylene Glycol}

Partial oxidation of propylene glycol (PG) under gas-phase conditions is studied in a lesser extent than EG, while a large number of valuable chemicals can be produced on the basis thereof (e.g., hydroxyacetone (HA), methyl glyoxal (MeGO), lactaldehyde (LAld), acetol (Ac), lactic acid (LA), etc. [98,99]). Various catalytic systems were proposed for partial oxidation of PG, including bimetallic NPs on the basis of $\mathrm{Au}$ and Pt subgroup metals [100,101], oxide Fe-Mo catalysts [102], supported $\mathrm{FePO}_{4} / \mathrm{SiO}_{2}$ catalysts [103], etc.

Shen et al. $[104,105]$ prepared a catalyst comprising Ag NPs supported on a zeolite film coated copper grid (ZFC) by combining an in situ electrolytic method to produce highly dispersed Ag NPs with the seed-film method to prepare an ultrathin zeolite film. Compared to conventional bulk electrolytic silver catalyst, the obtained catalysts $(7 \mathrm{wt} \% \mathrm{Ag})$ showed higher activity in the oxidation of monoalcohols (3,5,5-trimethylhexanal, 2-ethyl hexanol) at moderate temperature $320-360^{\circ} \mathrm{C}$ and higher 
selectivity towards ketonic aldehydes in the oxidation of dialcohols (1,2-butylene glycol, 2,3-butylene glycol, PG). High catalytic performance was attributed to the highly dispersed Ag NPs containing a large amount of $\mathrm{Ag}^{+}$ions and $\mathrm{Ag}_{\mathrm{n}}{ }^{\delta+}$ clusters, while zeolite film prevented their sintering.

Mao et al. [106] prepared an Ag catalyst supported on a sinter-locked three-dimensional microfibrous network made up of Ni or stainless steel (SS) fibers and studied the catalyst in the gas-phase selective oxidation of mono-, di- and aromatic alcohols. The authors used papermaking/sintering processes to prepare the supports and the incipient wetness impregnation method to deposit silver. Silver amount was $20 \mathrm{wt} \%$ for $\mathrm{Ag} / \mathrm{Ni}$-fiber and $\mathrm{Ag} / \mathrm{SS}$-fiber catalysts. High catalytic activity was achieved at $380^{\circ} \mathrm{C}$, with the activity of $\mathrm{Ag} / \mathrm{Ni}$-fiber being superior to the one of the Ag/SS-fiber. The conversion of PG and selectivity towards MeGO for the $\mathrm{Ag} / \mathrm{Ni}$-fiber and the electrolytic silver were $99 \%$ and $83 \%$ at $330{ }^{\circ} \mathrm{C}$ and $90 \%$ and $42 \%$ at $450{ }^{\circ} \mathrm{C}$, respectively. A synergistic effect caused by the interaction of $\mathrm{Ag}-\mathrm{Ni}$ particles enhanced the performance of active and selective Ag ions/charged clusters and facilitated their low-temperature reducibility and ability to activate oxygen. The samples were characterized by a large void volume, open structure, high thermal conductivity and permeability. The authors did not present the alcohol content in the reaction mixture. No data on the durability of the desired catalysts, their characteristics after catalytic experiment were presented as well.

Shen et al. [107] prepared $\mathrm{Ag} / \mathrm{ZrO}_{2}$ catalysts by impregnation technique and tested them in partial oxidation of PG to MeGO. The alcohol conversion was $95.7 \%$ at a selectivity towards MeGO of $55.3 \%$. The enhanced activity as compared to electrolytic Ag was shown to be caused by the large amount of partially charged $\mathrm{Ag}^{\delta+}$ species. Yang et al. [108] showed that the $\mathrm{Ag} / \mathrm{ZrO}_{2}$ catalysts can be prepared by a green and facile microwave-assisted biosynthesis method using the leaf extract of Cinnamomum camphoraas a reducing and capping agent to produce Ag NPs. At $340{ }^{\circ} \mathrm{C}$, the catalyst shows the alcohol conversion of $96 \%$ at $79 \%$ selectivity towards the desired aldehyde. The catalyst sample with $5 \mathrm{wt} \%$ of silver shows the highest catalyst performance during the $50 \mathrm{~h}$ of assessment. The authors concluded that small and uniform sizes of the Ag NPs as well as their dispersity are of importance to achieve the high catalyst performance. The role of the support in the above-described catalysts is not clear.

Thus, the authors of abovementioned publications share the opinion that the main approach to achieve high activity of Ag-containing catalysts for the gas-phase PG oxidation into MeGO is the use of silver NPs and / or clusters. To achieve the enhanced catalyst performance, the use of the supports with good thermal conductivity (such as Ni- or SS fibers or Cu grid) was proposed [106], while another way is to control the sizes of the Ag NPs at the stage of the catalyst preparation [107]. Unfortunately, the majority of the described publications do not contain a sufficient description of the conditions of PG oxidation that hinders the detailed comparison of the activity of various Ag-containing catalysts in this process. Nevertheless, the application of silver to develop the highly efficient catalysts for selective oxidation of diols is a promising approach. A comparison of the results obtained for EG and PG (e.g., $[84,86]$ and $[105,106])$ shows that the temperature of PG oxidation is lower that is connected with higher reaction ability of the secondary $\mathrm{OH}$ group towards its oxidation into ketone. The common feature for oxidation of both diols is an enhancement of the catalyst activity, when Ag NPs are used as active sites.

\subsubsection{Glycerol}

Glycerol (GLY) is known to be a source of a number of value-added products [109]. Although several different catalytic systems were proposed for gas-phase selective oxidation of GLY [110-112], Ag based catalysts have recently attracted an interest. Thus, Lari et al. [113] developed the $\mathrm{Ag} / \mathrm{Al}_{2} \mathrm{O}_{3}$ catalysts (Ag loading of $5 \mathrm{wt} \%, \mathrm{~S}_{\mathrm{BET}}=74 \mathrm{~m}^{2} / \mathrm{g}$ ) for oxidehydration of GLY to MeGO. The authors showed superior performance of the synthesized materials as compared to other $\mathrm{M} / \mathrm{Al}_{2} \mathrm{O}_{3}$ catalysts $(\mathrm{M}=\mathrm{V}$, $\mathrm{Ni}, \mathrm{Fe}, \mathrm{Sn}, \mathrm{Cu}, \mathrm{Ru}, \mathrm{Pd}, \mathrm{Pt}, \mathrm{Au}$ ), which was connected with optimal redox potential of silver and higher concentration of Lewis acid sites accompanied by the limited Brønsted acidity of the support. Tuning the reaction conditions allowed increasing the MeGO yield (80\%) and maintaining it in a 
24-h test. Using DFT it was shown that the oxidation of Ac intermediate is both kinetically and thermodynamically favorable over the partially oxidized silver surface as compared to metallic or completely oxidized ones (Figure 14).

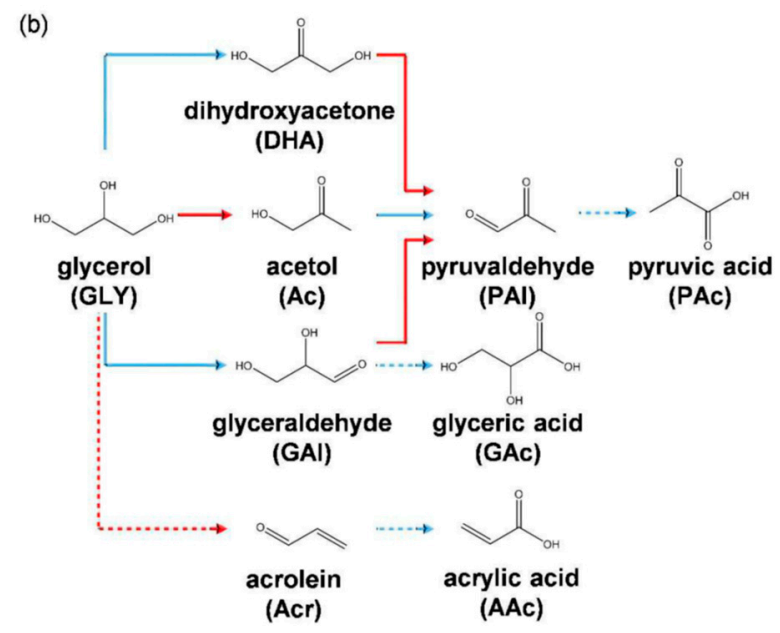

Figure 14. Reaction network envisaged for the gas-phase conversion of glycerol to pyruvaldehyde. The dashed arrows identify competitive oxidative and dehydrative pathways. Reprinted with permission from reference [113]. Copyright 2016 Royal Society of Chemistry.

Thus, oxidation of polyalcohols into valuable carbonyl compounds over Ag-based catalysts attracts a vivid interest in the field of processing of biorenewable sources, namely, PG and GLY. The advantage of selective oxidation of these alcohols in the gas phase over the supported Ag catalysts is the opportunity to obtain the rather concentrated solutions of MeGO without its further transformation into lactic acid.

\section{Heterogeneous Liquid-Phase Selective Oxidation}

In comparison with the gas phase processes, the liquid-phase oxidation of alcohols requires lower reaction temperatures, energy consumption and allows synthesizing the products that cannot be obtained in a vapor-phase reaction. At the same time, boiling of some substrates with decomposition and leaching of the active component are crucial issues for practical application of liquid-phase heterogeneous catalytic processes, especially for polar oxygen-containing substrates and products [114]. The noble metal-based composites $(\mathrm{M}=\mathrm{Pt}, \mathrm{Pd}, \mathrm{Au}, \mathrm{Ru})$ are currently widely used as heterogeneous catalysts for liquid-phase oxidative transformations of alcohols $[13,115]$. However, these materials demonstrate low activity in the oxidation of non-activated substrates. Their large-scale application is still limited due to high costs, toxicity and low selectivity towards carbonyl compounds caused by overoxidation. It is noteworthy also that platinum group metals tend to deactivate quickly [116].

Although silver-based catalysts are widely used in gas-phase oxidation there are few publications reporting the catalytic activity of silver in the liquid-phase alcohol oxidation, while a number of articles demonstrate its high potential to be used in such reactions [117-121]. A recent review by Kolobova et al. [117] considers the state of the art in a liquid-phase Ag-catalyzed oxidation of alkyland halogen derivatives of monoalcohols (methanol, ethanol, BA, etc.), cyclic and macrocyclic alcohols (cyclohexanol, cyclododecanol), polyalcohols (GLY), unsaturated alcohols (cinnamyl alcohol, crotyl alcohol, allylcarbinol, 2-cyclohexenol) and fatty alcohols (e.g., 1-octanol). Thus, in the present review we will focus mostly on the selective liquid-phase oxidation of BA and biomass-derived polyols (PG and GLY). 


\subsection{Benzyl Alcohol}

L.F. Liotta and co-authors added silver to palladium supported on pumice in order to improve the lifetime and catalytic performance of the catalyst in liquid-phase selective oxidation of BA [122]. Addition of silver led to a 10-times decrease of the rate constant, but the selectivity towards BAld enhanced from $95 \%$ to $100 \%$ at a complete BA conversion. The activity of a physical mixture of monometallic catalysts was found higher than the one for individual monometallic component showing a certain synergism between the uncharged $\mathrm{Ag}$ and Pd active species (Table 4). The authors proposed the role of Pd to be connected with an activation of the substrate, whereas highly dispersed Ag is important for the activation of molecular oxygen.

M.J. Beier et al. explored the activity of the Ag-based catalysts promoted by the presence of ceria as catalysts for aerobic oxidation of various primary and secondary alcohols [119]. Although the $\mathrm{Ag} / \mathrm{SiO}_{2}$ and $\mathrm{CeO}_{2} \mathrm{NPs}$ were almost inactive, their physical mixture was found extremely catalytically active and selective towards the formation of the corresponding carbonyl compounds (Table 4). A soluble cerium source did not increase the activity of the catalytic system. Both higher $\mathrm{Ag}$ and $\mathrm{CeO}_{2}$ loading improved the selectivity towards aldehyde in oxidation of BA as a model substrate (Figure 15). The authors supposed that the role of $\mathrm{CeO}_{2}$ may be connected with the reversibly storing oxygen. The calcination temperature played an important role due to the formation of the oxidized silver species on mostly metallic silver. Low concentration of both active components was found in filtrate after the catalysis, but the hot catalyst filtration test confirmed the heterogeneous nature of catalysis.

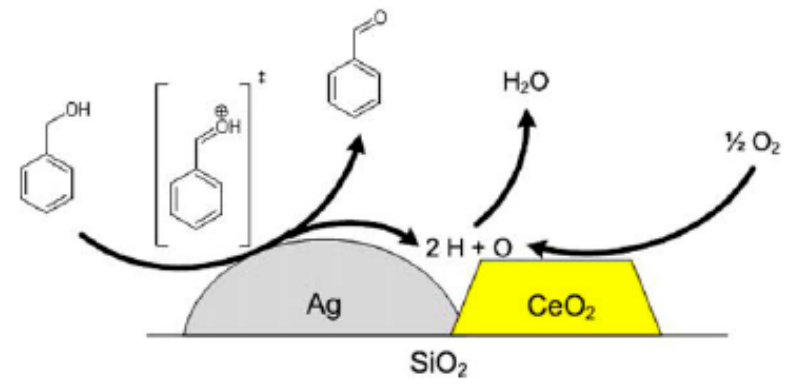

Figure 15. Schematic and simplified reaction mechanism of benzyl alcohol oxidation with $\mathrm{O}_{2}$ over $\mathrm{Ag} / \mathrm{SiO}_{2}$ in presence of ceria. Benzyl alcohol oxidation occurs via adsorption of substrate on silver surface, dehydrogenation followed by desorption of benzaldehyde. Hydrogen is removed from the silver surface by means of atomic oxygen provided by the $\mathrm{CeO}_{2}$-Ag interface.Reprinted with permission from reference [119]. Copyright 2009 Elsevier.

Huang et al. investigated the kinetics of aerobic oxidation of BA over the colloidal Au-Ag alloy NPs with various Ag/Au molar ratios [123]. They found that the addition of silver not only significantly enhanced the reaction rate, but also increased the apparent activation energy in comparison with the monometallic Au NPs. The apparent reaction orders decreased with the increase in the Ag/ $\mathrm{Au}$ molar ratio. The charge transfer between the $\mathrm{Au}$ and $\mathrm{Ag}$ produced a synergetic effect, resulting in a different reaction mechanism. The electron-poorer Au atoms with higher electron-accepting ability caused an increase of the deprotonation rate of adsorbed alcohol species. During the subsequent research, Huang and co-workers investigated the activity of the Au-Ag NPs in aerobic oxidation of BA in the presence of $\mathrm{Na}_{2} \mathrm{CO}_{3}$ (Table 4) [124]. The reaction rate in this case increased with an increase of an Ag molar content to up to $10 \%$, after that it began to decline. The authors proposed that the reason lies in a decrease of the Au active sites and the change in the coordination environments of the Au atoms on the surface. The colloidal $\mathrm{Au}_{0.95} \mathrm{Ag}_{0.05}$ alloy NPs were investigated in aerobic oxidation of various kinds of alcohols. Although the selective oxidation of aliphatic alcohols with molecular oxygen is a more demanding transformation than that for BA and the majority of known catalysts had a poor activity the P123-stabilized Au-Ag NPs showed an excellent catalytic activity in the oxidation of aliphatic and cycloaliphatic alcohols under the presented conditions. 
Zahed et al. investigated the support effect of three different forms of graphene oxide on the catalytic performance of the supported Ag NPs in aerobic oxidation of BA in the presence of $N$-hydroxyphthalimide (NHPI) as a radical activator [125]. The Ag NPs are believed to play the role of a generator of $\mathrm{N}$-oxyl radicals from the NHPI by electron transfer, which initiated the radical chain oxidation process. Nanocomposites of the Ag NPs with the reduced graphene oxide $(\mathrm{Ag} / \mathrm{rGO})$, partially reduced graphene oxide $(\mathrm{Ag} / \mathrm{GO})$ and thiolated partially reduced graphene oxide (Ag/GOSH) were synthesized and characterized by IR, UV-Vis and Raman spectroscopy, ICP, X-ray diffraction, SEM and TEM methods. Despite the smallest size of the Ag NPs and the highest metal content (Table 4) the $\mathrm{Ag} / \mathrm{rGO}$ catalyst showed the lowest activity. The authors explained this phenomenon by the loss of a wrinkled morphology. Moreover, because of the weak interaction between the silver NPs and a reduced graphene oxide with a low content of oxygen-containing groups Ag leached after the first catalytic cycle. Ag/GOSH catalyst showed higher activity and selectivity towards BAld compared with both $\mathrm{Ag} / \mathrm{GO}$ and $\mathrm{Ag} / \mathrm{rGO}$. The strong adhesion between the GOSH and Ag NPs inhibited the aggregation of silver during the catalytic reaction and resulted in high activity and stability to obtain the materials in at least five cycles.

The oxidation of BA and its derivatives into corresponding aldehydes with high conversion and selectivity (yield $>70 \%$ ) was performed by Adil et al. [126] over the nanosilver-doped manganese oxide. It was observed that the calcination temperature affected significantly the Mn-containing phase distribution, surface area and as a consequence the catalytic activity of the obtained materials. The catalysts containing $\beta-\mathrm{MnO}_{2}$ gave the best catalytic activity. The TEM data showed a good dispersion of spherical silver NPs in $\mathrm{MnO}_{2}$.

Alabbad et al. compared the activity of gold and silver NPs supported on manganese oxide calcined at different temperatures in the oxidation of BA with molecular oxygen [127]. The increase in calcination temperature led to an increasing in average particle sizes from $\sim 3 \mathrm{~nm}$ to $4.4 \mathrm{~nm}$. At the same time, BET surface area changed in a more difficult way. The catalyst calcined at $400{ }^{\circ} \mathrm{C}$ was found to possess the highest $S_{B E T}\left(86.9 \mathrm{~m}^{2} / \mathrm{g}\right)$ compared to those calcined at 300 and $500{ }^{\circ} \mathrm{C}(26.82$ and $48.95 \mathrm{~m}^{2} / \mathrm{g}$, respectively). It was observed that the catalyst calcined at 300 and $500{ }^{\circ} \mathrm{C}$ displayed lower catalytic activity than those calcined at $400{ }^{\circ} \mathrm{C}$ (Table 4).

Recently, Assal et al. used highly reduced graphene (HRG) as a dopant to enhance the catalytic activity of $\mathrm{Ag}_{2} \mathrm{O}$-doped $\mathrm{MnO}_{2}$ in aerobic oxidation of alcohols [128]. The effect of dopant amount was examined. The enhancement of the HRG weight percentage to up to $5 \%$ led to a significant increase in the specific activity and yielded a complete conversion within $35 \mathrm{~min}$ (Table 4). Further increase of the HRG amount in catalyst resulted in a slight reduction of the catalytic activity, which is attributed to the blocking of the active sites. The authors claimed that the role of graphene doping was connected with the adsorption of the aromatic alcohols on the catalyst surface through the $\pi-\pi$ interaction. Furthermore, the existence of carbon defects and oxygen carrying functional groups on the HRG plane facilitated the anchoring of the $\mathrm{Ag}_{2} \mathrm{O}$ NPs. The temperature of the calcination treatment affected significantly the phase composition, surface area and catalytic activity of the obtained materials (Table 4). Both aromatic and aliphatic alcohols were converted completely into corresponding aldehydes with almost $100 \%$ selectivity under mild reaction conditions. The catalyst showed good reusability during five reaction cycles, however, the possible leaching of the active components was not investigated. $\mathrm{Ag}_{2} \mathrm{O}$ NPs-doped manganese immobilized on graphene nanocomposites were also successfully employed for aerobic oxidation of various kinds of secondary alcohols [129].

The oxidant-free alcohol dehydrogenation in the liquid phase over hydrotalcite- [130] and silica-coated ferrite-supported [131] silver NPs was found to be highly atom-efficient and reusable. Over Ag/hydrotalcite catalyst, the selectivity towards the corresponding carbonyl compounds for different types of alcohols was above $90 \%$ [130]. Generally, the conversion was also close to $100 \%$. Only aliphatic alcohols such as 1-octanol were not dehydrogenated efficiently over such system. The use of magnetic silica-coated ferrite as a support for Ag NPs enabled the catalyst separation process from the reaction mixture and its reuse [131]. The proposed reaction mechanism in the case of 
BA dehydrogenation over $\mathrm{Fe}_{3} \mathrm{O}_{4} @ \mathrm{SiO}_{2}-\mathrm{Ag}$ catalyst is presented in Figure 16. The alcohol molecule adsorbed on the silica surface through the hydrogen bond interaction with $\mathrm{Si}-\mathrm{OH}$ groups and the Ag NPs are responsible for hydrogen abstraction and $\mathrm{H}_{2}$ formation. Qi et al. [132] also investigated the magnetic Ag-containing catalysts in BA oxidation. The $\mathrm{Ag} / \mathrm{Fe}_{2} \mathrm{O}_{3}$ catalyst was prepared by the solvent thermal reduction method. However, in this case hydrogen peroxide was used as an oxidant. The dependence of BA conversion on the Ag content in the catalyst had a volcano-type shape, while the selectivity towards BAld slightly decreased with the increase of silver content. The highest BAld yield was observed for the catalyst with $2 \% \mathrm{Ag}$ (mol). The authors assumed that the reason was the agglomeration of silver and the increase in particles size. The catalytic activity of $\mathrm{Ag} / \mathrm{Fe}_{2} \mathrm{O}_{3}$ in oxidation of $\mathrm{BA}$ with $\mathrm{H}_{2} \mathrm{O}_{2}$ tended to reduce gradually in each cycle.

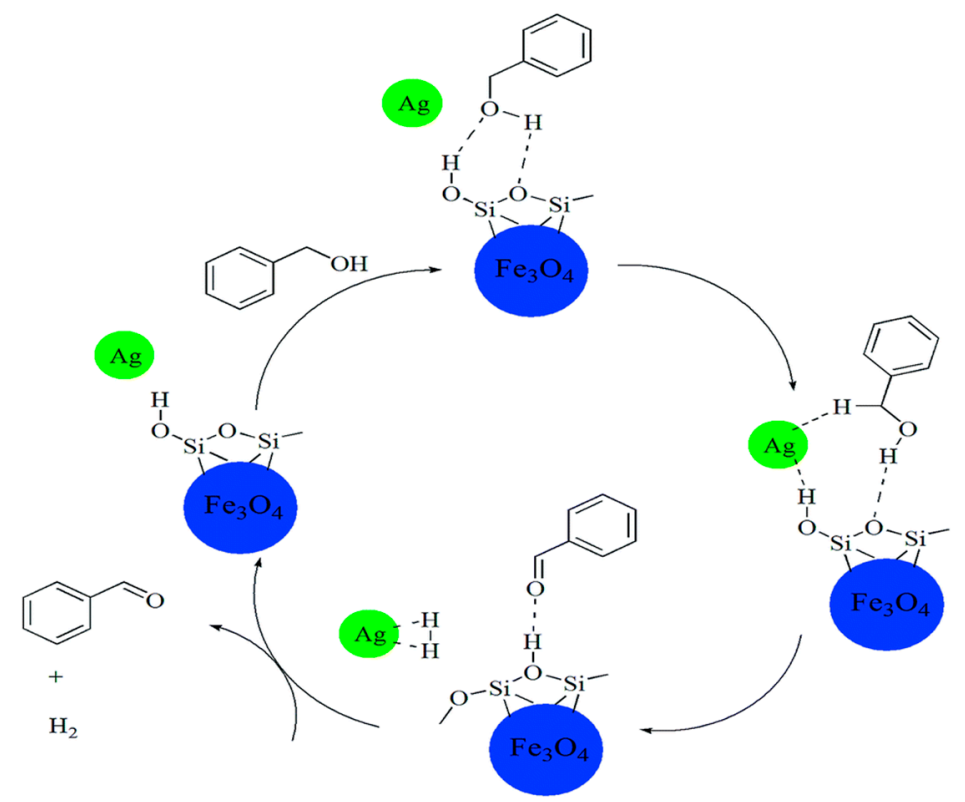

Figure 16. Mechanism of benzyl alcohol dehydrogenation by $\mathrm{Fe}_{3} \mathrm{O}_{4} @ \mathrm{SiO}_{2}-\mathrm{Ag}$ catalyst. Reprinted with permission from reference [131]. Copyright 2014 Asian Publication Corporation.

Bhuyan et al. [133] used biosynthesized silver NPs dispersed in a water extract of fly ash (WEFA) for green oxidant-free dehydrogenation of BA under mild conditions. Fly ash is a coal combustion residue predominantly consisting of $\mathrm{Si}, \mathrm{Al}, \mathrm{Ca}, \mathrm{Fe}, \mathrm{Mg}$, $\mathrm{K}$ and $\mathrm{Na}$ oxides. The high concentration of $\mathrm{SiO}_{2}$ stabilizes the Ag NPs. The as-prepared NPs are polydispersed and consistently spherical with a size in the range of 10-20 nm. A uniform dispersion of the Ag NPs in the WEFA was observed. The effect of the reaction conditions (the amount of Ag@WEFA, reaction time and temperature) was studied in the dehydrogenation of 4-methylbenzyl alcohol as a model substrate. Under the optimized reaction conditions, the dehydrogenative oxidation of a wide range of BA bearing electron-withdrawing and electron-donating groups over Ag@WEFA catalytic system proceeded with an excellent yield of the desired product within a very short reaction time. Despite the attractive reaction conditions and utilization of the waste for production of carbonyl compounds with high yield there are some difficulties with the industrial application of that kind of materials, reproducibility of results and debating issues in the understanding of reaction mechanism due to an incompletely clear variable composition of fly ash.

Yadav G.D. and Yadav A.K. [134] investigated the oxidation of various secondary aliphatic and aromatic alcohols to ketones with tert-butylhydroperoxide over nano-fibrous silver-containing cryptomelane type octahedral molecular sieve type 2 (Ag-OMS-2). The samples were synthesized by the precipitation method with manganese acetate, silver nitrate and $\mathrm{KMnO}_{4}$. The synergistic effect of $\mathrm{Ag}$, Mn and $\mathrm{K}$ is believed to be responsible for the high catalytic activity of the catalysts. The effect of solvent on the oxidation of 1-phenylethanol was examined. No clear dependence of the substrate 
conversion on the solvent polarity and protic/aprotic properties was found, and acetonitrile was the best solvent under the optimized reaction conditions. Other oxidants such as hydrogen peroxide and molecular oxygen did not give any conversion of alcohols. Similar solvent and oxidant effect was demonstrated for alcohol oxidation over Ag-doped $\mathrm{ZnO}$ composite for BA oxidation (Table 4) [135]. The presence of induction period in $\mathrm{BA}$ oxidation over $\mathrm{Ag} / \mathrm{ZnO}$ allowed the authors to assume that the metallic silver particles are required to activate the dissociation of adsorbed oxygen molecules with the formation of charged $\mathrm{Ag}$ species $\left(\mathrm{Ag}^{+}\right)$. The atomic oxygen species such as $\mathrm{O}_{\mathrm{ad}}^{-\mathrm{x}}$ has a nucleophilic character and activates the $\mathrm{C}-\mathrm{H}$ and $\mathrm{O}-\mathrm{H}$ bonds in $\mathrm{BA}$ to produce the corresponding aldehyde (Figure 17). However, the authors emphasize that the $\mathrm{ZnO}$ support also plays an important role in alcohol oxidation. If metal and support are separated from each other, the transportation of oxygen species is inhibited.

Table 4. Benzyl alcohol oxidation over silver containing catalysts.

\begin{tabular}{|c|c|c|c|c|c|c|c|c|c|c|}
\hline \multirow{2}{*}{ Catalyst } & \multirow{2}{*}{$\omega(\mathrm{Ag}), \%(w t)$} & \multirow{2}{*}{ Oxidant } & \multirow{2}{*}{$\mathrm{T},{ }^{\circ} \mathrm{C}$} & \multirow{2}{*}{$t, h$} & \multirow{2}{*}{ Solvent } & \multirow{2}{*}{$X, \%$} & \multicolumn{3}{|c|}{ Selectivity, \% } & \multirow{2}{*}{ Ref. } \\
\hline & & & & & & & BAld & BA & BB & \\
\hline Ag/pumice & 0.6 & $\mathrm{O}_{2}$ & 75 & & $\mathrm{CH}_{3} \mathrm{CN}$ & $4.5^{\mathrm{a}}$ & 100 & & & [122] \\
\hline $\mathrm{Ag} / \mathrm{SiO}_{2}+\mathrm{CeO}_{2}$ & 10 & $\mathrm{O}_{2}$ & reflux & 2 & xylene & 98 & 95 & & & [119] \\
\hline $\mathrm{Ag} / \mathrm{MnO}_{2}$ & 1 & $\mathrm{O}_{2}$ & 100 & 2 & toluene & 100 & $>99$ & & & [126] \\
\hline $\mathrm{Ag}_{2} \mathrm{O}-\mathrm{MnO}_{2}$ & $1^{b}$ & $\mathrm{O}_{2}$ & 100 & 0.6 & toluene & 67.0 & $>99$ & & & [128] \\
\hline $\mathrm{Ag}_{2} \mathrm{O}-\mathrm{MnO}_{2} / 1 \% \mathrm{HRG}$ & $1^{b}$ & $\mathrm{O}_{2}$ & 100 & 0.6 & toluene & 70.6 & $>99$ & & & [128] \\
\hline $\mathrm{Ag}_{2} \mathrm{O}-\mathrm{MnO}_{2} / 3 \% \mathrm{HRG}$ & $1^{b}$ & $\mathrm{O}_{2}$ & 100 & 0.6 & toluene & 84.0 & $>99$ & & & [128] \\
\hline $\mathrm{Ag}_{2} \mathrm{O}-\mathrm{MnO}_{2} / 5 \% \mathrm{HRG}$ & $1^{b}$ & $\mathrm{O}_{2}$ & 100 & 0.6 & toluene & 100.0 & $>99$ & & & [128] \\
\hline $\mathrm{Ag}_{2} \mathrm{O}-\mathrm{MnO}_{2} / 7 \% \mathrm{HRG}$ & $1^{b}$ & $\mathrm{O}_{2}$ & 100 & 0.6 & toluene & 96.0 & $>99$ & & & [128] \\
\hline $\mathrm{Ag}_{2} \mathrm{O}-\mathrm{MnO}_{2} / 5 \% \mathrm{HRG}^{\mathrm{c}}$ & $1^{b}$ & $\mathrm{O}_{2}$ & 100 & 0.6 & toluene & 95 & $>99$ & & & [128] \\
\hline $\mathrm{Ag}_{2} \mathrm{O}-\mathrm{MnO}_{2} / 5 \% \mathrm{HRG}^{\mathrm{d}}$ & $1^{b}$ & $\mathrm{O}_{2}$ & 100 & 0.6 & toluene & 100 & $>99$ & & & [128] \\
\hline $\mathrm{Ag}_{2} \mathrm{O}-\mathrm{MnO}_{2} / 5 \% \mathrm{HRG}^{\mathrm{e}}$ & $1^{b}$ & $\mathrm{O}_{2}$ & 100 & 0.6 & toluene & 44 & $>99$ & & & [128] \\
\hline $\mathrm{Ag} 5 \% \mathrm{Au} / \mathrm{MnO}_{2}{ }^{\mathrm{c}}$ & 5 & $\mathrm{O}_{2}$ & 100 & 1.5 & toluene & 69.51 & $>99$ & & & [127] \\
\hline $\mathrm{Ag} 5 \% \mathrm{Au} / \mathrm{MnO}_{2} \mathrm{~d}$ & 5 & $\mathrm{O}_{2}$ & 100 & 1.5 & toluene & 100 & $>99$ & & & [127] \\
\hline $\mathrm{Ag} 5 \% \mathrm{Au} / \mathrm{MnO}_{2}$ e & 5 & $\mathrm{O}_{2}$ & 100 & 1.5 & toluene & 19.90 & $>99$ & & & [127] \\
\hline $\mathrm{Ag} / \mathrm{GOSH}$ & 9.58 & $\mathrm{O}_{2}$ & 80 & 24 & $\mathrm{MeCN}$ & 7 & 19 & 36 & 45 & [125] \\
\hline $\mathrm{Ag} / \mathrm{GOSH}+\mathrm{NHPI}$ & 9.58 & $\mathrm{O}_{2}$ & 80 & 24 & $\mathrm{MeCN}$ & 61 & 58 & 13 & 29 & [125] \\
\hline $\mathrm{Ag} / \mathrm{GO}+\mathrm{NHPI}$ & 5.41 & $\mathrm{O}_{2}$ & 80 & 24 & $\mathrm{MeCN}$ & 33 & 55 & 18 & 27 & [125] \\
\hline $\mathrm{Ag} / \mathrm{rGO}+\mathrm{NHPI}$ & 15.14 & $\mathrm{O}_{2}$ & 80 & 24 & $\mathrm{MeCN}$ & 12 & 8 & 25 & 67 & [125] \\
\hline $\mathrm{Ag} / \mathrm{ZnO}$ & 3 & TBHР & reflux & 0.25 & $\mathrm{CH}_{3} \mathrm{CN}$ & 90 & & & & [135] \\
\hline $\mathrm{Ag} / \mathrm{ZnO}$ & 3 & ТВНР & reflux & 0.25 & $\mathrm{C}_{2} \mathrm{H}_{5} \mathrm{OH}$ & 40 & & & & [135] \\
\hline $\mathrm{Ag} / \mathrm{ZnO}$ & 3 & TBHP & reflux & 0.25 & $\mathrm{CH}_{2} \mathrm{Cl}_{2}$ & 30 & & & & [135] \\
\hline $\mathrm{Ag} / \mathrm{ZnO}$ & 3 & $\mathrm{H}_{2} \mathrm{O}_{2}$ & reflux & 1 & $\mathrm{CH}_{3} \mathrm{CN}$ & 30 & & & & [135] \\
\hline $0.005 \% \mathrm{Ag} / \mathrm{HT}$ & 0.005 & $-f^{2}$ & 130 & 16 & p-xylene & $>99$ & $>99$ & & & [130] \\
\hline $\mathrm{Fe}_{3} \mathrm{O}_{4} @ \mathrm{SiO}_{2}-\mathrm{Ag}$ & 3.2 & $-f$ & reflux & 24 & toluene & 98 & 99 & & & [131] \\
\hline $\mathrm{Ag} / \mathrm{Fe}_{2} \mathrm{O}_{3}$ & $2(\mathrm{~mol})$ & $\mathrm{H}_{2} \mathrm{O}_{2}$ & 80 & 12 & & $\sim 69$ & $\sim 90$ & & & [132] \\
\hline Ag@WEFA & - & $-f^{2}$ & & 4 & - & & $96^{g}$ & & & [133] \\
\hline $\mathrm{Au}$ & & $\mathrm{O}_{2}$ & 30 & 2 & $\mathrm{P} 123-\mathrm{H}_{2} \mathrm{O}$ & 50 & 21 & 50 & 28 & [124] \\
\hline $\mathrm{Au}_{0.99} \mathrm{Ag}_{0.01}$ & & $\mathrm{O}_{2}$ & 30 & 2 & $\mathrm{P} 123-\mathrm{H}_{2} \mathrm{O}$ & 65 & 16 & 57 & 27 & [124] \\
\hline $\mathrm{Au}_{0.98} \mathrm{Ag}_{0.02}$ & & $\mathrm{O}_{2}$ & 30 & 2 & $\mathrm{P} 123-\mathrm{H}_{2} \mathrm{O}$ & 74 & 10 & 65 & 25 & [124] \\
\hline $\mathrm{Au}_{0.95} \mathrm{Ag}_{0.05}$ & & $\mathrm{O}_{2}$ & 30 & 2 & $\mathrm{P} 123-\mathrm{H}_{2} \mathrm{O}$ & 82 & 9 & 67 & 24 & [124] \\
\hline $\mathrm{Au}_{0.90} \mathrm{Ag}_{0.10}$ & & $\mathrm{O}_{2}$ & 30 & 2 & $\mathrm{P} 123-\mathrm{H}_{2} \mathrm{O}$ & 77 & 10 & 65 & 25 & [124] \\
\hline $\mathrm{Au}_{0.85} \mathrm{Ag}_{0.15}$ & & $\mathrm{O}_{2}$ & 30 & 2 & $\mathrm{P} 123-\mathrm{H}_{2} \mathrm{O}$ & 63 & 12 & 59 & 29 & [124] \\
\hline
\end{tabular}

BAld—benzaldehyde, BA—benzoic acid, BB-benzyl benzoate. ${ }^{\mathrm{a}}$ — specific rate constant $\mathrm{k}\left(\mathrm{mol} \mathrm{h}^{-1} \mathrm{~g}^{-1}\right)$ instead of conversion; ${ }^{\mathrm{b}}$-mass weight of $\mathrm{Ag}_{2} \mathrm{O}$ instead of $\mathrm{Ag}$; ${ }^{\mathrm{c}}$-calcination temperature was $300{ }^{\circ} \mathrm{C}$; ${ }^{\mathrm{d}}$-calcination temperature was $400{ }^{\circ} \mathrm{C}$; ${ }^{\mathrm{e}}$-calcination temperature was $500{ }^{\circ} \mathrm{C}$; —oxidant-free dehydrogenation. Inert atmosphere; g_BAld yield. 


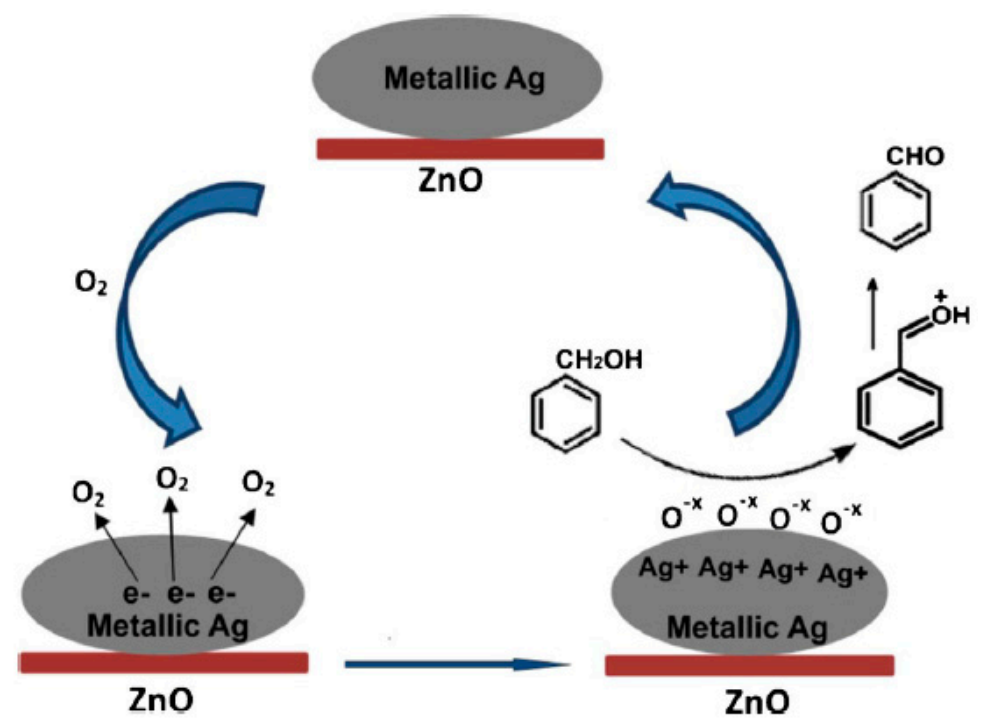

Figure 17. Schematic reaction mechanism of benzyl alcohol oxidation over Ag/ZnO nanocomposite. Reprinted with permission from reference [135]. Copyright 2015 Hindawi publishers.

Kolobova et al. [136] studied several silver-promoted titania catalysts with or without the addition of $\mathrm{Ce}, \mathrm{Fe}$ and $\mathrm{Mg}$ oxides in selective oxidation of n-octanol and betulin. The highest conversion value of n-octanol of $12 \%$ after $6 \mathrm{~h}$ experiment was reached over the $\mathrm{Ag} / \mathrm{CeO}_{2} / \mathrm{TiO}_{2}$ system. According to the authors, caprylic aldehyde was the main product of the reaction, with the selectivity above $90 \%$ for most of the samples. Still, octanoic acid and octyloctanoate appeared at longer reaction times, with $\mathrm{Ag} / \mathrm{TiO}_{2}$ reaching a selectivity of $11-12 \%$ towards the ester after $6 \mathrm{~h}$ of the reaction. An investigation of betulin oxidation was carried out with the use of $\mathrm{Ag} / \mathrm{TiO}_{2}$ and $\mathrm{Ag} / \mathrm{CeO}_{2} / \mathrm{TiO}_{2}$, with resulting conversions of $11 \%$ and $27 \%$, respectively. Betulone was the main product of the reaction, with the selectivity over $60 \%$ in all $6 \mathrm{~h}$ experiments. For $\mathrm{Ag} / \mathrm{TiO}_{2}$, the largest secondary products were betulinic aldehyde $(6 \%)$ and betulinic acid $(7 \%)$, while in the case of the modified catalyst, the betulinic aldehyde $(22 \%)$ and betulonic aldehyde ( $8 \%$ ) were detected. The authors emphasize $\mathrm{Ag}^{+}$ions as the active sites for the liquid-phase oxidation. It should be noted that the authors did not provide a comparison with unmodified $\mathrm{TiO}_{2}$ in any of the described reactions.

Nagaraiju et al. [137] investigated the selective oxidation of allylic alcohols catalyzed by silver exchanged molybdovanado phosphoric acid (MPA) catalyst with molecular oxygen. Not only does the exchange by silver change the catalytic properties of the MPA, but also make the catalyst insoluble in organic solvents. The Ag- and V-modified MPA showed a substantially enhanced activity in the oxidation of cinnamyl alcohol in comparison with pure MPA and the one modified with only V or Ag. The authors proposed that the formation of Lewis acid-base silver species and vanadium hydroperoxide species may be a reason for high activity and selectivity. The cinnamaldehyde yield reached $93 \%$ versus $15-36 \%$ in much shorter reaction time. The choice of the solvent was found to significantly influence on the oxidation process. Different primary and secondary allylic alcohols were converted into the corresponding carbonyl compounds with high yield. However, the prolonged reaction time was needed for oxidation of the aliphatic alcohols. A negligible leaching of the active components was observed. The catalyst preserved its catalytic activity after the third cycle.

\subsection{Propylene Glycol}

Oxidation of polyols is more challenging than the oxidation of monatomic alcohols due to difficulties in controlling of the reaction regioselectivity, a formation of a wide range of products and their high affinity to $\mathrm{C}-\mathrm{C}$ bond cleavage. In this section we survey the recent results in the field of oxidation of important biorenewable polyols (PG and GLY) over silver-containing catalysts. Various catalytic materials were proposed for the selective oxidation of PG $[101,138]$. 
Xue et al. $[98,139,140]$ explored the PG oxidation over unsupported and hydroxyapatite-supported silver and silver-palladium NPs as catalysts and molecular oxygen as an oxidant. According to the literature, the PG oxidation proceeds through two parallel mechanisms: (1) oxidation of the primary hydroxyl group of PG to LAld, which further rapidly transforms into LA; (2) oxidation of the secondary hydroxyl group of PG to yield HA, which can be further oxidized into MeGO or converted into LAld through tautomeric equilibration in alkaline media. The obtained MeGO is highly susceptible to $\mathrm{C}-\mathrm{C}$ bond cleavage to yield acetic (AcA) and formic (FA) acids [139], $\mathrm{CO}$ and $\mathrm{CO}_{2}$ [140] or can be converted to LA through the Canizzarro reaction in alkaline media. The possible ways of PG transformation under oxidative conditions are presented in Figure 18.

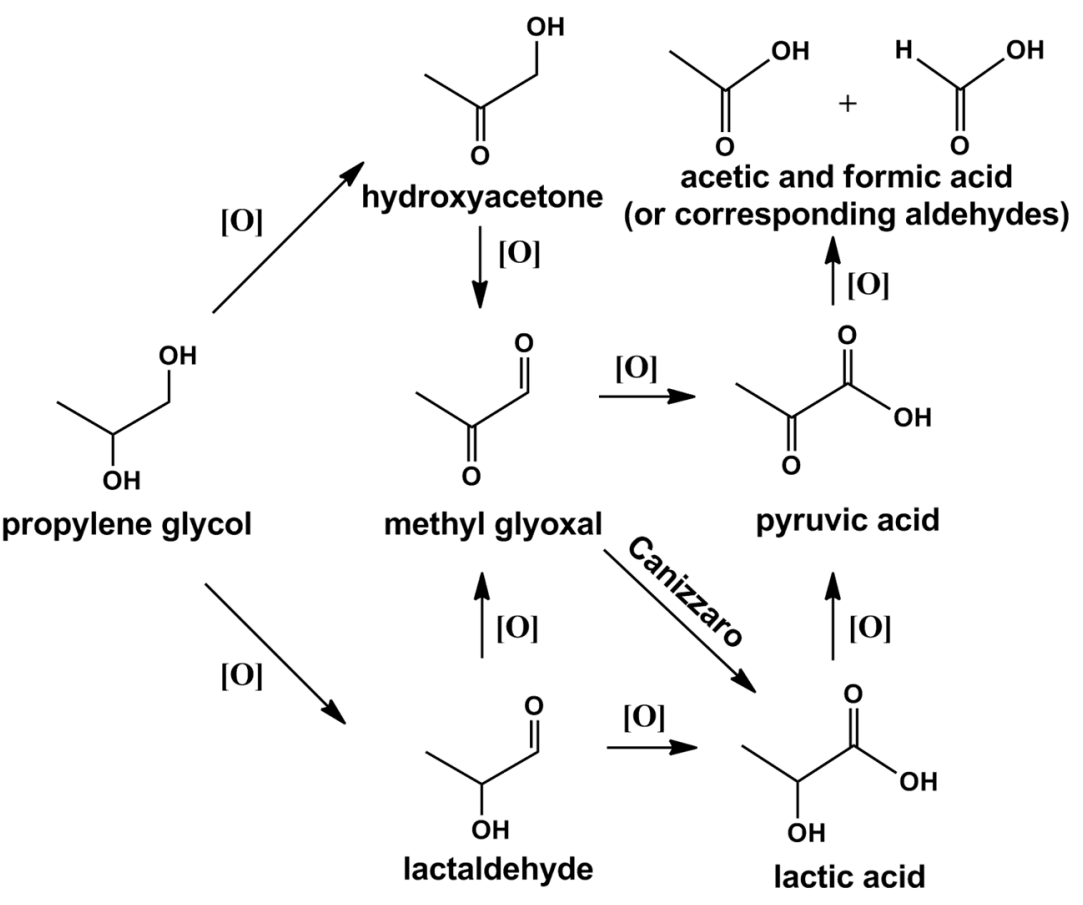

Figure 18. Oxidative transformations of PG. Reprinted with permission from reference [138]. Copyright 2016 Elsevier.

The first example of PG oxidation over Ag catalysts to produce LA, FA and AcA was published by Feng and coworkers [98]. Generally, all catalysts were prepared by wet chemical reduction method in the presence of different organic modifiers such as tween-80 (Tween), polyvinylpyrrolidone (PVP, K90), sodiumdodecyl-benaenesulfonate (SDBS), d-sorbitol (DS) and citric acid (CA). Typically, a small amount of organic modifier and silver nitrate were dissolved in the distilled water by ultrasonic treatment. Then hydrazine hydrate was added to the reaction mixture dropwise at $30^{\circ} \mathrm{C}$. The obtained silver NPs were isolated by centrifugation and washed three times with an anhydrous ethanol. The size of the prepared NPs was shown to depend on the organic modifier. The samples prepared with citric acid had an average particle size about $15 \mathrm{~nm}$, with tween $-25 \mathrm{~nm}$, polyvinylpyrrolidone $-44 \mathrm{~nm}$. The catalytic tests demonstrated the increase of TOF and the PG conversion with the average silver particle size decrease, but the correlation between the average particle size and oxidation product selectivity was not observed. The sample prepared with organic modifier Tween $\left(\mathrm{Ag}_{\text {Tween }}\right)$ demonstrated the highest selectivity towards LA (Table 5). The optimal particle size was about $25 \mathrm{~nm}$. The decreasing or increasing of the size of silver NPs led to the preferable formation of the C-C bond cleavage products. The highest selectivities towards FA and AcA were obtained over the sample prepared with citric acid as an organic modifier $\left(\mathrm{Ag}_{\mathrm{CA}}\right)$. The $\mathrm{Ag}_{\text {Tween }}$ was chosen to study the effect of catalytic reaction conditions on the activity of the silver catalyst. The increase of the temperature from $80^{\circ} \mathrm{C}$ to $120^{\circ} \mathrm{C}$ led to an increasing of the PG conversion and LA selectivity and reduction of the selectivity towards AcA and FA. The enhancement of PG concentration from $0.14 \mathrm{M}$ to $0.56 \mathrm{M}$ reduced 
the substrate conversion, but led to the selective LA formation. The increase of oxygen pressure led to oxidative $\mathrm{C}-\mathrm{C}$ bond cleavage. The use of $\mathrm{NaOH}$ in the $\mathrm{PG}$ oxidation over unsupported silver is an important point. In the absence of base, the PG conversion was less than $1.5 \%$ and no LA, FA and AcA were obtained. The addition of $\mathrm{NaOH}$ in a molar ratio $\mathrm{NaOH} / \mathrm{PG}=1$ led to a substrate conversion of $58.3 \%$ and a formation of LA, FA and AcA with the selectivities of $31,25 \%$ and $44 \%$, respectively. The increase of the $\mathrm{NaOH} / \mathrm{PG}$ molar ratio to up to 2 was favorable for the LA production. However, a further increase of $\mathrm{NaOH}$ concentration did not affect the PG oxidation process. The recycling test of $\mathrm{Ag}_{\text {Tween }}$ and $\mathrm{Ag}_{\mathrm{CA}}$ catalysts in the PG oxidation demonstrated a slight activity loss after five catalytic cycles. Only LA, FA and AcA were detected as products of PG oxidation. Carbon mass balance was $100 \%$ in all catalytic tests.

Table 5. Propylene glycol oxidation over silver-containing catalysts.

\begin{tabular}{|c|c|c|c|c|c|c|c|c|c|c|}
\hline \multirow{2}{*}{ Catalyst } & \multirow{2}{*}{$\mathrm{P}\left(\mathrm{O}_{2}\right)$, bar } & \multirow{2}{*}{$\mathrm{T},{ }^{\circ} \mathrm{C}$} & \multirow{2}{*}{$t, h$} & \multirow{2}{*}{\multicolumn{2}{|c|}{$\mathrm{NaOH} / \mathrm{PG} \mathrm{X}, \%$}} & \multicolumn{4}{|c|}{ Selectivity, \% } & \multirow{2}{*}{ Ref. } \\
\hline & & & & & & LA & HA & FA & AcA & \\
\hline AgCA & 10 & 120 & 4 & 2 & 100 & 6.3 & - & 30.5 & 63.2 & [98] \\
\hline AgSDBS & 10 & 120 & 4 & 2 & 81.9 & 48.1 & - & 17.6 & 35.3 & [98] \\
\hline AgTween & 10 & 120 & 4 & 2 & 65.6 & 62.0 & - & 13.8 & 24.2 & [98] \\
\hline AgDS & 10 & 120 & 4 & 2 & 58.8 & 27.4 & - & 23.8 & 48.8 & [98] \\
\hline AgPVP & 10 & 120 & 4 & 2 & 42.6 & 22.1 & - & 22.1 & 42.5 & [98] \\
\hline AgTween & 10 & 80 & 4 & 2 & 28.0 & 41.0 & - & 20 & 39 & [98] \\
\hline $\mathrm{Ag}_{2} / \mathrm{HAP}$ & 10 & 100 & 2 & 2 & 15.7 & 57.2 & - & 14.4 & 28.4 & [140] \\
\hline $\mathrm{Ag}_{1.8} \mathrm{Pd}_{0.2} / \mathrm{HAP}$ & 10 & 100 & 2 & 2 & 22.6 & 69.4 & - & 9.8 & 20.8 & [140] \\
\hline $\mathrm{Ag}_{1.5} \mathrm{Pd}_{0.5} / \mathrm{HAP}$ & 10 & 100 & 2 & 2 & 64.3 & 85.0 & - & 4.5 & 10.5 & [140] \\
\hline $\mathrm{Ag}_{1} \mathrm{Pd}_{1} / \mathrm{HAP}$ & 10 & 100 & 2 & 2 & 86.3 & 88.8 & - & 3.1 & 8.1 & [140] \\
\hline $\mathrm{Ag}_{1} \mathrm{Pd}_{1} / \mathrm{HAP}$ & 10 & 80 & 2 & 2 & 62.3 & 91.0 & - & 3.1 & 5.9 & [140] \\
\hline $\mathrm{Ag}$ & 1 & 85 & 4 & 2 & 8.6 & 73.2 & 7.1 & 5.7 & 14.4 & [139] \\
\hline $\mathrm{Ag}_{0.95} \stackrel{\stackrel{P}{ }}{\mathrm{P}}_{0.05}$ & 1 & 85 & 4 & 2 & 31.2 & 87.4 & 5.8 & 2.2 & 4.6 & [139] \\
\hline $\mathrm{Ag}_{0.85} \mathrm{Pd}_{0.15}$ & 1 & 85 & 4 & 2 & 61.8 & 93.3 & 3.1 & 1.32 & 2.3 & [139] \\
\hline $\mathrm{Ag}_{0.7} \mathrm{Pd}_{0.3}$ & 1 & 85 & 4 & 2 & 88.2 & 78.4 & 0 & 6.4 & 15.2 & [139] \\
\hline $\mathrm{Ag}_{0.5} \mathrm{Pd}_{0.5}$ & 1 & 85 & 4 & 2 & 99.8 & 76.0 & 0 & 8.6 & 15.5 & [139] \\
\hline $\mathrm{Ag}_{0.85} \mathrm{Pd}_{0.15}$ & 1 & 95 & 4 & 2 & 73.2 & 96.2 & 0 & 1.2 & 2.6 & [139] \\
\hline
\end{tabular}

Unsupported silver-palladium NPs and those supported on hydroxyapatite (HAP) as the catalyst of PG selective oxidation were investigated in by Xue et al. [139] and Feng et al. [140]. Supported catalysts were prepared by sol-immobilization method. In general, the calculated amount of silver nitrate added to ascorbic acid (AA) and PVP aqueous solution under vigorous stirring at $60^{\circ} \mathrm{C}$. Than the PVP, AA and $\mathrm{KBr}$ were added to freshly prepared Ag colloid and preheated at $60^{\circ} \mathrm{C}$. Then the aqueous solution of $\mathrm{PdCl}_{2}$ was added dropwise under vigorous stirring. After cooling to room temperature the $\mathrm{Ag}-\mathrm{Pd}$ colloid was immobilized by the addition of HAP nanorods under stirring for $2 \mathrm{~h}$. The as-prepared samples were filtrated and washed with distilled water. The HAP-supported bimetallic $\mathrm{AgPd}\left(\mathrm{Ag}_{2} / \mathrm{HAP}, \mathrm{Ag}_{1.2} \mathrm{Pd}_{0.8} / \mathrm{HAP}, \mathrm{Ag}_{1.5} \mathrm{Pd}_{0.5} / \mathrm{HAP}, \mathrm{Ag}_{1} \mathrm{Pd}_{1} / \mathrm{HAP}, \mathrm{Pd}_{2} / \mathrm{HAP}\right.$, an index is a metal to HAP weight ratio) catalysts with different metal content were prepared. The XRD patterns of the $\mathrm{Ag}_{1.5} \mathrm{Pd}_{0.5} / \mathrm{HAP}$ and $\mathrm{Ag}_{1} \mathrm{Pd}_{1} / \mathrm{HAP}$ samples indicate the formation of bimetallic NPs.

The unsupported samples were prepared by a wet chemical reduction method. Typically, the calculated amounts of metal nitrates were dissolved in $100 \mathrm{~mL} 0.05 \%$ Tween aqueous solution by ultrasonication. Then the aqueous solution of hydrazine hydrate was added dropwise during $2 \mathrm{~h}$ under stirring. The obtained NPs were collected by centrifugation and washed with anhydrous ethanol prior to their use in the catalytic tests or characterization. The $\mathrm{Ag}_{\mathrm{x}} \mathrm{Pd}_{\mathrm{y}}(\mathrm{x}, \mathrm{y}$ denoted the metal molar ratio) NPs were prepared via wet chemical reduction method.

All bimetallic silver-palladium NPs (unsupported and HAP-supported) showed the higher catalytic activity than the monometallic samples. A synergistic effect of silver-palladium catalysts in PG oxidation was proposed to be caused by a strong interaction (electrons transfer) between the coalesced $\mathrm{Pd}$ and $\mathrm{Ag}$ bimetallic NPs. An increase of $\mathrm{NaOH} / \mathrm{PG}$ molar ratio to up to 1 for $\mathrm{Ag}_{\mathrm{x}} \mathrm{Pd}_{\mathrm{y}} / \mathrm{HAP}$ and up to 2 for unsupported $\mathrm{Ag}_{\mathrm{x}} \mathrm{Pd}_{\mathrm{y}}$ led to rising of the substrate conversion and LA selectivity. Further increasing of the base concentration had only minor effect on PG selective oxidation process. 
The effect of reaction temperature and substrate concentration was similar to that for monometallic silver NPs [98]. The effect of the $\mathrm{O}_{2}$ amount in the catalytic system was explored by variation of $\mathrm{O}_{2}$ pressure in the case of $\mathrm{Ag}_{\mathrm{x}} \mathrm{Pd}_{\mathrm{y}} / \mathrm{HAP}$ samples and by variation of $\mathrm{O}_{2}$ flow rate in the case of unsupported $\mathrm{Ag}_{\mathrm{x}} \mathrm{Pd}_{\mathrm{y}}$ catalyst. An increasing of $\mathrm{O}_{2}$ pressure or flow rate gave a great boost to the catalytic activity of all bimetallic catalysts until the saturation of the catalyst surface with molecular oxygen was achieved. Further increase of $\mathrm{O}_{2}$ flow rate or pressure practically had no effect on the oxidation process.

When the bimetallic Pd-Ag/HAP samples were used for the catalytic oxidation of PG, both substrate conversion and LA selectivity increased with the increase of the Pd content (Table 5). The results indicated that high Pd loading favored the PG oxidation with selective formation of LA. Only LA, AcA and FA were detected in the reaction mixture after all catalytic tests. For the unsupported bimetallic catalysts, the dependence of the catalytic activity and product distribution on the $\mathrm{Ag} / \mathrm{Pd}$ molar ratio revealed different character. The addition of $\mathrm{Pd}$ to Ag-rich catalyst improved the catalytic activity, but the dependence of LA selectivity on the Pd content had a volcano-shape type. The highest LA selectivity was obtained over the catalyst with $85 \% \mathrm{Ag}$ and $15 \% \mathrm{Pd}$. For this type of catalysts, the formation of a small amount of HA was demonstrated over samples with low palladium content (up to $0.15 \mathrm{Pd} / \mathrm{Ag}$ weight ratio).

Xue et al. [140] carried out a study of reaction kinetics of PG oxidation over monometallic and bimetallic catalysts. The activation energy over $\mathrm{Pd}_{1} \mathrm{Ag}_{1} / \mathrm{HAP}$ was found to be lower than those over $\mathrm{Pd} / \mathrm{HAP}$ and $\mathrm{Ag} / \mathrm{HAP}$ (20.8 versus 24.1 and $30.8 \mathrm{~kJ} / \mathrm{mol}$, respectively). Lower reaction order over the bimetallic catalyst in comparison with both monometallic is proposed to result from stronger PG adsorption over $\mathrm{Ag}_{1} \mathrm{Pd}_{1} / \mathrm{HAP}$. For the unsupported catalysts, both activation energies and the reaction orders with respect to PG concentration were also affected by the content of Pd and $\mathrm{Ag}$ in the bimetallic catalyst [139]. With increasing of the Pd content to up to molar ratio $\mathrm{Ag} / \mathrm{Pd}=0.5$, the reaction kinetics was close to that over the Pd monometallic catalyst indicating that in this case Pd NPs in Ag-Pd catalyst predominantly catalyzed the PG oxidation with molecular oxygen.

It is noteworthy that despite the thorough investigations in the field of PG oxidation with $\mathrm{O}_{2}$ there are many opened questions. The sum of LA, FA and AcA in Xue's group research is $100 \%$ in both catalytic tests. If only three kinds of products are formed (LA, FA and AcA), the selectivities to FA and AcA must be equal, because FA and AcA can be formed from one PG molecule. Moreover, it is not completely clear how they prevented pyruvic acid formation by LA oxidation. It was reported that pyruvic acid can be formed through HA oxidation in an alkaline medium [141]. According to the literature, silver and silver-palladium particles have a great catalytic activity in the dehydrogenation of FA under similar conditions [142,143]. However, the authors claim that the mass balance in all catalytic tests is close to $100 \%$, and no formation of carbon oxides was detected. Variation of reaction temperature, catalyst loading, substrate and $\mathrm{NaOH}$ concentration, $\mathrm{O}_{2}$ pressure or flow rate had no effect on the carbon mass balance. It is not clear how the FA dehydrogenation was prevented, while so many reaction parameters were changed.

Thus, the catalytic activity of Ag NPs was studied at a variation of the sizes of metal particles in selective oxidation of PG is the aqueous solution. The main reaction product is LA, and the transformation is accompanied by the formation of the products of destructive oxidation, namely, AcA and FA. A key role of $\mathrm{NaOH}$ in the formation of LA at a NaOH/PG molar ratio of 2 was shown $[98,139]$.

The use of Ag-Pd alloys as unsupported and hydroxyapatite-supported NPs allowed increasing the rate of $P G$ oxidation in aqueous solution. Introduction of $\mathrm{Pd}$ into the composition of $\mathrm{Pd}_{1} \mathrm{Ag}_{1}$ NPs results in decreasing of the activation energy of direct oxidation of the terminal hydroxyl group with the formation of LA [140]. The supporting of the bimetallic particles of active component on the hydroxyapatite allows reducing the content of $\mathrm{NaOH}$ in the aqueous solution.

Thus, a trend in the selective oxidation of PG into LA is connected with the achieving of the basic properties of the supports used that influences on the state of metal NPs. This allows reducing the 
concentration of alkali agent in the reaction mixture. The effective oxidation of PG is carried out at a relatively low oxygen pressure $(0.5 \mathrm{MPa})$ and a temperature of $100^{\circ} \mathrm{C}$.

\subsection{Glycerol}

Glycerol (GLY) is included in the top 10 value-added chemicals from biomass [144]. Its oxidation over Ag-based catalysts has been studied more extensively compared to PG. The GLY oxidation leads to the formation of a large number of products (Figure 19) [145]. Oxidation of primary hydroxyl group gives GlyAld and GlyA, while when secondary groups are oxidized, dihydroxyacetone (DHA) is formed. Further oxidation leads to the formation of a number of $C_{1}-C_{3}$ acids, with DHA being one of these important products due to its application in cosmetics. Currently, no catalytic method of DHA manufacturing was applied in industry. Another important product is LA used as a top platform molecule for polymers, solvents, etc. The selectivity of GLY transformation depends on the catalytic composition and reaction conditions.

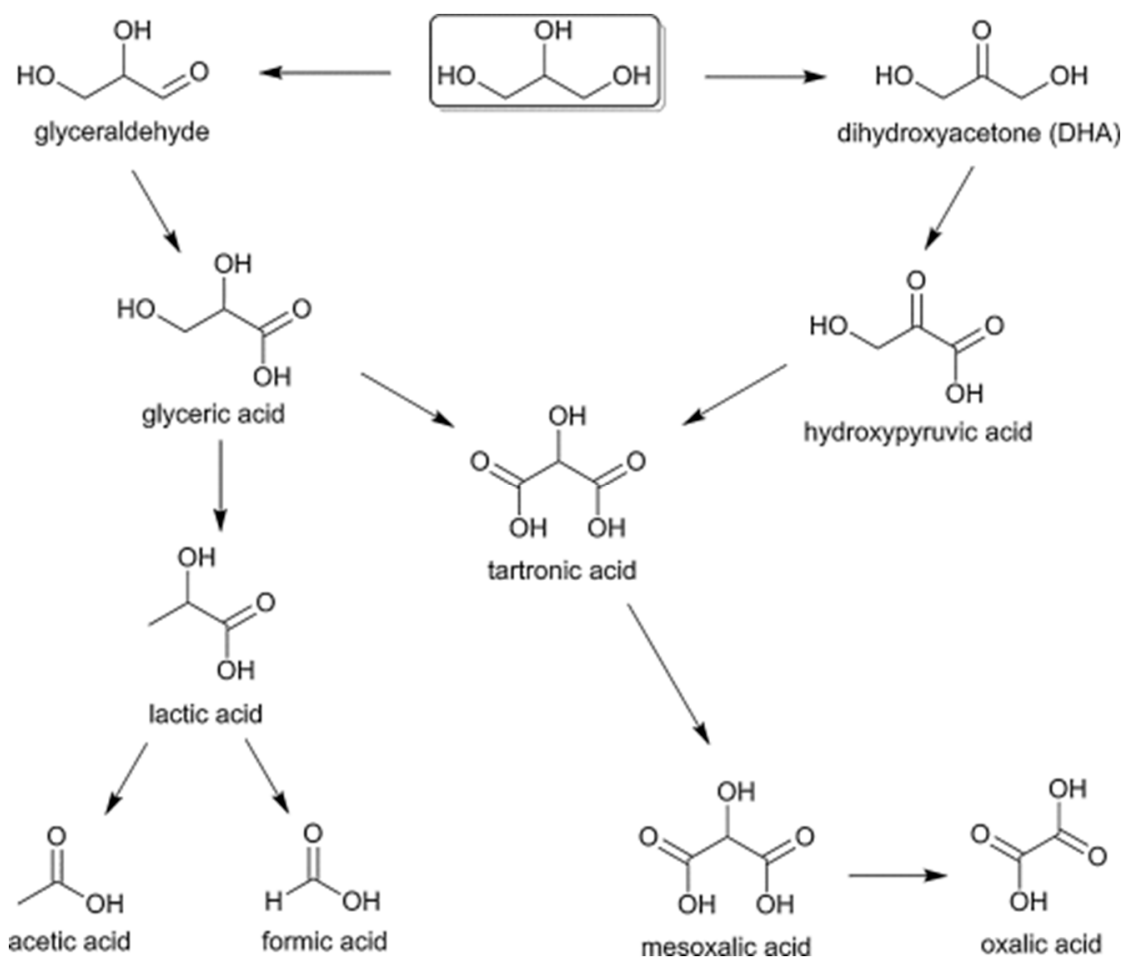

Figure 19. Products of the glycerol oxidation. Reprinted with permission from reference [145]. Copyright 2015 Elsevier.

Hirasawa et al. [146] reported the GLY oxidation over Ag-containing catalysts. The Pd-Ag alloy catalyst was found effective for selective aerobic oxidation of GLY to DHA without addition of alkali agent into the reaction mixture. Monometallic $\mathrm{Ag} / \mathrm{C}$ showed higher selectivity than $\mathrm{Pd} / \mathrm{C}$, while much lower activity was observed. The activity of a physical mixture of $\mathrm{Ag} / \mathrm{C}$ and $\mathrm{Pd} / \mathrm{C}$ was much lower than that of alloy catalyst indicating the synergetic effect of two metals in contact. Prolongation of the reaction time and oxidative pretreatment of $\mathrm{Pd}-\mathrm{Ag} / \mathrm{C}$ led to a more selective formation of DHA than at the initial stage (Table 6). The authors also mentioned that Pd-Ag catalysts on oxide support were also active, but less selective. After optimization of the reaction conditions and catalyst composition, the authors managed to obtain DHA with the selectivity of $85 \%$ at a conversion of $52 \%$. The activity of the catalyst slightly decreased in each cycle, however, the selectivity almost did not change. Only minor leaching of $\mathrm{Pd}$ and $\mathrm{Ag}(0.1 \%$ and $0.5 \%$, respectively) was detected by the ICP analysis of the filtrate. A poisoning by the produced glycolic (GlycA) and propionic acids was found to be a reason for the catalyst deactivation. The TEM measurements showed that particles with sizes 
of 3-4 nm were predominated. After the catalysis, a slight shift to larger sizes was observed in the distribution. The characterization results indicated that the uniform crystalline phase of the $\mathrm{Pd}-\mathrm{Ag}$ alloy was formed and can be responsible for the selective DHA formation.

The same group further investigated the reaction mechanism and kinetics of oxidation of GLY and other alcohols over Ag-Pd catalysts with various structure and types of the support [147]. The authors also compared the performance of $\mathrm{Pd}-\mathrm{M} / \mathrm{C}$ catalysts with $\mathrm{Ag}$, Ti, Mn, Ni, Re, Ir, Au, and Bi. However, $\mathrm{Pd}-\mathrm{Ag} / \mathrm{C}$ showed the highest GLY conversion and DHA selectivity (Table 6). The DHA yield over $\mathrm{Pd}-\mathrm{Ag}$ catalysts with various supports decreased in the following order: carbon $>\mathrm{SiO}_{2}>\mathrm{Al}_{2} \mathrm{O}_{3}>\mathrm{ZrO}_{2}$ $>\mathrm{TiO}_{2}>\mathrm{CeO}_{2}$. The catalysts with higher $\mathrm{Ag}$ content tended to be more selective towards the DHA formation, while Pd-rich catalysts were more active. Although the initial reaction rate over $\mathrm{Ag}-\mathrm{Pd} / \mathrm{SiO}_{2}$ was comparable to that over $\mathrm{Ag}-\mathrm{Pd} / \mathrm{C}$, the latter revealed an induction period. The authors speculated that the active structure of $\mathrm{Ag}-\mathrm{Pd} / \mathrm{SiO}_{2}$ is easily formed by the reduction. The heterogeneity of catalysis in GLY oxidation over Ag-Pd/C was proved by a "hot catalyst filtration test". A kinetic study of the reaction indicated that the addition of $\mathrm{Ag}$ to Pd improved the interaction between the substrate and the catalyst surface and the involving of oxygen species is the rate-determining step. The proposed reaction mechanism is the dehydrogenation route, where both substrate and oxygen are activated on the catalyst surface (Figure 20). The main factor of the deactivation of Pd-Ag/C in GLY oxidation is a strong adsorption of GlyA on the Pd followed by blocking the sites for oxygen activation.

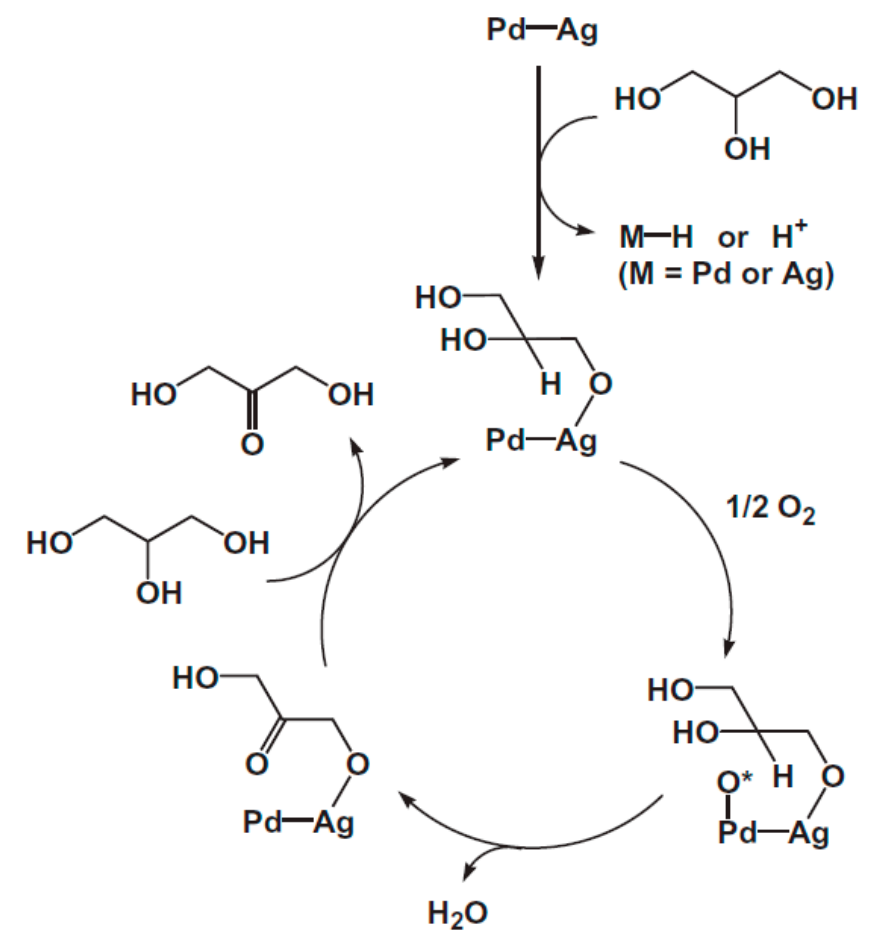

Figure 20. Proposed mechanism of glycerol oxidation over $\mathrm{Pd}-\mathrm{Ag} / \mathrm{C}$. Reprinted with permission from reference [147]. Copyright 2013 Elsevier.

Skrzyńska et al. oxidized the "crude GLY", a cheap dirty waste by-produced with biodiesel, over four different supported noble metals ( $\mathrm{Au}, \mathrm{Pd}, \mathrm{Pt}, \mathrm{Ag}$ ) at $\mathrm{NaOH} / \mathrm{GLY}$ molar ratio of 4 [148]. The $\mathrm{Au} / \mathrm{Al}_{2} \mathrm{O}_{3}$ catalyst was the most active in pure GLY oxidation (Table 6). The main detected products at the beginning of the reaction were GlyA ( $60 \%$ selectivity), GlycA ( $20 \%$ selectivity) and FA (10-12\% selectivity). Pt- and Pd-based catalysts were less active but more selective towards GlyA (74 and $85.8 \%$ at $30 \%$ conversion, respectively). However, the $\mathrm{Ag} / \mathrm{Al}_{2} \mathrm{O}_{3}$ showed different activity concerning the distribution of the main products. The highest selectivity was observed for GlycA (about $45 \%$ ). The initial selectivity towards GlyA was $34 \%$ and decreased after a few minutes of reaction to up to $23-26 \%$. The authors explained such a big difference between the activities of the catalysts by 
the metallic particle distribution on the catalyst surface. The main particle diameter increased in the order: $\mathrm{Pd} / \mathrm{Al}_{2} \mathrm{O}_{3}(3.5 \pm 1.5 \mathrm{~nm})<\mathrm{Pt} / \mathrm{Al}_{2} \mathrm{O}_{3}(4.2 \pm 2.5 \mathrm{~nm})<\mathrm{Au} / \mathrm{Al}_{2} \mathrm{O}_{3}(4.7 \pm 2.6 \mathrm{~nm})<\mathrm{Ag} / \mathrm{Al}_{2} \mathrm{O}_{3}$ $(21.2 \pm 18.6 \mathrm{~nm})$. The supported silver catalyst with the highest average diameter and the widest particle size distribution was the least active in the pure GLY oxidation, but very high selectivity towards GlyA was characteristic for this metal. Application of crude GLY blocked the activity of all catalysts. The highest resistance to GLY impurities was exhibited by both $\mathrm{Pd}$ and $\mathrm{Ag}$ particles with the highest and lowest average diameter. In the case of $\mathrm{Ag} / \mathrm{Al}_{2} \mathrm{O}_{3}$, the selectivities towards $\mathrm{C}_{1}$ and $\mathrm{C}_{2}$ products decreased, while the selectivity towards GlyA was enhanced from 27.8 to $49.5 \%$. Thus, the authors concluded that the impurities in the crude GLY blocked the sites responsible for the oxidative $\mathrm{C}-\mathrm{C}$ bond cleavage of GLY, keeping active the sites responsible for the non-destructive oxidation of hydroxyl groups. The experiments with the addition of single impurities showed a different activity of the catalysts depending on the crude GLY composition.

Skrzyńska et al. [149] reported the effect of preparation method and reaction conditions on the catalytic performance of $\mathrm{Ag} / \mathrm{Al}_{2} \mathrm{O}_{3}$ in aerobic oxidation of GLY to GlycA. A thorough study of this type of catalyst is caused by the lack of known metallic catalytic systems able to transform GLY to GlycA. A large number of catalysts prepared by different methods of reduction and the type of reducing agent and support used were tested (Table 6). The catalysts prepared in methanol solution were more active than those prepared with water, whereas the changing of the support altered the oxidation state and the mean diameter of silver NPs and, as a consequence, their catalytic performance in GLY oxidation. Despite a wide range of samples with similar mean particle size prepared by different techniques and using different supports, a clear relationship between the particle diameter and GLY conversion and catalyst selectivity was not observed. However, the results obtained for the series of catalysts prepared by the same method, but with different concentrations of reducer $\left(\mathrm{NaBH}_{4}\right)$, showed that the highest activity and selectivity to GlycA was observed over the catalyst with the biggest mean particle diameter, while the smallest particles were the least active. The selectivity to FA was generally comparable. The authors explained this phenomenon by the base-dependent character of the oxidative $\mathrm{C}-\mathrm{C}$ bond cleavage of GLY to FA. A decreasing of $\mathrm{NaOH} / \mathrm{GLY}$ molar ratio during the reaction rather than the catalyst deactivation caused an incomplete GLY conversion. The addition of fresh $\mathrm{NaOH}$ to the reaction mixture rebooted the reaction. It is noteworthy that the high concentration of the base at high reaction temperatures (i.e., $100{ }^{\circ} \mathrm{C}$ ) led to a GLY conversion in the absence of any metal catalyst [150]. At the same time, the presence of base was required for the initial activation of GLY molecule, and silver-based catalysts were practically inactive in the absence of the base. The selectivity towards GlyA increased significantly with the increase of the metal loading. The selected catalyst was shown to be able to run in a continuous process without any alteration of the conversion and the selectivity to GlyA ( $43-44 \%$ and $52-53 \%$, respectively).

Zaid et al. investigated the ceria-supported silver-based catalysts promoted by noble metal ( $\mathrm{Au}, \mathrm{Pd}$ or Pt) for GLY oxidation with molecular oxygen at $\mathrm{NaOH} / \mathrm{GLY}$ ratio of 4/1 $\mathrm{mol} / \mathrm{mol}$ [151]. GlyA was the main oxidation product, and the catalyst selectivity was not affected by the nature of promoter (Table 6). The presence of silver in the catalyst and the basic conditions directed the $\mathrm{C}-\mathrm{C}$ bond cleavage with selective formation of GlycA. The catalytic activity in terms of GLY conversion decreased in the following row: $\mathrm{Ag}-\mathrm{Pt}(54.2 \%)>\mathrm{Ag}-\mathrm{Au}(43.8 \%)>\mathrm{Ag}-\mathrm{Pd}(37.1 \%)$. The initial reaction rate over $\mathrm{Ag}-\mathrm{Pt}$ was twice higher than in other bimetallic systems. However, the increasing of the amount of $\mathrm{Pt}$ in the $\mathrm{Ag}-\mathrm{Pt} / \mathrm{CeO}_{2}$ catalyst generally decreased the GLY conversion and GlycA yield. In the catalysts with high platinum content, $\mathrm{Pt}$ dominates the activity of silver by changing the mechanism and directing the reaction towards the formation of GlyA. The authors explained a plateau at low GLY conversions in this case by deactivation of $\mathrm{Pt}$ under high $\mathrm{O}_{2}$ pressure. This phenomenon is well known for aerobic oxidation of alcohols [116,152].

Taking into account the outstanding behavior of $\mathrm{Ag}$ as catalytically active components in aerobic oxidation of GLY in comparison with other noble metals, Diaz et al. developed the kinetic model of this reaction over $\mathrm{M} / \mathrm{Al}_{2} \mathrm{O}_{3}(\mathrm{M}=\mathrm{Ag}, \mathrm{Pt}, \mathrm{Au})$ in order to provide the comparative information and 
find the reason for higher selectivity of Ag towards GlycA [153]. A power-law kinetic model was developed. The reaction pathways included in the kinetic models are shown in Figure 21. DHA and GlyAld were not observed in the reaction mixture in all cases due to their low stability in the presence of the base [150]. It was found that FA can be obtained from the direct GLY decomposition. Due to high average metal particle size in $\mathrm{Ag} / \mathrm{Al}_{2} \mathrm{O}_{3}$ (21.2 versus 2.95 and $4.7 \mathrm{~nm}$ for $\mathrm{Pt}$ and $\mathrm{Au}$, respectively), the share of active sites was much lower than over the other catalysts leading to lower catalytic activity. A temperature dependence of product selectivities and the initial reaction rates for Au differed from that for $\mathrm{Pt}$ and $\mathrm{Ag}$-based catalysts. Under reaction conditions, unlike $\mathrm{Au}$ and $\mathrm{Ag}, \mathrm{Pt}$ was able to dissociate $\mathrm{O}_{2}[154]$ and catalyze the initial step of GLY oxidation, namely the proton abstraction from the substrate molecule [116]. The Pt-based catalyst was the most active, while showing the highest activation energies. The authors connected this fact with the adsorption phenomena. Moreover, based on the deactivation parameters the $\mathrm{Pt} / \mathrm{Al}_{2} \mathrm{O}_{3}$ and $\mathrm{Au}$ - and Ag-containing catalysts were considered more resistant to deactivation. The latter two catalysts cannot oxidize GLY under base-free conditions and prone to produce $\mathrm{C}-\mathrm{C}$ bond cleavage step, especially Ag. The authors assumed the ability of these active phases to catalyze the direct synthesis of $\mathrm{H}_{2} \mathrm{O}_{2}$, which plays a key role in C-C cleavage bond process leading to the formation of GlycA. The $\mathrm{r}_{3} / \mathrm{r}_{1}$ ratio (see Figure 21) in the proposed kinetic model was higher for $\mathrm{Ag}(2.5)$ than those of $\mathrm{Pt}(0.16)$ and $\mathrm{Au}$ (0.54) supporting the high selectivity of this system towards GlycA.

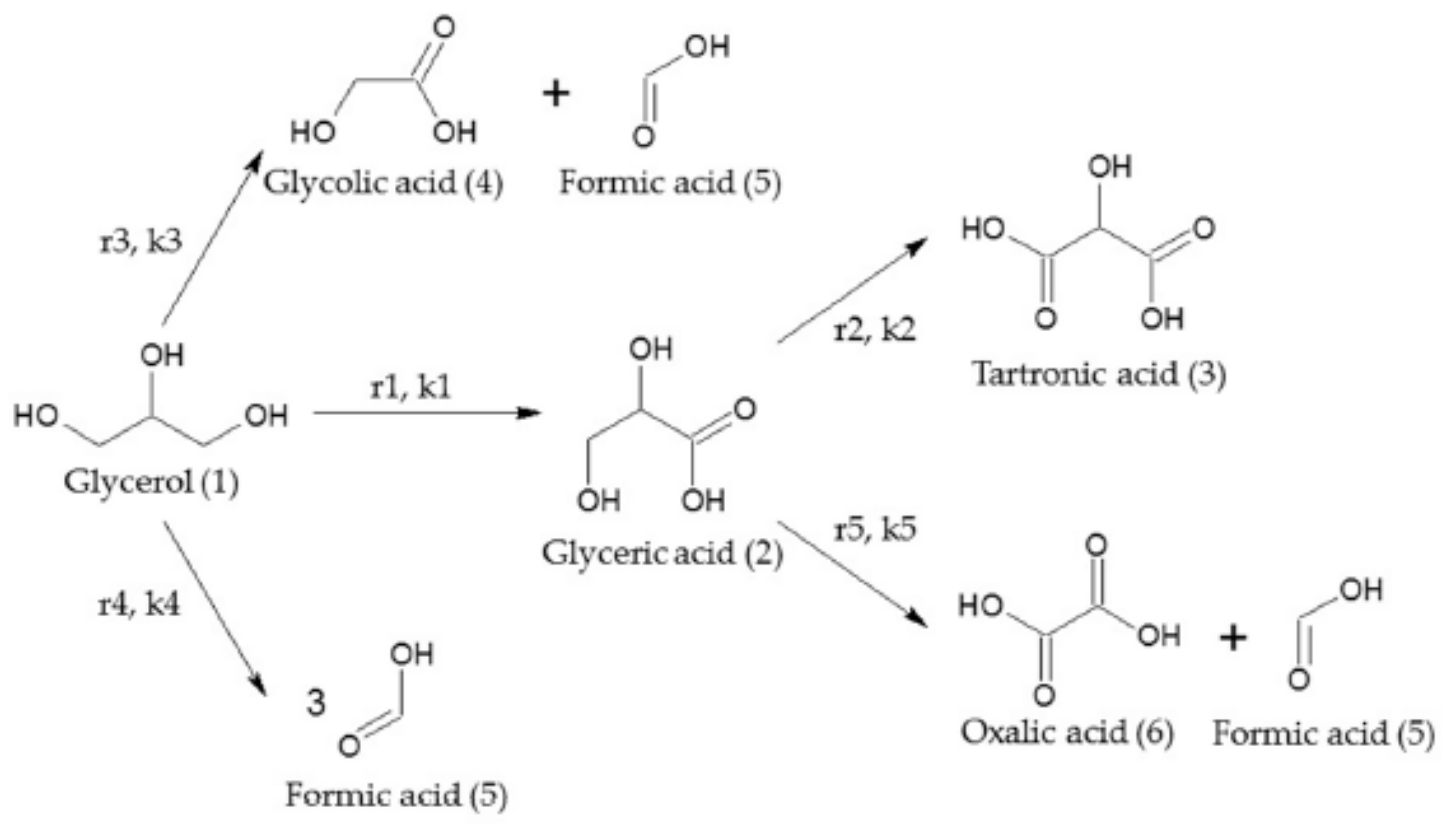

Figure 21. Proposed reaction pathways of glycerol oxidation. Reprinted with permission from reference [153]. Copyright 2017 Wiley. 
Table 6. Oxidation of glycerol over Ag-containing catalysts.

\begin{tabular}{|c|c|c|c|c|c|c|c|c|c|c|c|c|}
\hline \multirow{2}{*}{ Catalyst } & \multirow{2}{*}{$\mathrm{P}\left(\mathrm{O}_{2}\right)$, Bar } & \multirow{2}{*}{$\mathrm{T},{ }^{\circ} \mathrm{C}$} & \multirow{2}{*}{$\mathrm{NaOH} / \mathrm{GLY}$} & \multirow{2}{*}{$t, h$} & \multirow{2}{*}{$X, \%$} & \multicolumn{6}{|c|}{ Selectivity, \% } & \multirow{2}{*}{ Ref } \\
\hline & & & & & & DHA & GlyAl & GlyA & GlycA & FA & LA & \\
\hline $\mathrm{Pd} / \mathrm{C}+\mathrm{Ag} / \mathrm{C}$ & 3 & 80 & 0 & 4 & 1.8 & 70.7 & 18.8 & 7.1 & 2.2 & - & - & [146] \\
\hline $\mathrm{AgPd} / \mathrm{C}$ & 3 & 80 & 0 & 4 & 6.7 & 74.6 & 14.6 & 7.2 & 1.4 & - & - & [146] \\
\hline $\mathrm{Ag} / \mathrm{C}$ & 3 & 80 & 0 & 24 & 0.3 & 84.0 & 5.0 & 11.0 & $<0.1$ & - & - & [146] \\
\hline $\mathrm{AgPd} / \mathrm{C}$ & 3 & 80 & 0 & 24 & 24.5 & 79.1 & 3.6 & 11.2 & 5.8 & - & - & [146] \\
\hline Pretreated $1 \mathrm{Ag} 2 \mathrm{Pd} / \mathrm{C}$ & 3 & 80 & 0 & 24 & 10.9 & 77.7 & 8.6 & 9.6 & 2.7 & - & - & [146] \\
\hline Pretreated 1Ag1Pd/C & 3 & 80 & 0 & 24 & 20.0 & 82.2 & 4.6 & 8.0 & 3.4 & - & - & [146] \\
\hline Pretreated 2Ag1Pd/C & 3 & 80 & 0 & 24 & 16.4 & 85 & 4.6 & 5.4 & 2.2 & - & - & [146] \\
\hline $1 \mathrm{Ag} 2 \mathrm{Pd} / \mathrm{SiO}_{2}$ & 3 & 80 & 0 & 4 & 7.0 & 76.4 & 13.5 & 6.9 & 1.4 & - & - & [147] \\
\hline $1 \mathrm{Ag} 1 \mathrm{Pd} / \mathrm{SiO}_{2}$ & 3 & 80 & 0 & 4 & 4.9 & 86.6 & 8.0 & 2.7 & 1.2 & - & - & [147] \\
\hline $1 \mathrm{Ag} 1 \mathrm{Pd} / \mathrm{TiO}_{2}$ & 3 & 80 & 0 & 4 & 1.7 & 90.0 & 5.9 & 2.9 & 0.7 & - & - & [147] \\
\hline $1 \mathrm{Ag} 1 \mathrm{Pd} / \mathrm{Al}_{2} \mathrm{O}_{3}$ & 3 & 80 & 0 & 4 & 6.8 & 86.4 & 7.3 & 3.4 & 0.6 & - & - & [147] \\
\hline $1 \mathrm{Ag} 1 \mathrm{Pd} / \mathrm{ZrO}_{2}$ & 3 & 80 & 0 & 4 & 3.2 & 91.3 & 6.2 & 2.1 & 0.2 & - & - & [147] \\
\hline $1 \mathrm{Ag} 1 \mathrm{Pd} / \mathrm{CeO}_{2}$ & 3 & 80 & 0 & 4 & 0.3 & 82.3 & 4.1 & 5.9 & 3.4 & - & - & [147] \\
\hline $\mathrm{Au} / \mathrm{Al}_{2} \mathrm{O}_{3}$ & 5 & 60 & 4 & - & - & - & - & $\begin{array}{l}59.8^{\mathrm{a}} \\
60.4^{\mathrm{b}}\end{array}$ & $\begin{array}{l}19.7^{\mathrm{a}} \\
20.7^{\mathrm{b}}\end{array}$ & $\begin{array}{l}10.2^{\mathrm{a}} \\
12.5^{\mathrm{b}}\end{array}$ & - & [148] \\
\hline $\mathrm{Pd} / \mathrm{Al}_{2} \mathrm{O}_{3}$ & 5 & 60 & 4 & - & - & - & - & $\begin{array}{l}91.7^{\mathrm{a}} \\
85.8^{\mathrm{b}}\end{array}$ & $\begin{array}{l}2.8^{\mathrm{a}} \\
2.6^{\mathrm{b}}\end{array}$ & $\begin{array}{c}0^{\mathrm{a}} \\
1.0^{\mathrm{b}}\end{array}$ & - & [148] \\
\hline $\mathrm{Pt} / \mathrm{Al}_{2} \mathrm{O}_{3}$ & 5 & 60 & 4 & - & - & - & - & $\begin{array}{l}75.6^{\mathrm{a}} \\
74.0^{\mathrm{b}}\end{array}$ & $\begin{array}{l}10.7^{\mathrm{a}} \\
9.9^{\mathrm{b}}\end{array}$ & $\begin{array}{l}11.0^{\mathrm{a}} \\
8.1^{\mathrm{b}}\end{array}$ & - & [148] \\
\hline $\mathrm{Ag} / \mathrm{Al}_{2} \mathrm{O}_{3}$ & 5 & 60 & 4 & - & - & - & - & $\begin{array}{l}27.8^{\mathrm{a}} \\
27.2^{\mathrm{b}}\end{array}$ & $\begin{array}{l}35.9^{\mathrm{a}} \\
44.8^{\mathrm{b}}\end{array}$ & $\begin{array}{l}35.3^{\mathrm{a}} \\
28.0^{\mathrm{b}}\end{array}$ & - & [148] \\
\hline $\mathrm{Ag} / \mathrm{Al}_{2} \mathrm{O}_{3}$ calcination & 5 & 100 & 1 & 2 & 42.6 & - & - & 13.0 & 51.4 & 33.5 & - & [149] \\
\hline $\begin{array}{c}0.7 \% \mathrm{Ag} / \mathrm{Al}_{2} \mathrm{O}_{3} \\
\mathrm{HCHO}-\mathrm{MeOH}\end{array}$ & 5 & 100 & 1 & 2 & 19.9 & - & - & 24.9 & 39.4 & 34.2 & - & [149] \\
\hline $\begin{array}{c}1.1 \% \mathrm{Ag} / \mathrm{Al}_{2} \mathrm{O}_{3} \\
\mathrm{HCHO}-\mathrm{MeOH}\end{array}$ & 5 & 100 & 1 & 2 & 48.3 & - & - & 9.7 & 51.6 & 32.4 & - & [149] \\
\hline $\begin{array}{c}2.3 \% \mathrm{Ag} / \mathrm{Al}_{2} \mathrm{O}_{3} \\
\mathrm{HCHO}-\mathrm{MeOH}\end{array}$ & 5 & 100 & 1 & 2 & 48.6 & - & - & 9.4 & 54.1 & 32.6 & - & [149] \\
\hline $\begin{array}{c}3.6 \% \mathrm{Ag} / \mathrm{Al}_{2} \mathrm{O}_{3} \\
\mathrm{HCHO}-\mathrm{MeOH}\end{array}$ & 5 & 100 & 1 & 2 & 48.8 & - & - & 7.6 & 56.0 & 33.3 & - & [149] \\
\hline $\begin{array}{c}\mathrm{Ag} / \mathrm{Al}_{2} \mathrm{O}_{3} \\
\mathrm{~N}_{2} \mathrm{H}_{4}-\mathrm{H}_{2} \mathrm{O}\end{array}$ & 5 & 100 & 1 & 2 & 32.8 & - & - & 15.8 & 44.8 & 32.3 & - & [149] \\
\hline $\begin{array}{c}\mathrm{Ag} / \mathrm{Al}_{2} \mathrm{O}_{3} \\
\mathrm{~N}_{2} \mathrm{H}_{4}-\mathrm{MeOH}\end{array}$ & 5 & 100 & 1 & 2 & 48.5 & - & - & 10.0 & 50.6 & 31.7 & - & [149] \\
\hline $\begin{array}{c}\mathrm{Ag} / \mathrm{Al}_{2} \mathrm{O}_{3} \\
\mathrm{NaBH}_{4}-\mathrm{H}_{2} \mathrm{O}\end{array}$ & 5 & 100 & 1 & 2 & 41.2 & - & - & 14.4 & 44.3 & 30.8 & - & [149] \\
\hline $\begin{array}{c}\mathrm{Ag} / \mathrm{Al}_{2} \mathrm{O}_{3} \\
\mathrm{NaBH}-\mathrm{MeOH}\end{array}$ & 5 & 100 & 1 & 2 & 47.6 & - & - & 10.7 & 50.6 & 32.0 & - & [149] \\
\hline
\end{tabular}


Table 6. Cont

\begin{tabular}{|c|c|c|c|c|c|c|c|c|c|c|c|c|}
\hline \multirow{2}{*}{ Catalyst } & \multirow{2}{*}{$\mathrm{P}\left(\mathrm{O}_{2}\right)$, Bar } & \multirow{2}{*}{$\mathrm{T},{ }^{\circ} \mathrm{C}$} & \multirow{2}{*}{$\mathrm{NaOH} / \mathrm{GLY}$} & \multirow{2}{*}{$t, h$} & \multirow{2}{*}{$X, \%$} & \multicolumn{6}{|c|}{ Selectivity, \% } & \multirow{2}{*}{ Ref } \\
\hline & & & & & & DHA & GlyAl & GlyA & GlycA & FA & LA & \\
\hline $95 \mathrm{Ag} 5 \mathrm{Au} / \mathrm{CeO}_{2}$ & 5 & 60 & 4 & 5 & 43.8 & - & - & 23.3 & 46.2 & 25.2 & - & {$[151$} \\
\hline $95 \mathrm{Ag} 5 \mathrm{Pt} / \mathrm{CeO}_{2}$ & 5 & 60 & 4 & 5 & 54.2 & - & - & 18.9 & 51.0 & 27.4 & - & [151 \\
\hline $95 \mathrm{Ag} 5 \mathrm{Pd} / \mathrm{CeO}_{2}$ & 5 & 60 & 4 & 5 & 37.1 & - & - & 25.8 & 44.9 & 24.5 & - & {$[151]$} \\
\hline $50 \mathrm{Ag} 50 \mathrm{Pt} / \mathrm{CeO}_{2}$ & 5 & 60 & 4 & 5 & 20.0 & - & - & 48.3 & 28.4 & 20.6 & - & {$[151$} \\
\hline $\mathrm{H}_{3} \mathrm{PMo}_{12} \mathrm{O}_{40}$ & 5 & 60 & 0 & 5 & 83 & 3 & 3 & 4 & - & - & 72 & {$[155$} \\
\hline $\mathrm{Ag}_{3} \mathrm{PMo}_{12} \mathrm{O}_{40}$ & 5 & 60 & 0 & 5 & 89 & 6 & 2 & 3 & - & - & 81 & {$[155$} \\
\hline $\mathrm{Ag}_{2} \mathrm{HPMo}_{12} \mathrm{O}_{40}$ & 5 & 60 & 0 & 5 & 87 & 5 & 3 & 3 & - & - & 78 & {$[155$} \\
\hline $\mathrm{Ag}_{1} \mathrm{H}_{2} \mathrm{PMo}_{12} \mathrm{O}_{40}$ & 5 & 60 & 0 & 5 & 85 & 5 & 3 & 4 & - & - & 75 & {$[155$} \\
\hline $2 \% A u 2 \% A g / Z n O$ & 6 & 60 & 2 & 5 & 10 & - & - & 77 & 8 & 7 & - & {$[156$} \\
\hline $2 \% \mathrm{Au} 1 \% \mathrm{Cu} / \mathrm{ZnO}$ & 6 & 60 & 2 & 5 & 95 & - & - & 59 & 17 & 12 & - & {$[156$} \\
\hline
\end{tabular}

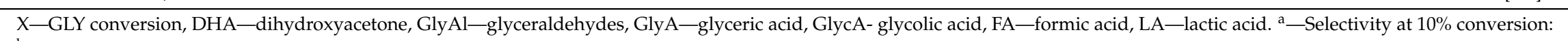
b_-Selectivity at $30 \%$ conversion: ${ }^{c}$ - Crude GLY was used. 
Another valuable product of GLY oxidation is LA. The production of LA from GLY generally requires the oxidation followed by dehydration/rehydration steps (Figure 22). Tao et al. developed a bifunctional catalyst by introducing silver to polyoxometalates (POMs) [155]. The authors confirmed that $\mathrm{Ag}$ could enhance both the redox potentials for $\mathrm{H}_{3} \mathrm{PMo}_{12} \mathrm{O}_{40}$ to be suitable to oxidize GLY to DHA rather than GlyAld, and Lewis acid sites favor further dehydration reaction pathway to LA. The reason why the undesired cascade oxidation of LA was hindered was explained by the hydrophobic surface characteristics of the catalyst. As soon as the LA was formed, the hydrophobic Ag ${ }_{x} P M o$ expelled the LA molecules from their catalytic sites diffusing to the liquid phase, and further oxidation was avoided. After the optimization of the reaction conditions, they managed to obtain LA with a 93\% selectivity at a $99 \%$ GLY conversion (Table 6).

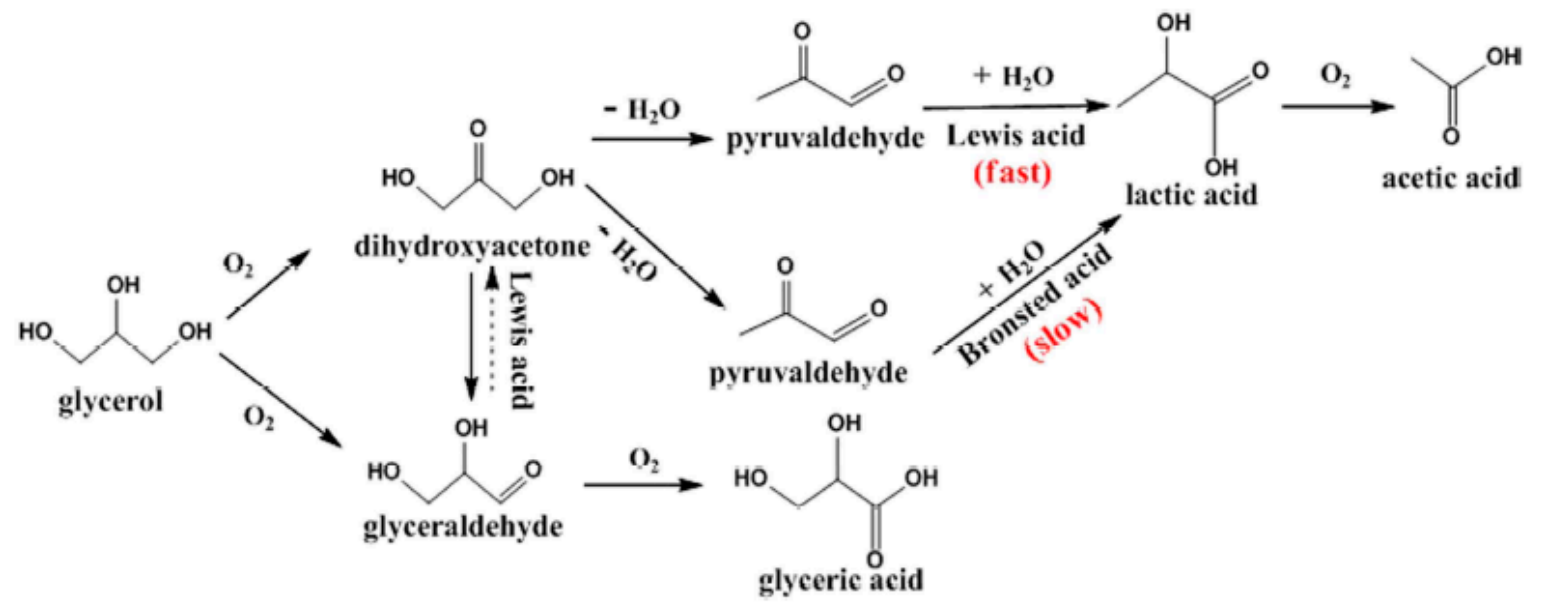

Figure 22. Proposed tandem reaction pathways for the selective oxidation of glycerol to lactic acid over $\mathrm{Ag}_{x} \mathrm{PMo}$ catalysts. Reprinted with permission from reference [155]. Copyright 2016 Nature Publishing Group.

Kaskow et al. compared the effect of copper and silver on the catalytic activity of gold-based catalysts in GLY oxidation [156]. It was shown that the $\mathrm{Cu}$ - and Ag-doped $\mathrm{Au} / \mathrm{ZnO}$ catalysts have different structure (Figure 23). $\mathrm{CuO} / \mathrm{Cu}_{2} \mathrm{O}$ are in the vicinity of metallic gold and $\mathrm{CuO} / \mathrm{Cu}_{2} \mathrm{O}$ patches on the surface of metallic $\mathrm{Au}$ particles. $\mathrm{Ag}_{2} \mathrm{O}$ in the vicinity of metallic gold and $\mathrm{AuAg}$ alloy (with low $\mathrm{Ag}$ content) decorated with a discontinuous $\mathrm{Ag}_{2} \mathrm{O}$ layer. The addition of copper to $\mathrm{Au} / \mathrm{ZnO}$ caused a significant increase in GLY conversion in comparison with monometallic catalyst (Table 6). At the same time, the presence of silver revealed the opposite effect. $\mathrm{Ag} / \mathrm{ZnO}$ with a domination of cationic silver was almost inactive. XPS studies showed that both $\mathrm{Cu}$ and Ag changed the electronic state of gold on $\mathrm{ZnO}$ due to strong $\mathrm{Au}-\mathrm{Cu}$ and $\mathrm{Au}-\mathrm{Ag}$ interactions. The amount of electrons surrounding the gold metallic particles is important for effective chemisorptions of oxygen. Metallic gold with the lowest negative charge on the surface of $\mathrm{AuCu} / \mathrm{ZnO}$ as found to be the most active as centers for oxygen chemisorptions. On the contrary, highly negatively charged Au particles on the surface of $\mathrm{AuAg} / \mathrm{ZnO}$ were not active in oxygen chemisorption. The chemical composition of active phase also influences on selectivity due to different adsorption and desorption rates of GlyA.

For the liquid-phase oxidation over all discussed catalytic composites, the addition of alkali agent is required, and almost no transformation of substrates occurs. Thus, in the liquid-phase oxidation, the mechanism of direct oxidation of primary hydroxyl into the carboxylic group is the predominant one. To increase the effectiveness, the addition of $\mathrm{Pd}$ is used due to the necessity to change the electronic properties of active Ag site. 
a) AuCu-Zno

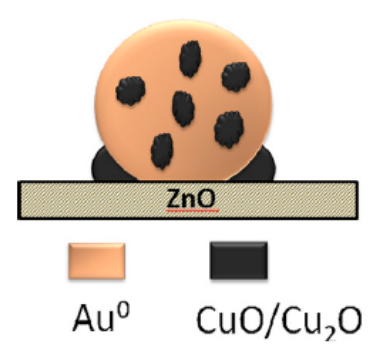

b) AuAg-ZnO

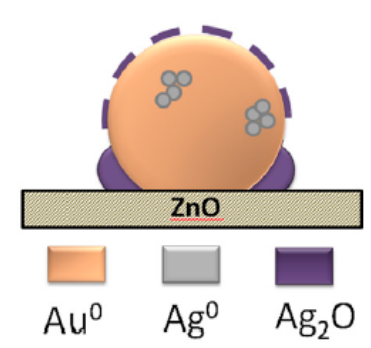

Figure 23. $\mathrm{AuCu}$ and $\mathrm{AuAg}$ structures in bimetallic catalysts loaded on $\mathrm{ZnO}$. Reprinted with permission from reference [156]. Copyright 2018 Elsevier.

\section{Selective Photooxidation of Alcohols}

Selective photooxidation of alcohols has received special attention from research groups in the recent years due to economical feasibility (no heating is applied) and ecofriendliness. A variety of studies dedicated to partial oxidation of aromatic alcohols features titania-based systems with such modifiers (or combination thereof) as $\mathrm{CdS}$ [157], $\mathrm{ZnO}$ [158], $\mathrm{WO}_{3}$ [159], $\mathrm{CeO}_{2}$ [160], $\mathrm{Fe}^{3+}$ [161], vanadyl species [162], Ag [163], AgBr [164,165], Au [166], Pt, Rh or Ir [167]. A selection of recent works on the subject also mention gold catalysts on different supports such as hydrotalcite [168], niobium oxide perovskites [169], zeolites [170] or $\mathrm{CeO}_{2}$ [171]. Some other composite catalysts are also mentioned such as $\mathrm{Pt} / \mathrm{Bi}_{2} \mathrm{WO}_{6}[172]$ or separate various bromide compounds [173,174]. Apart from that, $\mathrm{Ag}_{3} \mathrm{PO}_{4}$ is also featured [175].

Other recently mentioned substrates are methanol, being selectively photooxidized on $\mathrm{Au} / \mathrm{WO}_{3}$ [176], $\mathrm{Au}$ - and/or Ag-modified $\mathrm{TiO}_{2}$ [177], $\mathrm{Ag}$-modified $\mathrm{TiO}_{2}$ and $\mathrm{SiO}_{2}$ [178], vanadia systems [179], 2-propanol, with a study featuring $\mathrm{Au} / \mathrm{TiO}_{2}$ [180]. A few other works discuss the same process for carbohydrates like glucose in the presence of $\mathrm{Fe}^{3+}$ ions on $\mathrm{TiO}_{2}$ [181] or undoped sol-gel $\mathrm{TiO}_{2}$ [182].

Selective oxidation of BA was carried out with the use of a sandwich-like $\mathrm{TiO}_{2} @ \mathrm{Me} @ \mathrm{ZnO}$ photocatalyst [158]. Amongst $\mathrm{Au}, \mathrm{Pt}, \mathrm{Ag}$, and $\mathrm{Pd}$, silver-doped systems proven to be the most effective in the production of BAld, with the conversion value of $86.2 \%$ and selectivity of $51.1 \%$ for the said compound, with BAc being also produced with the selectivity of $33 \%$ (Table 7). Higher BAld selectivities of $84.9 \%$ and $81.3 \%$ were demonstrated by the $\mathrm{TiO}_{2} @ \mathrm{Pd} @ \mathrm{ZnO}$ and unmodified $\mathrm{TiO}_{2} @ \mathrm{ZnO}$ systems, but the conversion values were shown to be only $49 \%$ and $30.2 \%$, respectively. Concerning $\mathrm{BAc}, \mathrm{TiO}_{2} @ \mathrm{Au} @ \mathrm{ZnO}$ turned to be the most effective photocatalyst, with the selectivity of $56.1 \%$ and a total BA conversion of $82.5 \%$. Still, BAld was also formed in the discussed reaction with a selectivity of $43.9 \%$. No data on unmodified $\mathrm{TiO}_{2}$ or commercial $\mathrm{TiO}_{2}$ for this experiment are presented in the study. The authors emphasize the increased amount of hydroxyl radicals and superoxide anions detected via EPR in the media during the involvement of the Ag-based catalyst compared to the others in the work. During the additional experiment of photoreduction of $\mathrm{Cr}(\mathrm{VI})$ species, $\mathrm{TiO}_{2} @ \mathrm{Ag} @ \mathrm{ZnO}$ photocatalyst proved to be the most effective in comparison with unmodified $\mathrm{TiO}_{2}$, commercial $\mathrm{TiO}_{2} \mathrm{P} 25$, and $\mathrm{TiO}_{2} @ \mathrm{ZnO} @ \mathrm{Ag}$ hollow sphere. The authors also state that metal NPs are removed easily from the catalyst surface if stationed either inside or outside the spherical structure of the composite. According to the data provided by electrochemical measurements, the $\mathrm{TiO}_{2} @ \mathrm{Ag} @ \mathrm{ZnO}$ catalyst shows generally a better ability to separate holes and electrons, and displays a minimal charge transfer resistance in comparison with the other composites described in the study. No additional explanations concerning the reaction mechanism or difference in activity/selectivity between the discussed $\mathrm{TiO}_{2} @ \mathrm{Me} @ \mathrm{ZnO}$ composites are given except the note that $\mathrm{Au}$ and Ag NPs might be responsible for the increased light absorption efficiency compared to the other systems. 
Table 7. A selection of Ag-containing photocatalysts for alcohol oxidation.

\begin{tabular}{|c|c|c|c|c|c|c|}
\hline Substrate & Products & Lamp Properties & Catalyst & Preparation Technique & Efficiency & Ref. \\
\hline BA & $\begin{array}{l}\text { BAld } \\
\text { BAc }\end{array}$ & $300 \mathrm{~W}$ Xe arc lamp & $\begin{array}{l}\mathrm{TiO}_{2} @ \mathrm{Ag} @ \mathrm{ZnO} \\
\mathrm{TiO}_{2} @ \mathrm{Au} @ \mathrm{ZnO} \\
\mathrm{TiO}_{2} @ \mathrm{Pt} @ \mathrm{ZnO} \\
\mathrm{TiO}_{2} @ \mathrm{Pd} @ \mathrm{ZnO}\end{array}$ & $\begin{array}{l}\text { Sol-gel (support) } \\
\text { Simple preparation (metal } \\
\text { NPs) }\end{array}$ & $\begin{array}{c}\mathrm{TiO}_{2} @ \mathrm{Ag} @ \mathrm{ZnO} \\
86.2 \% \text { conversion } \\
\text { 51.1\% BAld selectivity } \\
33 \% \text { BAc selectivity }\end{array}$ & [158] \\
\hline BA & $\begin{array}{l}\text { BAld } \\
\text { BAc }\end{array}$ & $\begin{array}{c}300 \mathrm{~W} \text { Xe arc lamp } \\
\lambda \mathrm{max} \geq 420 \mathrm{~nm} \\
\text { cut-off filter }\end{array}$ & $\begin{array}{c}\mathrm{AgBr} @ \mathrm{TiO}_{2} \\
\mathrm{AgBr} @ \mathrm{Ag} @ \mathrm{TiO}_{2}\end{array}$ & $\begin{array}{l}\text { Double-jet precipitation } \\
\quad\left(\mathrm{AgBr} @ \mathrm{TiO}_{2}\right) \\
\text { Photodeposition }(\mathrm{Ag})\end{array}$ & $\begin{array}{c}\mathrm{O}_{2} \text { atmosphere } \\
\mathrm{AgBr} @ \mathrm{Ag} @ \mathrm{TiO}_{2}-0.325 \\
\text { In acetonitrile: } \\
90 \% \text { conversion, } 95 \% \text { selectivity } \\
\text { In water: } \\
38 \% \text { conversion, } 47 \% \text { selectivity }\end{array}$ & [165] \\
\hline BA & BAld & $\begin{array}{l}300 \mathrm{~W} \text { Xe arc lamp } \\
\lambda \text { max } \geq 420 \mathrm{~nm} \\
\text { cut-off filter }\end{array}$ & $\mathrm{AgBr@TiO} / 2 / \mathrm{GO}$ & $\begin{array}{c}\text { Hummers method } \\
\text { (GO support) } \\
\text { Hydrothermal method } \\
\text { (core-shell structured catalyst) }\end{array}$ & $\begin{array}{l}\text { 78\% yield of BAld for } \\
\mathrm{AgBr} @ \mathrm{TiO}_{2} / \mathrm{GO}\end{array}$ & [164] \\
\hline $\begin{array}{l}\text { 4-methoxybenzyl } \\
\text { alcohol (MBA) }\end{array}$ & $\begin{array}{l}\text { 4-methoxybenzyl } \\
\text { aldehyde }\end{array}$ & $\begin{array}{l}1500 \mathrm{~W} \text { solar } \\
\text { simulator } \\
\text { (Xe lamp) }\end{array}$ & $\begin{array}{l}\mathrm{Ag} / \mathrm{TiO}_{2}, \mathrm{Pt} / \mathrm{TiO}_{2} \\
\mathrm{Au} / \mathrm{TiO}_{2}, \mathrm{Pd} / \mathrm{TiO}_{2}\end{array}$ & Photodeposition & $\begin{array}{c}\text { Aldehyde selectivity: } \\
\mathrm{pH}=1 \\
100 \% \text { for most catalysts } \\
\mathrm{pH}=7 \\
30 \% \text { for } \mathrm{Pd}-\mathrm{TiO}_{2}-0.5 \%-100 \\
30 \% \text { for } \mathrm{Pt}-\mathrm{TiO}_{2}-0.5 \%-100 \\
15 \% \text { for } \mathrm{Ag}-\mathrm{TiO}_{2}-0.5 \%-100 \\
13 \% \text { for } \mathrm{Ag}-\mathrm{TiO}_{2}-1 \%-100 \\
\mathrm{pH}=13 \\
32 \% \text { for } \mathrm{Au}-\mathrm{TiO}_{2}-0.5 \%-100 \\
33 \% \text { for } \mathrm{Pt}-\mathrm{TiO}_{2}-0.5 \%-100 \\
12 \% \text { for } \mathrm{Ag}-\mathrm{TiO}_{2}-0.5 \%-100 \\
21.5 \% \text { for } \mathrm{Ag}_{-}-\mathrm{TiO}_{2}-1 \%-100\end{array}$ & [164] \\
\hline $\begin{array}{c}\text { BA } \\
\text { 4-MBA } \\
\text { Cinnamyl alcohol }\end{array}$ & BAld & Sunlight simulator & $\mathrm{Ag}_{3} \mathrm{PO}_{4}$ & Precipitation & $\begin{array}{c}\text { BAld: } \\
>85 \% \text { conversion } \\
>99 \% \text { selectivity } \\
\sim 85 \% \text { yield } \\
\text { p-Anisaldehyde } \\
>85 \% \text { conversion } \\
>99 \% \text { selectivity } \\
\sim 85 \% \text { yield } \\
\text { Cinnamyl alcohol } \\
\sim 90 \% \text { conversion } \\
>90 \% \text { selectivity } \\
\sim 81 \% \text { yield }\end{array}$ & [175] \\
\hline
\end{tabular}


Table 7. Cont.

\begin{tabular}{|c|c|c|c|c|c|c|}
\hline Substrate & Products & Lamp Properties & Catalyst & Preparation Technique & Efficiency & Ref. \\
\hline $\begin{array}{l}\text { Cyclohexanol } \\
\text { Cycloheptanol }\end{array}$ & $\begin{array}{l}\text { Cyclohexanone } \\
\text { Cycloheptanone } \\
\text { \&others }\end{array}$ & $\begin{array}{l}125 \mathrm{~W} \mathrm{Hg} \mathrm{lamp} \\
10.4 \mathrm{~mW} / \mathrm{cm}^{2}\end{array}$ & $\begin{array}{c}0.5-20 \% \text { wt. } \mathrm{Ag} / \mathrm{TiO}_{2} \\
\text { \&others }\end{array}$ & Chemical reduction by $\mathrm{NaBH}_{4}$ & $\begin{array}{l}75 \mathrm{mmol} \text { of product vs. } 375 \mathrm{mmol} \text { for } \\
\mathrm{TiO}_{2} \mathrm{P} 25\end{array}$ & [185] \\
\hline Methanol & Methyl formate & 500 W Hg lamp & $\begin{array}{l}\mathrm{Ag} / \mathrm{TiO}_{2} \\
\mathrm{Ag} / \mathrm{SiO}_{2}\end{array}$ & Chemical reduction by $\mathrm{NaBH}_{4}$ & $\begin{array}{l}\sim 22 \mathrm{mmol} \cdot \mathrm{g}^{-1} \cdot \mathrm{h}^{-1} \text { for } 3 \% \mathrm{Ag} / \mathrm{TiO}_{2} \\
\sim 22 \mathrm{mmol} \cdot \mathrm{g}^{-1} \cdot \mathrm{h}^{-1} \text { for } 3 \% \mathrm{Ag} / \mathrm{SiO}_{2}\end{array}$ & [178] \\
\hline BA & $\begin{array}{c}\text { BAld } \\
\text { BAc } \\
\text { Benzylbenzoate } \\
\mathrm{CO}_{2} \\
\text { \&others }\end{array}$ & $\begin{array}{l}250 \mathrm{~W} \mathrm{Hg} \mathrm{lamp} \\
\lambda \max =365 \mathrm{~nm}\end{array}$ & $\begin{array}{c}\mathrm{Ag} / \mathrm{TiO}_{2} \\
\mathrm{Au} / \mathrm{TiO}_{2} \\
\mathrm{Pt} / \mathrm{TiO}_{2} \\
\mathrm{Pd} / \mathrm{TiO}_{2} \\
\mathrm{Rh} / \mathrm{TiO}_{2} \\
\mathrm{Ir} / \mathrm{TiO}_{2} \\
\end{array}$ & Photodeposition & $\begin{array}{c}81 \% \text { BAld selectivity for } \mathrm{Ag} / \mathrm{TiO}_{2} \\
92 \% \text { BAld selectivity for } \mathrm{Ir} / \mathrm{TiO}_{2}\end{array}$ & [167] \\
\hline
\end{tabular}


Another work described the same process with the involvement of core-shell AgBr@Ag@ $\mathrm{TiO}_{2}$ systems [165]. AgBr-based series were prepared with the varied $\mathrm{TiO}_{2}$ shell thickness. Metallic silver was generated in the structure of the catalysts via photoreduction of $\mathrm{Ag}^{+}$ions. According to the results of photocatalytic measurements carried out in acetonitrile media, a conversion of $89.2 \%$ and BAld selectivity of $97.3 \%$ was reached by AgBr@Ag@TiO ${ }_{2}-0.35$ photocatalyst having $70 \mathrm{~nm} \mathrm{TiO}_{2}$ shell thickness, being the most active from the discussed series (Table 7). It was noted that the photoactivity increases with the growth of the outer $\mathrm{TiO}_{2}$ shell from $30 \mathrm{~nm}$ up to $70 \mathrm{~nm}$, with unmodified $\mathrm{TiO}_{2}$ or AgBr@Ag also being inferior to all of the core-shell structured composites. With the further increase in the shell thickness over $70 \mathrm{~nm}$, a rapid decline in activity was observed. The authors explain this phenomenon with the difficulties for the light to be absorbed as well as the inability of the substrate to effectively reach the $\mathrm{AgBr}$ core through a thicker shell of titania. It was stated that both Ag NPs and $\mathrm{AgBr}$ core are responsible for the absorption of light and subsequent generation of the electron-hole pairs, while the interaction between $\mathrm{AgBr}$ core and $\mathrm{TiO}_{2}$ shell favors a more effective charge separation (Figure 24).

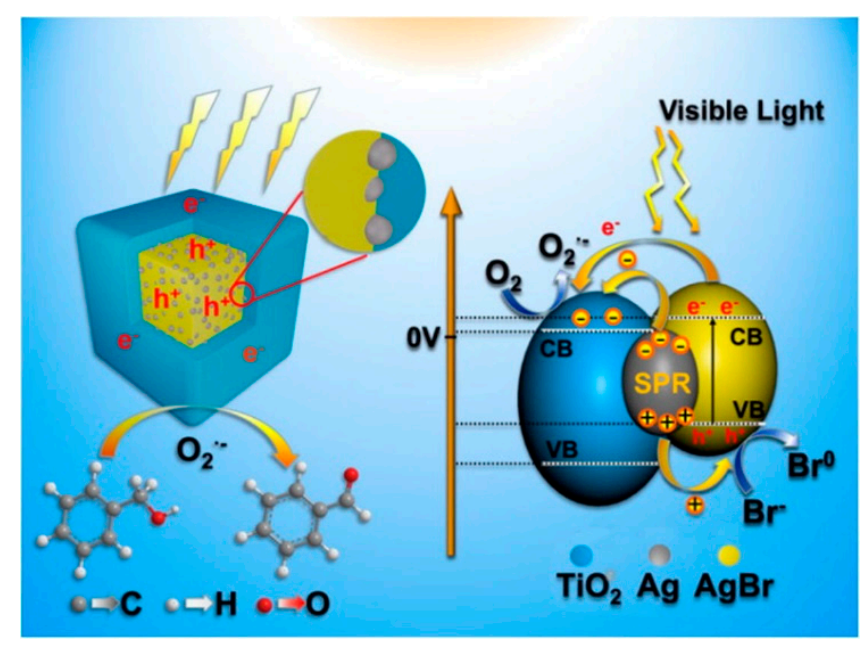

Figure 24. Proposed reaction mechanism from benzyl alcohol to benzaldehyde over the sandwich structured AgBr@Ag@ $\mathrm{TiO}_{2}$ under visible light irradiation. Reprinted with permission from reference [165]. Copyright 2016 Elsevier.

An additional experiment employing AgBr@Ag@ $\mathrm{TiO}_{2}-0.325$ having a 50 nm shell thickness was carried out several times with different solvents and atmosphere. It was demonstrated that $\mathrm{O}_{2}$ atmosphere is more beneficial than air or $\mathrm{N}_{2}$, with the largest conversion of $91 \%$ obtained with the use of benzotrifluoride as the solvent. The selectivity in the experiment reached $95 \%$. $\mathrm{CH}_{3} \mathrm{CN}$ as another solvent also demonstrated similar conversion of $90 \%$ and selectivity of $95 \%$, with the investigated $\mathrm{AgBr} @ \mathrm{Ag} @ \mathrm{TiO}_{2}-0.325$ sample being second in activity to the $\mathrm{AgBr} @ \mathrm{Ag} @ \mathrm{TiO}_{2}-0.35$ sample described above. Acetonitrile was also used in experiments employing air or pure nitrogen atmospheres, with conversions of $56 \%$ and $6 \%$, respectively. BAld selectivities were determined as $98 \%$ for both cases. Apart from that, additional experiment employing $\mathrm{O}_{2}$ atmosphere and being carried out in water provided different results, with the conversion value of $38 \%$ and selectivity of $47 \%$. It was also shown that BAld did not decompose in the blank experiment despite the oxygen atmosphere. The authors note the crucial role of $\mathrm{O}_{2}$ in the catalytic process. It is also stated that acetonitrile as a solvent favors the selectivity towards BAld due to the formation of $\mathrm{h}^{+}$and $\mathrm{O}_{2}{ }^{-}$species, contrary to the additional presence of hydroxyl radicals and hydrogen peroxide generated in water during the course of the experiment, and leading to a wider distribution of products.

Finally, the same study features another series of experiments, which were carried out with the use of $\mathrm{AgBr} @ \mathrm{Ag} @ \mathrm{TiO}_{2}-0.325$ sample in acetonitrile media, but the irradiation time was reduced from $8 \mathrm{~h}$ to $6 \mathrm{~h}$. The substrates investigated include BA and a selection of nitro-substituted aromatic alcohols, 
with the corresponding aldehydes being detected and their selectivity measured. It was shown that the largest conversion of $98 \%$ was attributed to m-nitrobenzyl alcohol, having a selectivity of $93 \%$. The aldehyde selectivities for all of the other substrates surpassed $93 \%$. The lowest conversion value of $68 \%$ was detected for p-methoxy benzyl alcohol. No additional explanation is provided for the difference between conversions.

One more study featured selective photooxidation of BA with the use of $\mathrm{AgBr} @ \mathrm{TiO}_{2} / \mathrm{GO}$ microspheres, with GO standing for graphene oxide [164]. It was shown that the highest BAld yield of $78 \%$ is demonstrated by the actual composite catalyst $\left(\mathrm{AgBr}: \mathrm{TiO}_{2}=2: 1, \mathrm{mGO}=18 \mathrm{mg}\right)$ compared to $\mathrm{AgBr} / \mathrm{GO}, \mathrm{AgBr} @ \mathrm{TiO}_{2}, \mathrm{AgBr}$, and mechanical mixture of $\mathrm{AgBr}, \mathrm{TiO}_{2}$, and $\mathrm{GO}$, all being mentioned from the largest to the lowest activity, respectively. The lowest activity of the mixture is explained by the inability of the charge carriers to be effectively separated, and it is stated that mechanical mixing does not promote the activity in any way (Table 7). Additionally, an influence of $\mathrm{AgBr}$ to $\mathrm{TiO}_{2}$ ratio was investigated. According to the presented data, the ratio of 2:1 was shown to be the most effective and optimal (yield $78 \%$ mentioned above), with the increasing amount of $\mathrm{AgBr}$ being detrimental for the activity, and with the ratio of 1:1 being the least effective of the whole series at the same time (with the yield slightly above $40 \%$ ). This effect is explained by the limited ability of $\mathrm{TiO}_{2}$ to favor charge separation: while the further increase of $\mathrm{AgBr}$ leads to a generation of more electron-hole pairs, the amount of titania in the composite keeps decreasing, thus leading to a decrease in activity. Finally, an influence of graphene oxide amount on the photocatalytic activity was investigated. Amongst the $4.5 \mathrm{mg}, 9 \mathrm{mg}, 18 \mathrm{mg}$, and $36 \mathrm{mg}$ of GO, the sample containing $18 \mathrm{mg}$ was shown to be the most effective, with the catalyst containing only $4.5 \mathrm{mg}$ being the most inferior in yield. The authors note that despite GO favors the charge separation and promotes the activity upon being added to the structure of the composite, further increase of GO amount from $18 \mathrm{mg}$ to $36 \mathrm{mg}$ blocks the access of light to AgBr core, thus leading to a decrease in BAld yield.

A solvent-free oxidation of $\mathrm{BA}$ to BAld in UV light was investigated in the presence of various $\mathrm{Me} / \mathrm{TiO}_{2}$ catalysts, including $\mathrm{Ir} / \mathrm{TiO}_{2}$ and $\mathrm{Ag} / \mathrm{TiO}_{2}$ [167]. According to the presented data, $\mathrm{Ag} / \mathrm{TiO}_{2}$ system was the least active, showing a conversion of $2.4 \%$, and being superior only to unmodified $\mathrm{TiO}_{2}$ with the conversion of $0.2 \%$. The largest conversion of $8.9 \%$ was shown by the $\mathrm{Ir} / \mathrm{TiO}_{2}$ photocatalyst, also demonstrating a $92 \%$ BAld selectivity (Table 7). Generally, all other catalysts save for unmodified $\mathrm{TiO}_{2}$ showed BAld selectivity over $80 \%$, including the silver-based sample. Although it is stated that the photogenerated electrons tend to migrate from the surface of $\mathrm{TiO}_{2}$ to noble metal clusters, no additional explanation of $\mathrm{Ag} / \mathrm{TiO}_{2}$ being the least active amongst the series is given.

A study on selective photooxidation of 4-methoxybenzyl alcohol (4-MBA) to the corresponding aldehyde was carried by Yurdakal et. al. [163], with titania-based catalysts employed. The experiment was carried out with $\mathrm{pH}$ values of 1, 7 and 13. It was shown that almost every catalyst of the discussed $\mathrm{Au}, \mathrm{Pd}, \mathrm{Ag}$, and $\mathrm{Pt}$ series achieved the selectivity towards aldehydes of $100 \%$ with $\mathrm{pH}=1$, with the metal-loaded catalysts performing better than unloaded $\mathrm{TiO}_{2}$ (Table 7). Note that all selectivities were correlated to the half-reaction time. With this, under neutral $\mathrm{pH}$ conditions $\mathrm{Ag}-\mathrm{TiO}_{2}-0.5 \%-100$ and $\mathrm{Ag}-\mathrm{TiO}_{2}-1 \%-100$ samples showed the selectivities of $15 \%$ and $13 \%$, respectively. Under basic conditions of $\mathrm{pH}=13$, the same samples provided selectivity values of $12 \%$ for $\mathrm{Ag}-\mathrm{TiO}_{2}-0.5 \%-100$ and $21.5 \%$ for $\mathrm{Ag}-\mathrm{TiO}_{2}-1 \%-100$. With this, the unmodified $\mathrm{TiO}_{2}$ Degussa support showed a $15 \%$ selectivity under $\mathrm{pH}=7$ and a $27 \%$ selectivity under $\mathrm{pH}=13$. The authors note the electron donor/acceptor characteristics of the substituent groups of aromatic alcohols being responsible for the difference in activity/selectivity under various $\mathrm{pH}$ conditions. They also mention the influence of the basic media on the formation of hydroxyl radicals participating in the reaction, and possible benefit of the hydrophobic nature of the catalyst surface for the degradation of aromatic alcohols.

BA, 4-MBA and cinnamyl alcohol were photooxidized to their respective aldehydes with the use of $\mathrm{Ag}_{3} \mathrm{PO}_{4}$ [175]. The determined conversion values were $85 \%, 85 \%$, and $90 \%$ for each aromatic alcohol, respectively. According to the obtained data, BAld and p-anisaldehyde were produced with the selectivity over 99\% (Table 7). In the case of cinnamaldehyde, however, the selectivity value 
was $90 \%$ with the detected traces of BAld and benzene acetaldehyde as secondary products in that experiment. The authors note poor physical adsorption of BA or BAld on the surface of $\mathrm{Ag}_{3} \mathrm{PO}_{4}$ being partially responsible for the displayed selectivity in photooxidation of BA. In the same experiment, it was shown that an excess of molecular oxygen did not influence on the activity in any way, which was explained by the difference between the redox potential of $\mathrm{O}_{2} / \mathrm{O}_{2}{ }^{-\cdot}$ and electrode potential of $\mathrm{Ag}_{3} \mathrm{PO}_{4}$. Also, it was stated that the process was carried out with the involvement of the holes of the valence band in that particular case. It should be mentioned that during the photoactivation process of the catalyst, silver ions were likely to form metallic $\mathrm{Ag}$ on the surface of $\mathrm{Ag}_{3} \mathrm{PO}_{4}$, which was confirmed by the XRD and gravimetrical analysis, with the amount of Ag increasing during the course of irradiation time. The authors state the forming conduction band electrons responsible for this process (Figure 25). Additionally, the presence of BA was shown to be detrimental for the formation of hydroxyl radicals from water oxidation. Finally, it is of utmost importance to note that the formation of BAld during the selective photooxidation of BA is notably suppressed in repeated cycles of the experiment, with the decrease in conversion of $12 \%, 28 \%$, and $48 \%$ for the first, second, and third repeated cycle, respectively. The authors conclude that this effect is caused by the irreversible photoreduction of silver ions described above.

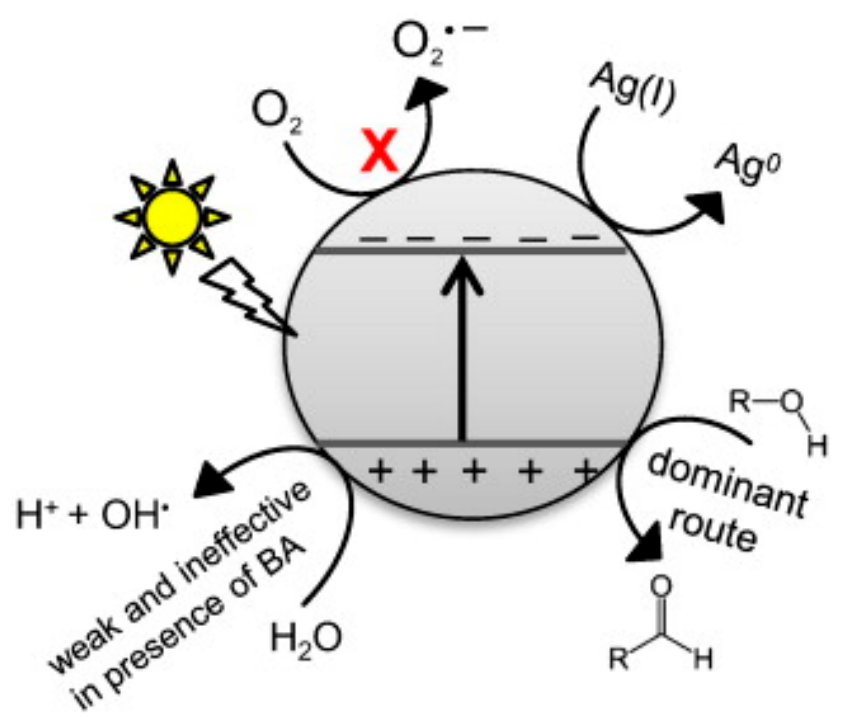

Figure 25. Schematic showing involvement of $\mathrm{O}_{2}^{-\bullet}, \mathrm{OH}^{\bullet}$ and holes in the selective photocatalytic oxidation of alcohols. $\mathrm{R}=$ aryl group. Reprinted with permission from reference [175]. Copyright 2015 Elsevier.

Apart from aromatic alcohol photooxidation, several other substrates were also investigated recently, such as photosynthesis of MF from methanol with the use of Au-Ag alloy NPs [177]. According to the presented data, $\mathrm{AuAgTiO}$ sample ( $\mathrm{Au}: \mathrm{Ag}=1: 1)$ showed the largest conversion (75-90\%), MF production rate, and selectivity ( $80-85 \%$ ) in $15-45^{\circ} \mathrm{C}$ temperature range, surpassing the samples with the ratios of 3:1, and 1:3, as well as single metal catalysts and unmodified $\mathrm{TiO}_{2}$ with the latter being the least active and selective towards MF (Table 7). This was attributed by the authors to specific properties of the samples such as electronic structure and spd hybridization, the formation of Schottky barriers, and interaction between metal and titania leading to electron transfer. Also, it is emphasized that the amount of $\mathrm{O}_{2}$ in the gas flow is crucial for the activity and selectivity in MF production, with the optimal conditions of methanol to oxygen ratio of 1:2 under the temperature range of $15-30{ }^{\circ} \mathrm{C}$. The authors also note that under higher temperatures of $30-45^{\circ} \mathrm{C}$, an increased amount of oxygen provides a comparable activity level. In short, the partial pressure of oxygen was noted to influence most remarkably on the reaction rate and distribution of the reaction products (Figure 26). Also, the photo-excitation of the sample was not considered as a rate-determining step by the authors, with conversion/selectivity increasing in a non-linear fashion with the increase in light 
intensity. In addition, it was also stated that localized surface plasma resonance effect under visible light irradiation does not provide any help in MF production. With this, the partial pressure of oxygen is stated to be the major factor for the efficiency of the selective photooxidation, with the dissociation of oxygen on the metal surface to be the rate-determining step.
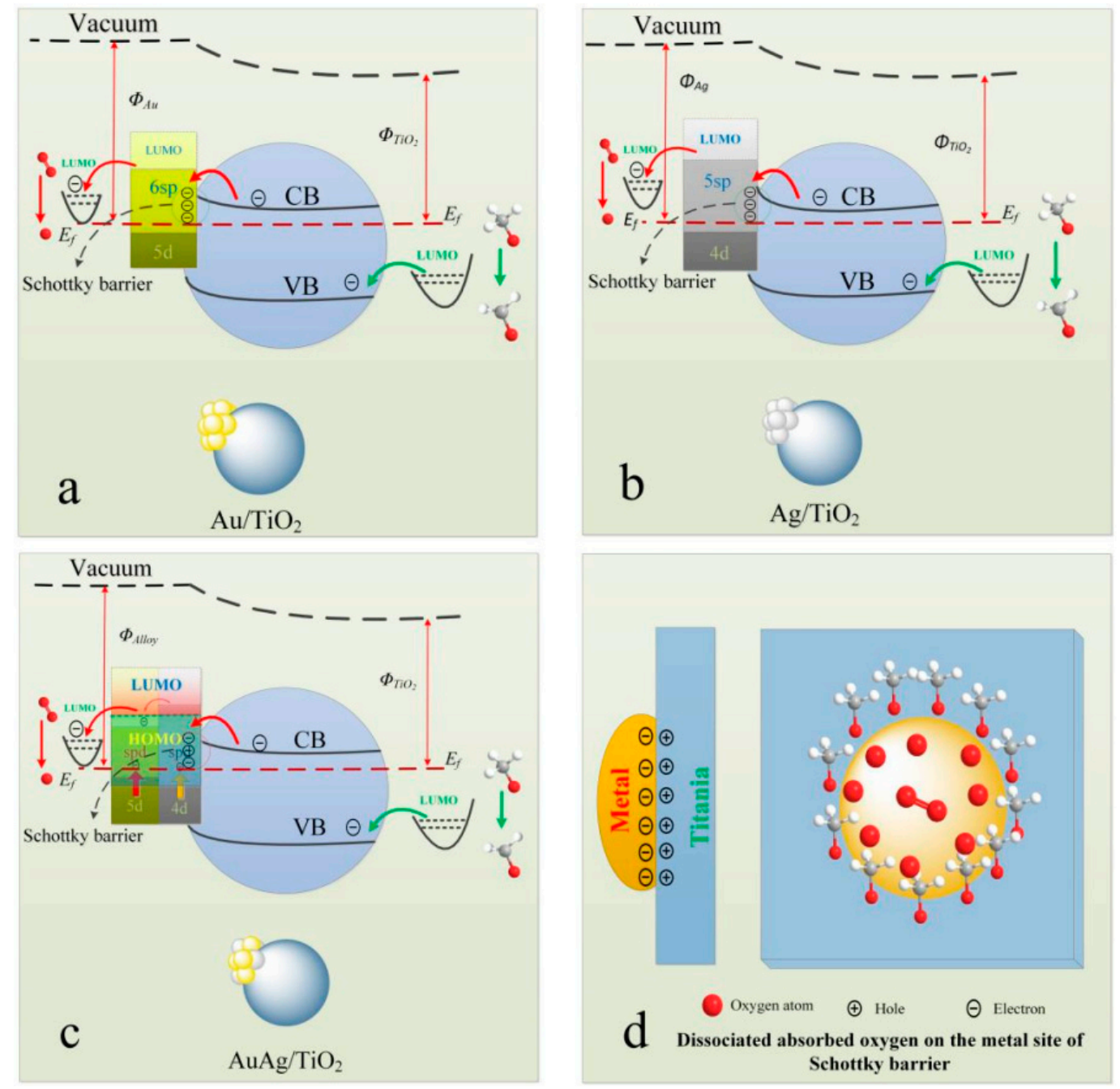

Figure 26. Schematic profile showing the formation of the Schottky barrier, the band bending, the electron transfer under UV irradiation and the oxygen dissociation on the metal surface near the perimeter. $(\mathbf{a}-\mathbf{c})$ Under UV irradiation, the excited electron from the valence band to the conduction band ejects to the metal, together with the excited electrons from the intraband and interband transition of the metal, making the metal surface more negative. The negative charge attracts oxygen and induces oxygen dissociation on the surface of the metal. The hole on the surface of titania captures electrons from the coordinated methoxy to give rise to the coordinated formaldehyde due to the higher redox potential of the hole. (d) Oxygen is dissociatively chemisorbed at the perimeter of the metal due to the negative charge in the metal site of the Schottky barrier. Methanol is dissociatively chemisorbed on the positively charged perimeter of the titania sites. Reprinted with permission from reference [177]. Copyright 2014 Royal society of chemistry.

Yang et al. [178] reported the photosynthesis of MF from methanol with the use of $\mathrm{Ag} / \mathrm{TiO}_{2}$ catalysts (Table 7). The largest MF formation rates of almost $22 \mathrm{mmol} \cdot \mathrm{g}^{-1} \cdot \mathrm{h}^{-1}$ and $23.46 \mathrm{mmol} \cdot \mathrm{g}^{-1} \cdot \mathrm{h}^{-1}$ for $3 \% \mathrm{Ag} / \mathrm{TiO}_{2}$ and $3 \% \mathrm{Ag} / \mathrm{SiO}_{2}$, respectively. With this, pure $\mathrm{TiO}_{2} \mathrm{P} 25$ and silica are stated to be even less efficient than simple UV irradiation of methanol due to the hole-electron recombination of titania and a general inability of silica to absorb UV light. The authors also suggest another reason for 
a further decrease in the activity related to the adsorption of MF on the surface of titania and/or silica. It is noted that the addition of silver forms a Schottky barrier as a result of silver-titania interaction. It is also noted that upon the addition of silver, the modified silica becomes sensitive to UV light due to surface plasmon resonance, with the photooxidation of methanol promoted at the hole-saturated locations, and the reduction of oxygen on the electron-rich ends of the dipoles taking place at the same time. With this, visible light was found to be useless for both $\mathrm{Ag} / \mathrm{TiO}$ and $\mathrm{Ag} / \mathrm{SiO}_{2}$ catalysts due to the inability of visible irradiation to excite an electron transition.

The only work discussing silver for selective photooxidation of cellobiose to glucose [183] featured a sheer comparison of $\mathrm{Ag} / \mathrm{TiO}_{2}$ and $\mathrm{Au} / \mathrm{TiO}_{2}$ systems prepared via different methods, with gold catalysts being generally superior in conversion of cellobiose ( $31 \% \mathrm{vs} .24 \%$ for $6 \mathrm{~h}$ of the experiment, with $2 \%$ vs. $0 \%$ of glucose yield, respectively), but not able to compete effectively with commercial Degussa P25 (57\% conversion, 3\% selectivity) (Table 7). At the same time, pure $\mathrm{TiO}_{2}$ anatase showed $28 \%$ conversion, $5 \%$ selectivity. Combined $\mathrm{Au} / \mathrm{Ag}$ systems prepared on different $\mathrm{TiO}_{2}$ supports also did not go past these numbers, with the top conversion of $36 \%$ and selectivity of $1 \%$. Adding small amounts of silver to gold-promoted catalysts resulted in silver acting like a poison, with the same effect for gold in an opposite situation.

A study on selective photocatalytic oxidation of 2-propanol was presented by Colmenares et al. [184], where the selectivity of acetone product reached $97 \%$ as with many other dopants studied, and Ag presence in the sol-gel-derived systems actually increased the selectivity from approximately $34-38 \%$ to up to $38-40 \%$ after promotion (Table 7). Commercial $\mathrm{TiO}_{2} \mathrm{P} 25$ sample showed a superior conversion of $46 \%$ with the same acetone selectivity.

$\mathrm{Ag} / \mathrm{TiO}_{2}$ catalysts were also featured in partial oxidation of cycloalkanols [185] to cycloalkanones and compared to some other metal- $\mathrm{TiO}_{2}$ systems. According to the authors, the addition of metal ions significantly reduced the amounts of cycloalkanol yield, with nanosized Ag and metallic Au being the most influential on the decrease in the activity, and nanosized Pd being relatively less poisonous in comparison, still being less selective than bare $\mathrm{TiO}_{2}$ (Table 7). Generally, the authors state that the nature of the substrate as well as $\mathrm{TiO}_{2}$ and metal co-catalyst particle size are crucially important for the activity.

Liu et al. [186] prepared the electrospun $\mathrm{CeO}_{2} / \mathrm{Ag} @$ carbon nanofiber hybrids using a combination of electrospinning and carbonization techniques. The as-prepared nanofiber hybrids showed high mechanical properties, high efficiency, recovery and cyclic utilization properties. The hybrids were found to keep their initial membranous structure after the reaction, and the selectivities towards BAld and benzylic acid were $69.04 \%$ and $5.87 \%$, respectively, at $96.25 \%$ conversion. The tentative reaction mechanism is represented in Figure 27.

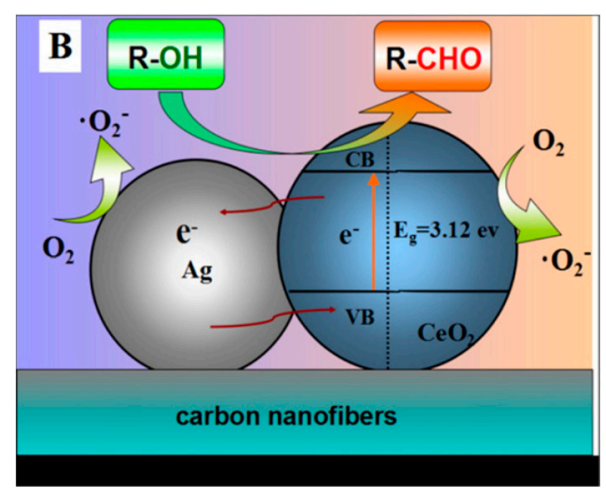

Figure 27. Schematic view of the proposed reaction mechanism over the $\mathrm{CeO}_{2} / \mathrm{Ag} @$ carbon nanofiber hybrids catalysts under visible light irradiation. Reprinted with permission from reference [186]. Copyright 2017 Elsevier. 
Under the visible light irradiation, the Ag NPs through their surface plasmon resonance absorbed the photons, and the generated electrons were injected into the ceria. The electrons excited from valence band to conduction band of ceria formed the electron-hole pairs that participate in electron transfer process.

Thus, the detailed analysis shows the prospects of application of Ag-containing composite catalysts in selective photooxidation of alcohols. The presence of silver salts (such as $\mathrm{AgX}(\mathrm{X}=\mathrm{Cl}, \mathrm{Br})$, $\left.\mathrm{Ag}_{3} \mathrm{PO}_{4}\right)[164,165,175]$ in the catalyst composition results in appearance of metallic silver clusters/NPs under the influence of $\mathrm{UV}$ irradiation or, as in the case of $\mathrm{Ag}_{3} \mathrm{PO}_{4}$, when the Ag ions are reduced by electrons generated as a result of excitation by the visible light. The stability of photocatalytic action of composite catalysts in selective oxidation of alcohols also depends on the opportunity of reverse transition of $\mathrm{Ag}^{0}$ into the ionic form that does not take place over $\mathrm{Ag}_{3} \mathrm{PO}_{4}$ without the addition of co-catalyst. Molecular oxygen transforms into superoxide radical with the participation of Ag NPs, and silver captures the electron from the conduction zone of $\mathrm{AgBr}$ or $\mathrm{ZnO}$ and holds it due to Schottky barrier formation. The $\mathrm{O}_{2}{ }^{-\bullet}$ species participate in selective oxidation of BA into aldehyde [177].

Photocatalysts based on $\mathrm{Ag} / \mathrm{TiO}_{2}$ and $\mathrm{Ag} / \mathrm{SiO}_{2}$ are active in selective oxidation of alcohols due to the presence of "dipole plasmon resonance", and, thus, methanol is oxidized over the hole-saturated ends of dipoles, while oxygen molecules are reduced to up to peroxide over electron-saturated ends of dipoles [178].

Formation of active sites of the hole nature over the composites such as $\mathrm{AgBr} @ \mathrm{TiO}_{2} @ \mathrm{GO}$ proceeds over $\mathrm{AgBr}$, while the superoxide oxygen anions are mainly concentrated over graphene oxide with the participation of electrons [164]. Both types of sites are able to facilitate in selective oxidation of alcohols.

\section{Conclusions and Outlook}

In the present review we have summarized the recent advances and trends in the field of development of the Ag-based catalysts for selective oxidation of alcohols in both gas- and liquid-phase processes as well as for photocatalytic applications. The Ag-based catalysts still bring about a vivid interest of researchers that pay more attention to revealing the factors that can be used to tune the Ag-support interaction, to provide synergistic effects of the active metal with the promoters and/or modifiers, and, thus, to control the catalyst performance in a wide range of process conditions. New materials, including highly heat-conductive composites and natural feedstock, are introduced as the supports. The state of silver in the catalysts determines the preferable reaction mechanism and can be controlled by the application of proper supports and modifiers. The use of the supports allows simultaneously addressing several important challenges:

(1) the stabilization of the Ag-containing species (ultrasmall nanoparticles, clusters, ions) over the support surface due to balancing of its redox and acid-base properties,

(2) the creating of the required "optimal" chemical surrounding for the metal site able to participate in the adsorption of the substrates, while the molecular oxygen is activated over the metal site,

(3) the reducing of the process temperature, while keeping both high activity and selectivity of the catalysts, preventing the undesired processes (e.g., sintering, formation of carbon deposits, etc.),

(4) the formation of surface oxygen species that promote the activation and transformation of the alcohol molecule, including the formation of $\mathrm{O}_{2}{ }^{-\bullet}$ species in photocatalytic applications.

The role of the support is as important as the role of the active component. A systematic control of the chemical surrounding of the active site will allow implementing the stereosensitive transformations more effectively.

It is noteworthy that even small amounts of silver used as a promoter or component of bimetallic alloys both in gas- and liquid-phase reactions of selective oxidation of alcohols may significantly enhance the catalyst performance. A combination of this feature with the unique characteristics of ordered mesostructured supports and metal-organic frameworks may open a new direction of research focused on designing of highly effective heterogeneous catalysts for selective oxidation of alcohols 
due to their own redox sites that are able to participate in the activation of molecular oxygen and/or alcohol molecule.

Acknowledgments: This research was financially supported by “The Tomsk State University competitiveness improvement programme" (grant No. 8.2.03.2018).

Funding: This research received no external funding.

Conflicts of Interest: The authors declare no conflict of interest.

$\begin{array}{ll}\text { Abbreviations } \\ \text { Ac } & \text { acetol } \\ \text { AcA } & \text { acetic acid } \\ \text { BA } & \text { benzoic acid } \\ \text { BAc } & \text { benzoic acid } \\ \text { BAld } & \text { benzaldehyde } \\ \text { BB } & \text { benzyl benzoate } \\ \text { DHA } & \text { dihydroxyacetone } \\ \text { EG } & \text { ethylene glycol } \\ \text { FA } & \text { formic acid } \\ \text { GLY } & \text { glycerol } \\ \text { GlyA } & \text { glyceric acid } \\ \text { GlyAl } & \text { glyceraldehydes } \\ \text { GlyAld } & \text { glycolic aldehyde } \\ \text { GlycA } & \text { glycolic acid } \\ \text { GO } & \text { glyoxal } \\ \text { GOA } & \text { glyoxalic acid } \\ \text { HA } & \text { hydroxyacetone } \\ \text { LA } & \text { lactic acid } \\ \text { LAld } & \text { lactaldehyde } \\ \text { MCF } & \text { mesostructured cellular foams } \\ \text { MF } & \text { methyl formate } \\ \text { MeGO } & \text { methyl glyoxal } \\ \text { NPs } & \text { nanoparticles } \\ \text { PG } & \text { propylene glycol } \\ \text { PVP } & \text { polyvinyl pyrrolidone } \\ \text { SS } & \text { stainless steel } \\ \text { ZFC } & \text { zeolite film coated copper grid } \\ & \end{array}$

\section{References}

1. Kopylovich, M.N.; Ribeiro, A.P.C.; Alegria, E.C.B.A.; Martins, N.M.R.; Martins, L.M.D.R.S.; Pombeiro, A.J.L. Chapter Three-Catalytic Oxidation of Alcohols: Recent Advances. Adv. Organomet. Chem. 2015, 63, 91-174. [CrossRef]

2. Mobley, J.K.; Crocker, M. Catalytic oxidation of alcohols to carbonyl compounds over hydrotalcite and hydrotalcite-supported catalysts. RSC Adv. 2015, 5, 65780-65797. [CrossRef]

3. Ciriminna, R.; Pandarus, V.; Béland, F.; Xu, Y.-J.; Pagliaro, M. Heterogeneously Catalyzed Alcohol Oxidation for the Fine Chemical Industry. Org. Process. Res. Dev. 2015, 19, 1554-1558. [CrossRef]

4. Xu, C.; Zhang, C.; Li, H.; Zhao, X.; Song, L.; Li, X. An Overview of Selective Oxidation of Alcohols: Catalysts, Oxidants and Reaction Mechanisms. Catal. Surv. Asia 2016, 20, 13-22. [CrossRef]

5. Sharma, A.; Kaur, H.; Shah, D. Selective Oxidation of Alcohols by Supported Gold Nanoparticles: Recent Advances. RSC Adv. 2016, 6, 28688-28727. [CrossRef]

6. Hussain, M.A.; Joseph, N.; Kang, O.; Cho, Y.-H.; Um, B.-H.; Kim, J.W. Supported Metal Nanoparticles: Their Catalytic Applications to Selective Alcohol Oxidation. Appl. Chem. Eng. 2016, 27, 227-238. [CrossRef] 
7. Vinod, C.P.; Wilson, K.; Lee, A.F. Recent advances in the heterogeneously catalysed aerobic selective oxidation of alcohols. J. Chem. Technol. Biotechnol. 2011, 86, 161-171. [CrossRef]

8. Liu, F.; Wang, H.; Sapi, A.; Tatsumi, H.; Zherebetskyy, D.; Han, H.-L.; Carl, L.M.; Somorjai, G.A. Molecular orientations change reaction kinetics and mechanism: A review on catalytic alcohol oxidation in gas phase and liquid phase on size-controlled Pt nanoparticles. Catalysts 2018, 8, 226. [CrossRef]

9. Parmeggiani, C.; Cardona, F. Transition metal based catalysts in the aerobic oxidation of alcohols. Green Chem. 2012, 14, 547-564. [CrossRef]

10. Ochoa, J.V.; Cavani, F. Gas-phase oxidation of alcohols: Innovation in industrial technologies and recent developments. RSC Green Chem. 2015, 28, 203-230. [CrossRef]

11. Dong, X.-Y.; Gao, Z.-W.; Yang, K.-F.; Zhang, W.-Q.; Xu, L.-W. Nanosilver as a new generation of silver catalysts in organic transformations for efficient synthesis of fine chemicals. Catal. Sci. Technol. 2015, 5, 2554-2574. [CrossRef]

12. Wen, C.; Yin, A.; Dai, W.-L. Recent advances in silver-based heterogeneous catalysts for green chemistry processes. Appl. Catal. B 2014, 160-161, 730-741. [CrossRef]

13. Davis, S.E.; Ide, M.S.; Davis, R.J. Selective oxidation of alcohols and aldehydes over supported metal nanoparticles. Green Chem. 2013, 15, 17-45. [CrossRef]

14. Vodyankina, O.V.; Mamontov, G.V.; Dutov, V.V.; Kharlamova, T.S.; Salaev, M.A. Ag-containing nanomaterials in heterogeneous catalysis: Advances and Recent Trends. In Advanced Nanomaterials for Catalysis and Energy: Synthesis, Characterization and Applications, 1st ed.; Sadykov, V., Ed.; Elsevier: New York, NY, USA, 2019; pp. 145-175.

15. Wisniewska, J.; Yang, C.-M.; Ziolek, M. Changes in bimetallic silver-Platinum catalysts during activation and oxidation of methanol and propene. Catal. Today 2018, in press. [CrossRef]

16. Abdel Dayem, H.M.; Al-Shihry, S.S.; Hassan, S.A. Selective Methanol Oxidation to Hydrogen over Ag/ZnO Catalysts Doped with Mono- and Bi-Rare Earth Oxides. Ind. Eng. Chem. Res. 2014, 53, 19884-19894. [CrossRef]

17. Ferrizz, R.M.; Wong, G.S.; Egami, T.; Vohs, J.M. Structure Sensitivity of the Reaction of Methanol on Ceria. Langmuir 2001, 17, 2464-2470. [CrossRef]

18. Bahmanpour, A.M.; Hoadley, A.; Tanksale, A. Critical review and exergy analysis of formaldehyde production processes. Rev. Chem. Eng. 2014, 30, 583-604. [CrossRef]

19. Brookes, C.; Bowker, M.; Wells, P.P. Catalysts for the Selective Oxidation of Methanol. Catalysts 2016, 6, 92. [CrossRef]

20. Ghahraloud, H.; Farsi, M. Modeling and optimization of methanol oxidation over metal oxide catalyst in an industrial fixed bed reactor. J. Taiwan Inst. Chem. Eng. 2017, 81, 95-103. [CrossRef]

21. Qian, M.; Liauw, M.A.; Emig, G. Formaldehyde synthesis from methanol over silver catalysts. Appl. Catal. A 2003, 238, 211-222. [CrossRef]

22. Waterhouse, G.I.N.; Bowmaker, G.A.; Metson, J.B. Mechanism and active sites for the partial oxidation of methanol to formaldehyde over an electrolytic silver catalyst. Appl. Catal. A 2004, 265, 85-101. [CrossRef]

23. Millar, G.J.; Collins, M. Industrial Production of Formaldehyde Using Polycrystalline Silver Catalyst. Ind. Eng. Chem. Res. 2017, 56, 9247-9265. [CrossRef]

24. Pestryakov, A.N. Modification of silver catalysts for oxidation of methanol to formaldehyde. Catal. Today 1996, 28, 239-244. [CrossRef]

25. Bartholomew, C.H.; Farrauto, R.J. Fundamentals of Industrial Catalytic Processes, 2nd ed.; John Wiley and Sons: Hoboken, NJ, USA, 2010; pp. 1-966.

26. Millar, G.J.; Metson, J.B.; Bowmaker, G.A.; Cooney, R.P. Characterization of the Active Site for the Selective Oxidation of Methanol to Formaldehyde on Polycrystalline Silver Catalyst. J. Chem. Soc. Chem. Commun. 1994, 1717-1718. [CrossRef]

27. Huang, W.; Sun, G.; Cao, T. Surface chemistry of group IB metals and related oxides. Chem. Soc. Rev. 2017, 46, 1977-2000. [CrossRef] [PubMed]

28. Galvanin, F.; Cao, E.; Al-Rifai, N.; Dua, V.; Gavriilidis, A. Optimal design of experiments for the identification of kinetic models of methanol oxidation over silver catalyst. Chim. Oggi-Chem. Today 2015, 33, 51-56.

29. Filho, A.C.P.; Filho, R.M. Hybrid training approach for artificial neural networks using genetic algorithms for rate of reaction estimation: Application to industrial methanol oxidation to formaldehyde on silver catalyst. Chem. Eng. J. 2010, 157, 501-508. [CrossRef] 
30. Aouat, Y.; Marom, G.; Avnir, D.; Gelman, V.; Shter, G.E.; Grader, G.S. Organically Doped Silver Nanoparticles Deposited on Titania Nanofibers: Enhanced Catalytic Methanol Oxidation. J. Phys. Chem. C 2013, 117, 22325-22330. [CrossRef]

31. Binyamin, Y.; Shter, G.E.; Gelman, V.; Avnir, D.; Grader, G.S. Activated organically doped silver: Enhanced catalysis of methanol oxidation. Catal. Sci. Technol. 2011, 1, 1593-1599. [CrossRef]

32. Halperin, V.; Shter, G.E.; Gelman, V.; Peselev, D.M.; Mann-Lahav, M.; Grader, G.S. Catalytic activity of electrospun $\mathrm{Ag}$ and $\mathrm{Ag} /$ carbon composite fibres in partial methanol oxidation. Catal. Sci. Technol. 2015, 5, 1153-1162. [CrossRef]

33. Sobczak, I.; Dembowiak, E. The effect of AuAg-MCF and AuAg-NbMCF catalysts pretreatment on the gold-silver alloy formation and the catalytic behavior in selective methanol oxidation with oxygen. J. Mol. Catal. A 2015, 409, 137-148. [CrossRef]

34. Wisniewska, J.; Ziolek, M. Formation of Pt-Ag alloy on different silicas-surface properties and catalytic activity in oxidation of methanol. RSC Adv. 2017, 7, 9534-9544. [CrossRef]

35. Wisniewska, J.; Ziolek, M.; Artioli, N.; Daturi, M. The effect of niobium and tantalum on physicochemical and catalytic properties of silver and platinum catalysts based on MCF mesoporous cellular foams. J. Catal. 2016, 336, 58-75. [CrossRef]

36. Aljama, H.; Yoo, J.S.; Nørskov, J.K.; Abild-Pedersen, F.; Studt, F. Methanol partial oxidation on Ag(111) from first principles. ChemCatChem. 2016, 8, 3621-3625. [CrossRef]

37. Montoya, A.; Haynes, B.S. Methanol and Methoxide Decomposition on Silver. J. Phys. Chem. C 2007, 111, 9867-9876. [CrossRef]

38. Montoya, A.; Haynes, B.S. DFT analysis of the reaction paths of formaldehyde decomposition on silver. J. Phys. Chem. A 2009, 113, 8125-8131. [CrossRef] [PubMed]

39. Shirman, T.; Lattimer, J.; Luneau, M.; Shirman, E.; Reece, C.; Aizenberg, M.; Madix, R.J.; Aizenberg, J.; Friend, C.M. New Architectures for Designed Catalysts: Selective Oxidation using AgAu Nanoparticles on Colloid-Templated Silica. Chem. Eur. J. 2018, 24, 1833-1837. [CrossRef] [PubMed]

40. Nadeema, M.A.; Idriss, H. Photo-thermal reactions of ethanol over $\mathrm{Ag} / \mathrm{TiO}_{2}$ catalysts. The role of silver plasmon resonance in the reaction kinetics. Chem. Commun. 2018, 54, 5197-5200. [CrossRef] [PubMed]

41. Pomalaza, G.; Capron, M.; Ordomsky, V.; Dumeignil, F. Recent Break throughs in the Conversion of Ethanol to Butadiene. Catalysts 2016, 6, 203. [CrossRef]

42. Sushkevich, V.L.; Ivanova, I.I.; Ordomsky, V.V.; Taarning, E. Design of a metal-promoted oxide catalyst for the selective synthesis of butadiene from ethanol. ChemSusChem 2014, 7, 2527-2536. [CrossRef] [PubMed]

43. Rodrigues, C.P.; da Costa Zonetti, P.; Appel, L.G. Chemicals from ethanol: The acetone synthesis from ethanol employing $\mathrm{Ce}_{0.75} \mathrm{Zr}_{0.25} \mathrm{O}_{2}, \mathrm{ZrO}_{2}$ and $\mathrm{Cu} / \mathrm{ZnO} / \mathrm{Al}_{2} \mathrm{O}_{3}$. Chem. Cent. J. 2017, 11, 30. [CrossRef] [PubMed]

44. Aditiya, H.B.; Mahlia, T.M.I.; Chong, W.T.; Nur, H.; Sebayang, A.H. Second generation bioethanol production: A critical review. Renew. Sustain. Energy Rev. 2016, 66, 631-653. [CrossRef]

45. Rana, P.H.; Parikh, P.A. Bioethanol selective oxidation to acetaldehyde over Ag-CeO ${ }_{2}$ : Role of metal-support interactions. New J. Chem. 2017, 41, 2636-2641. [CrossRef]

46. Rana, P.H.; Parikh, P.A. Bioethanol valorization via its gas phase oxidation over Au \&/or Ag supported on various oxides. J. Ind. Eng. Chem. 2017, 47, 228-235. [CrossRef]

47. Guan, Y.; Hensen, E.J.M. Selective oxidation of ethanol to acetaldehyde by Au-Ir catalysts. J. Catal. 2013, 305, 135-145. [CrossRef]

48. Sobolev, V.I.; Danilevich, E.V.; Koltunov, K.Y. Role of vanadium species in the selective oxidation of ethanol on $\mathrm{V}_{2} \mathrm{O}_{5} / \mathrm{TiO}_{2}$ catalysts. Kinet. Catal. 2013, 54, 730-734. [CrossRef]

49. Silbaugh, T.L.; Devlaminck, P.; Sofranko, J.A.; Barteau, M.A. Selective oxidation of ethanol over Ag, $\mathrm{Cu}$ and Au nanoparticles supported on $\mathrm{Li}_{2} \mathrm{O} / \gamma-\mathrm{Al}_{2} \mathrm{O}_{3}$. J. Catal. 2018, 364, 40-47. [CrossRef]

50. Lippits, M.J.; Nieuwenhuys, B.E. Direct conversion of ethanol into ethylene oxide on gold-based catalysts: Effect of $\mathrm{CeOx}$ and $\mathrm{Li}_{2} \mathrm{O}$ addition on the selectivity. J. Catal. 2010, 274, 142-149. [CrossRef]

51. Lippits, M.J.; Nieuwenhuys, B.E. Direct conversion of ethanol into ethylene oxide on copper and silver nanoparticles: Effect of addition of $\mathrm{CeOx}$ and $\mathrm{Li}_{2} \mathrm{O}$. Catal. Today 2010, 154, 127-132. [CrossRef]

52. Janlamool, J.; Jongsomjit, B. Oxidative dehydrogenation of ethanol over AgLi- $\mathrm{Al}_{2} \mathrm{O}_{3}$ catalysts containing different phases of alumina. Catal. Commun. 2015, 70, 49-52. [CrossRef]

53. Shimizu, K.-I.; Satsuma, A. Silver Cluster Catalysts for Green Organic Synthesis. J. Jpn. Petrol. Inst. 2011, 54, 347-360. [CrossRef] 
54. Kolobova, E.; Pestryakov, A.; Mamontov, G.; Kotolevich, Y.; Bogdanchikova, N.; Farias, M.; Vosmerikov, A.; Vosmerikova, L.; Cortes Corberan, V. Low-temperature CO oxidation on Ag/ZSM-5 catalysts: Influence of $\mathrm{Si} / \mathrm{Al}$ ratio and redox pretreatments on formation of silver active sites. Fuel 2017, 188, 121-131. [CrossRef]

55. Xu, J.; Xu, X.-C.; Yang, X.-J.; Han, Y.-F. Silver/hydroxyapatite foam as a highly selective catalyst for acetaldehyde production via ethanol oxidation. Catal. Today 2016, 276, 19-27. [CrossRef]

56. Blokhina, A.S.; Kurzina, I.A.; Sobolev, V.I.; Koltunov, K.Y.; Mamontov, G.V.; Vodyankina, O.V. Selective Oxidation of Alcohols over $\mathrm{Si}_{3} \mathrm{~N}_{4}$ Supported Silver Catalysts. Kinet. Catal. 2012, 53, 477-481. [CrossRef]

57. Vodyankina, O.V.; Blokhina, A.S.; Kurzina, I.A.; Sobolev, V.I.; Koltunov, K.Y.; Chukhlomina, L.N.; Dvilis, E.S. Selective oxidation of alcohols over Ag-containing $\mathrm{Si}_{3} \mathrm{~N}_{4}$ catalysts. Catal. Today 2013, 203, 127-132. [CrossRef]

58. Dutov, V.V.; Mamontov, G.V.; Sobolev, V.I.; Vodyankina, O.V. Silica-supported silver-containing OMS-2 catalysts for ethanol oxidative dehydrogenation. Catal. Today 2016, 278, 164-173. [CrossRef]

59. Chen, J.; Li, J.; Liu, Q.; Huang, X.; Shen, W. Facile Synthesis of Ag-Hollandite Nanofibers and Their Catalytic Activity for Ethanol Selective Oxidation. Chin. J. Catal. 2007, 28, 1034-1036. [CrossRef]

60. Chen, J.; Tang, X.; Liu, J.; Zhan, E.; Li, J.; Huang, X.; Shen, W. Synthesis and Characterization of Ag-Hollandite Nanofibers and Its Catalytic Application in Ethanol Oxidation. Chem. Mater. 2007, 19, 4292-4299. [CrossRef]

61. Li, Z.; Xu, J.; Gu, X.; Wang, K.; Wang, W.; Zhang, X.; Zhang, Z.; Ding, Y. Selective Gas-Phase Oxidation of Alcohols over Nanoporous Silver. ChemCatChem 2013, 5, 1705-1708. [CrossRef]

62. Liu, P.; Zhu, X.; Yang, S.; Li, T.; Hensen, E.J.M. On the metal-support synergy for selective gas-phase ethanol oxidation over $\mathrm{MgCuCr}_{2} \mathrm{O}_{4}$ supported metal nanoparticle catalysts. J. Catal. 2015, 331, 138-146. [CrossRef]

63. Mamontov, G.V.; Grabchenko, M.V.; Sobolev, V.I.; Zaikovskii, V.I.; Vodyankina, O.V. Ethanol dehydrogenation over Ag- $\mathrm{CeO}_{2} / \mathrm{SiO}_{2}$ catalyst: Role of Ag-CeO 2 interface. Appl. Catal. A 2016, 528, 161-167. [CrossRef]

64. Guan, Y.; Hensen, E.J.M. Ethanol dehydrogenation by gold catalysts: The effect of the gold particle size and the presence of oxygen. Appl. Catal. A Gen. 2009, 361, 49-56. [CrossRef]

65. Grabchenko, M.V.; Mamontov, G.V.; Zaikovskii, V.I.; La Parola, V.; Liotta, L.F.; Vodyankina, O.V. Design of $\mathrm{Ag}-\mathrm{CeO}_{2} / \mathrm{SiO}_{2}$ catalyst for oxidative dehydrogenation of ethanol: Control of $\mathrm{Ag}-\mathrm{CeO}_{2}$ interfacial interaction. Catal. Today 2018, in press. [CrossRef]

66. Grabchenko, M.V.; Mamontov, G.V.; Zaikovskii, V.I.; Vodyankina, O.V. Effect of the metal-Support interaction in $\mathrm{Ag} / \mathrm{CeO}_{2}$ catalysts on their activity in ethanol oxidation. Kinet. Catal. 2017, 58, 642-648. [CrossRef]

67. Rodrigues, C.P.; Zonetti, P.C.; Silva, C.G.; Gaspar, A.B.; Appel, L.G. Chemicals from ethanol-The acetone one-pot synthesis. Appl. Catal. A 2013, 458, 111-118. [CrossRef]

68. De Lima, A.F.F.; Zonetti, P.C.; Rodrigues, C.P.; Appel, L.G. The first step of the propylene generation from renewable raw material: Acetone from ethanol employing $\mathrm{CeO}_{2}$ doped by Ag. Catal. Today 2017, 279, $252-259$. [CrossRef]

69. Yamamoto, R.; Sawayama, Y.; Shibahara, H.; Ichihashi, Y.; Nishiyam, S.; Tsuruy, S. Promoted partial oxidation activity of supported Ag catalysts in the gas-phase catalytic oxidation of benzyl alcohol. J. Catal. 2005, 234, 308-317. [CrossRef]

70. Jia, L.; Zhang, S.; Gu, F.; Ping, Y.; Guo, X.; Zhong, Z.; Su, F. Highly selective gas-phase oxidation of benzyl alcohol to benzaldehyde over silver-containing hexagonal mesoporous silica. Microporous Mesoporous Mater. 2012, 149, 158-165. [CrossRef]

71. Ma, L.; Jia, L.; Guo, X.; Xiang, L. Catalytic activity of Ag/SBA-15 for low-temperature gas-phase selective oxidation of benzyl alcohol to benzaldehyde. Chin. J. Catal. 2014, 35, 108-119. [CrossRef]

72. Mao, J.; Deng, M.; Xue, Q.; Chen, L.; Lu, Y. Thin-sheet Ag/Ni-fiber catalyst for gas-phase selective oxidation of benzyl alcohol with molecular oxygen. Catal. Commun. 2009, 10, 1376-1379. [CrossRef]

73. Deng, M.; Zhao, G.; Xue, Q.; Chen, L.; Lu, Y. Microfibrous-structured silver catalyst for low-temperature gas-phase selective oxidation of benzyl alcohol. Appl. Catal. B 2010, 99, 222-228. [CrossRef]

74. Zhao, L.; Kong, L.; Liu, C.; Wang, Y.; Dai, L. AgCu/SiC-powder: A highly stable and active catalyst for gas-phase selective oxidation of alcohols. Catal. Commun. 2017, 98, 1-4. [CrossRef]

75. Liu, K.; Qin, T.; Sun, Y.; Hou, C.; Cao, X.; Jiang, S. Synergistic effect between Ag and $\mathrm{Mn}_{3} \mathrm{O}_{4}$ in the gas phase oxidation of alcohols. Catal. Commun. 2018, 113, 15-18. [CrossRef] 
76. Sawayama, Y.; Shibahara, H.; Ichihashi, Y.; Nishiyama, S.; Tsuruya, S. Promoting Effect and Role of Alkaline Earth Metal Added to Supported Ag Catalysts in the Gas-Phase Catalytic Oxidation of Benzyl Alcohol. Ind. Eng. Chem. Res. 2006, 45, 8837-8845. [CrossRef]

77. Nguyen, T.T.N.; Huchede, M.; Blanco, E.; Morfin, F.; Rousset, J.L.; Massin, L.; Aouine, M.; Bellière-Baca, V.; Millet, J.M.M. An attempt to improve Ag-based catalysts for allyl alcohol oxidative dehydrogenation to acrolein. Appl. Catal. A 2018, 549, 170-178. [CrossRef]

78. Yue, H.; Zhao, Y.; Ma, X.; Gong, J. Ethylene glycol: Properties, synthesis, and applications. Chem. Soc. Rev. 2012, 41, 4218-4244. [CrossRef] [PubMed]

79. Vodyankina, O.V.; Kurina, L.N.; Boronin, A.I.; Salanov, A.N. Glyoxal Synthesis by Vapour-Phase Ethylene Glycol Oxidation on a Silver and Copper Catalysts. Stud. Surf. Sci. Catal. B 2000, 130, 1775-1780. [CrossRef]

80. Xu, H.; Yin, G.; Deng, Z.; Yan, H.; Qin, F.; Shen, W. Method for Synthesizing Low-Impurity Content Glyoxal through Gas Phase Oxidation. Patent CN103,772,169A, 27 May 2015.

81. Vodyankina, O.V.; Koscheev, S.V.; Yakushko, V.T.; Salanov, A.N.; Boronin, A.I.; Kurina, L.N. Physicochemical investigation of the copper and silver catalysts of the ethylene glycol oxidation. J. Mol. Catal. A Chem. 2000, 158, 381-387. [CrossRef]

82. Gallezot, P.; Tretjak, S.; Christidis, Y.; Mattioda, G.; Schouteenten, A. Oxidative dehydrogenation of ethylene glycol into glyoxal: Effect of diethylphosphite on SiC-supported silver catalysts. J. Catal. 1993, 142, 729-734. [CrossRef]

83. Deng, J.F.; Wang, J.; Xu, X. Oxidative dehydrogenation of glycol to glyoxal on a P-modified electrolytic silver catalyst. Catal. Lett. 1996, 36, 207-214. [CrossRef]

84. Magaev, O.V.; Knyazev, A.S.; Vodyankina, O.V.; Dorofeeva, N.V.; Salanov, A.N.; Boronin, A.I. Active surface formation and catalytic activity of phosphorous-promoted electrolytic silver in the selective oxidation of ethylene glycol to glyoxal. Appl. Catal. A 2008, 344, 142-149. [CrossRef]

85. Method for Continuous Industrial Production of Glyoxal. RU2,599,247 (C1), 2016.

86. Salaev, M.A.; Krejker, A.A.; Magaev, O.V.; Malkov, V.S.; Knyazev, A.S.; Borisova, E.S.; Khanaev, V.M.; Vodyankina, O.V.; Kurina, L.N. Ethylene glycol oxidation over supported catalyst in tubular reactor. Chem. Eng. J. 2011, 172, 399-409. [CrossRef]

87. Mamontov, G.V.; Magaev, O.V.; Knyazev, A.S.; Vodyankina, O.V. Influence of phosphate addition on activity of $\mathrm{Ag}$ and $\mathrm{Cu}$ catalysts for partial oxidation of alcohols. Catal. Today 2013, 203, 122-126. [CrossRef]

88. Mamontov, G.V.; Knyazev, A.S.; Paukshtis, E.A.; Vodyankina, O.V. Adsorption and conversion of ethylene glycol on the surface of Ag-containing catalyst modified with phosphate. Kinet. Catal. 2013, 54, 735-743. [CrossRef]

89. Knyazev, A.S.; Magaev, O.V.; Krejker, A.A.; Mamontov, G.V.; Knyazeva, E.M.; Dahnavi, E.M.; Vodyankina, O.V. Self-Organized nanostructured $\mathrm{Ag} / \mathrm{P}_{2} \mathrm{O}_{5} / \mathrm{SiO}_{2}$ material as a catalyst for high-temperature selective oxidation of alcohols. Key Eng. Mater. 2015, 670, 126-132. [CrossRef]

90. Mamontov, G.V.; Izaak, T.I.; Magaev, O.V.; Knyazev, A.S.; Vodyankina, O.V. Reversible Oxidation/Reduction of Silver Supported on Silica Aerogel: Influence of the Addition of Phosphate. Russ. J. Phys. Chem. A 2011, 85, 1540-1545. [CrossRef]

91. Epiphanova, A.; Magaev, O.; Vodyankina, O. Formation and characterization of phosphate-modified silicate materials derived from sol-gel process. J. Sol-Gel Sci. Technol. 2012, 61, 509-517. [CrossRef]

92. Dorofeeva, N.V.; Vodyankina, O.V.; Pavlova, O.S.; Mamontov, G.V. Synthesis of mixed zirconium-silver phosphates and formation of active catalyst surface for the ethylene glycol oxidation process. Stud. Surf. Sci. Catal. 2010, 175, 759-762. [CrossRef]

93. Dorofeeva, N.V.; Vodyankina, O.V.; Sobolev, V.I.; Koltunov, K.Y.; Zaykovskii, V.I. Main routes of ethanol conversion under aerobic/anaerobic conditions over Ag-containing zirconium phosphate catalyst. Curr. Org. Synth. 2017, 14, 389-393. [CrossRef]

94. Brik, Y.; Kacimi, M.; Bozon-Verduraz, F.; Ziyad, M. Characterization of active sites on $\mathrm{AgHf}_{2}\left(\mathrm{PO}_{4}\right)_{3}$ inbutan-2-ol conversion. Microporous Mesoporous Mater. 2001, 43, 103-112. [CrossRef]

95. Arsalane, S.; Ziyad, M.; Coudurier, G.; Védrine, J.C. Silver-cluster formation on $\mathrm{AgZr}_{2}\left(\mathrm{PO}_{4}\right)_{3}$ and catalytic decomposition of butan-2-ol. J. Catal. 1996, 159, 162-169. [CrossRef]

96. Salaev, M.A.; Poleshchuk, O.K.; Vodyankina, O.V. Ethylene glycol oxidation over Ag-containing catalysts: A theoretical study. J. Mol. Catal. A Chem. 2015, 396, 61-67. [CrossRef] 
97. Capote, A.J.; Madix, R.J. O-H and C-H Bond Activation in Ethylene Glycol by Atomic Oxygen on Ag(110): Heterometallacycle Formation and Selective Dehydrogenation to Glyoxal. J. Am. Chem. Soc. 1989, 111, 3570-3577. [CrossRef]

98. Feng, Y.; Yin, H.; Wang, A.; Xue, W. Selectively catalytic oxidation of 1,2-propanediol to lactic, formic, and acetic acids over Ag nanoparticles under mild reaction conditions. J. Catal. 2015, 326, 26-37. [CrossRef]

99. Salaev, M.A.; Poleshchuk, O.K.; Vodyankina, O.V. Propylene glycol oxidation over silver catalysts: A theoretical study. J. Mol. Catal. A Chem. 2016, 417, 36-42. [CrossRef]

100. Xue, W.; Yin, H.; Lu, Z.; Feng, Y.; Wang, A.; Liu, S.; Shen, L.; Jia, X. Catalytic Oxidation of 1,2-Propanediol over Bimetallic Cu@Au Core/Shell Nanoparticles. Catal. Lett. 2016, 146, 1139-1152. [CrossRef]

101. Griffin, M.B.; Rodriguez, A.A.; Montemore, M.M.; Monnier, J.R.; Williams, C.T.; Will Medlin, J. The selective oxidation of ethylene glycol and 1,2-propanediol on Au, Pd, and Au-Pd bimetallic catalysts. J. Catal. 2013, 307, 111-120. [CrossRef]

102. Ebert, D.Y.; Dorofeeva, N.V.; Savel'eva, A.S.; Kharlamova, T.S.; Salaev, M.A.; Svetlichnyi, V.A.; Magaev, O.V.; Vodyankina, O.V. Silica-supported Fe-Mo-O catalysts for selective oxidation of propylene glycol. Catal. Today 2018, in press. [CrossRef]

103. Ebert, D.Y.; Savel'eva, A.S.; Dorofeeva, N.V.; Vodyankina, O.V. $\mathrm{FePO}_{4} / \mathrm{SiO}_{2}$ Catalysts for Propylene Glycol Oxidation. Kinet. Catal. 2017, 58, 720-725. [CrossRef]

104. Shen, J.; Shan, W.; Zhang, Y.; Du, J.; Xu, H.; Fan, K.; Shen, W.; Tang, Y. A novel catalyst with high activity for polyhydric alcohol oxidation: Nanosilver/zeolite film. Chem. Commun. 2004, 2880-2881. [CrossRef] [PubMed]

105. Shen, J.; Shan, W.; Zhang, Y.; Du, J.; Xu, H.; Fan, K.; Shen, W.; Tang, Y. Gas-phase selective oxidation of alcohols: In situ electrolytic nano-silver/zeolite film/copper grid catalyst. J. Catal. 2006, 237, 94-101. [CrossRef]

106. Mao, J.; Deng, M.; Chen, L.; Liu, Y.; Lu, Y. Novel Microfibrous-Structured Silver Catalyst for High Efficiency Gas-Phase Oxidation of Alcohols. AIChE J. 2010, 56, 1545-1556. [CrossRef]

107. Shen, J.; Du, J.-M.; Huang, J.-J.; Yang, X.-Y.; Shen, W.; Xu, H.-L.; Fan, K.-N. Gas-phase selective oxidation of 1, 2-propylene glycol over Ag/ $\mathrm{ZrO}_{2}$ catalyst. Acta Chim. Sin. 2007, 65, 403-408.

108. Yang, F.; Jing, X.; Huang, J.; Sun, D.; Li, Q. Microwave-Assisted Biosynthesis of $\mathrm{Ag} / \mathrm{ZrO}_{2}$ Catalyst with Excellent Activity toward Selective Oxidation of 1,2-Propanediol. Ind. Eng. Chem. Res. 2015, 54, 5373-5380. [CrossRef]

109. Pagliaro, M.; Ciriminna, R.; Kimura, H.; Rossi, M.; Della Pina, C. From Glycerol to Value-Added Products. Angew. Chem. Int. Ed. 2007, 46, 4434-4440. [CrossRef] [PubMed]

110. Dodekatos, G.; Schünemann, S.; Tüysüz, H. Recent Advances in Thermo-, Photo-, and Electrocatalytic Glycerol Oxidation. ACS Catal. 2018, 8, 6301-6333. [CrossRef]

111. Lari, G.M.; Mondelli, C.; Pérez-Ramírez, J. Gas-Phase Oxidation of Glycerol to Dihydroxyacetone over Tailored Iron Zeolites. ACS Catal. 2015, 5, 1453-1461. [CrossRef]

112. Zhang, J.; Sun, M.; Han, Y. Selective oxidation of glycerol to formic acid in highly concentrated aqueous solutions with molecular oxygen using V-substituted phosphomolybdic acids. RSC Adv. 2014, 4, 35463-35466. [CrossRef]

113. Lari, G.M.; García-Muelas, R.; Mondelli, C.; López, N.; Pérez-Ramírez, J. Glycerol oxidehydration to pyruvaldehyde over silver-based catalysts for improved lactic acid production. Green Chem. 2016, 18, 4682-4692. [CrossRef]

114. Sheldon, R.A.; Wallau, M.; Arends, I.W.C.E.; Schuchardt, U. Heterogeneous catalysts for liquid-phase oxidations: Philosophers' stones or Trojan Horses? Acc. Chem. Res. 1998, 31, 485-493. [CrossRef]

115. Cortes Corberan, V.; Gonzalez-Perez, M.E.; Martinez-Gonzalez, S.; Gomez-Aviles, A. Green oxidation of fatty alcohols: Challenges and opportunities. Appl. Catal. A 2014, 474, 211-223. [CrossRef]

116. Mallat, T.; Baiker, A. Oxidation of alcohols with molecular oxygen on platinum metal catalysts in aqueous solutions. Catal. Today 1994, 19, 247-283. [CrossRef]

117. Kolobova, E.N.; Pestryakov, A.N.; Bogdanchikova, N.; Cortés Corberán, V. Silver catalysts for liquid-phase oxidation of alcohols in green chemistry: Challenges and outlook. Catal. Today 2018, in press. [CrossRef]

118. Yang, Z.; Li, J.; Yang, X.; Xie, X.; Wu, Y. Gas-phase oxidation of alcohols over silver: The extension of catalytic cycles of oxidation of alcohols in liquid-phase. J. Mol. Catal. A 2005, 241, 15-22. [CrossRef] 
119. Beier, M.J.; Hansen, T.W.; Grunwaldt, J.-D. Selective liquid-phase oxidation of alcohols catalyzed by a silver-based catalyst promoted by the presence of ceria. J. Catal. 2009, 266, 320-330. [CrossRef]

120. Olenin, A.Y.; Mingalev, P.G.; Lisichkin, G.V. Partial Catalytic Oxidation of Alcohols: Catalysts Based on Metals and Metal Coordination Compounds (a Review). Pet. Chem. 2018, 58, 577-592. [CrossRef]

121. Park, Y.; Na, Y.; Pradhan, D.; Sohn, Y. Liquid-phase ethanol oxidation and gas-phase CO oxidation reactions over $\mathrm{M}$ doped $\left(\mathrm{M}=\mathrm{Ag}, \mathrm{Au}, \mathrm{Pd}\right.$, and $\mathrm{Ni}$ ) and $\mathrm{MM}^{\prime}$ codoped $\mathrm{CeO}_{2}$ nanoparticles. J. Chem. 2016, 2176576. [CrossRef]

122. Liotta, L.F.; Venezia, A.M.; Deganello, G.; Longo, A.; Martorana, A.; Schay, Z.; Guczi, L. Liquid phase selective oxidation of benzyl alcohol over Pd-Ag catalysts supported on pumice. Catal. Today 2011, 66, 271-276. [CrossRef]

123. Huang, X.; Wang, X.; Wang, X.; Wang, X.; Tan, M.; Ding, W.; Lu, X. P123-stabilized Au-Ag alloy nanoparticles for kinetics of aerobic oxidation of benzyl alcohol in aqueous solution. J. Catal. 2013, 301, 217-226. [CrossRef]

124. Huang, X.; Wang, X.; Tan, M.; Zou, X.; Ding, W.; Lu, X. Selective oxidation of alcohols on P123-stabilized $\mathrm{Au}-\mathrm{Ag}$ Alloy nanoparticles in aqueous solution with molecular oxygen. Appl. Catal. A 2013, 467, 407-413. [CrossRef]

125. Zahed, B.; Hosseini-Monfared, H. A comparative study of silver-graphene oxide nanocomposites as a recyclable catalyst for the aerobic oxidation of benzyl alcohol: Support effect. Appl. Surf. Sci. 2015, 328, 536-547. [CrossRef]

126. Adil, S.F.; Assal, M.E.; Khan, M.; Al-Warthan, A.; Rafiq, H.; Siddiqui, M. Nano silver-doped manganese oxide as catalyst for oxidation of benzyl alcohol and its derivatives: Synthesis, characterization, thermal study and evaluation of catalytic properties. Oxid. Commun. 2013, 36, 778-791.

127. Alabbad, S.; Adil, S.F.; Assal, M.E.; Khan, M.; Alwarthan, A.; Siddiqui, M.R.H. Gold \& silver nanoparticles supported on manganese oxide: Synthesis, characterization and catalytic studies for selective oxidation of benzyl alcohol. Arab. J. Chem. 2014, 7, 1192-1198. [CrossRef]

128. Assal, M.E.; Shaik, M.R.; Kuniyil, M.; Khan, M.; Al-Warthan, A.; Alharthi, A.I.; Varala, R.; Siddiqui, M.R.H.; Adil, S.F. $\mathrm{Ag}_{2} \mathrm{O}$ nanoparticles $/ \mathrm{MnCO}_{3},-\mathrm{MnO}_{2}$ or $-\mathrm{Mn}_{2} \mathrm{O}_{3} /$ highly reduced graphene oxide composites as an efficient and recyclable oxidation catalyst. Arab. J. Chem. 2018, in press. [CrossRef]

129. Assal, M.E.; Shaik, M.R.; Kuniyil, M.; Khan, M.; Al-Warthan, A.; Siddiqui, M.R.H.; Adil, S.F. Ag $2 \mathrm{O}$ nanoparticles-doped manganese immobilized on graphene nanocomposites for aeral oxidation of secondary alcohols. Metals 2018, 8, 468. [CrossRef]

130. Mitsudome, T.; Mikami, Y.; Funai, H.; Mizugaki, T.; Jitsukawa, K.; Kaneda, K. Oxidant-free alcohol dehydrogenation using a reusable hydrolactite-supported silver nanoparticle catalyst. Angew. Chem. Int. Ed. 2008, 120, 140-147. [CrossRef]

131. Bayat, A.; Shakourian-Fard, M.; Ehyaei, N.; Hashemi, M.M. Silver nanoparticles supported on silica-coated ferrite as magnetically and reusable catalyst for oxidant-free alcohol dehydrogenation. RSC Adv. 2015, 5, 22503-22509. [CrossRef]

132. Qi, G.; Zhang, W.; Dai, Y. Selective catalysis for synthesis of benzaldehyde by magnetic $\mathrm{Ag} / \mathrm{Fe}_{2} \mathrm{O}_{3}$. Asian J. Chem. 2014, 26, 6383-6386. [CrossRef]

133. Bhuyan, B.; Paul, A.; Devi, M.; Dhar, S.S. A silver NP-dispersed water extract of fly ash as a green and efficient medium for oxidant-free dehydrogenation of benzyl alcohols. RSC Adv. 2018, 8, 1313-1319. [CrossRef]

134. Yadav, G.D.; Yadav, A.K. Selective liquid phase oxidation of secondary alcohols into ketones by tert-butyl hydroperoxide on nano-fibrous Ag-OMS-2 catalyst. J. Mol. Catal. A Chem. 2013, 380, 70-77. [CrossRef]

135. Shojaei, A.F.; Tabatabaeian, K.; Zanjanchi, M.A.; Moafi, H.F.; Modirpanah, N. Synthesis, characterization and study of catalytic activity of silver doped $\mathrm{ZnO}$ nanocomposite as an efficient catalyst for selective oxidation of benzyl alcohol. J. Chem. Sci. 2015, 127, 481-491. [CrossRef]

136. Kolobova, E.; Kotolevich, Y.; Pakrieva, E.; Mamontov, G.; Farias, M.H.; Cortés Corberán, V.; Bogdanchikova, N.; Hemming, J.; Smeds, A.; Mäki-Arvela, P.; et al. Modified Ag/ $\mathrm{TiO}_{2}$ systems: Promising catalysts for liquid-phase oxidation of alcohols. Fuel 2018, 234, 110-119. [CrossRef]

137. Nagaraiju, P.; Balaraju, M.; Mohan Reddy, K.; Sai Prasad, P.S.; Lingaiah, N. Selective oxidation of allylic alcohols catalyzed by silver exchanged molybdovanado phosphoric acid catalyst in the presence of molecular oxygen. Catal. Commun. 2008, 9, 1389-1393. [CrossRef] 
138. Torbina, V.V.; Ivanchikova, I.D.; Kholdeeva, O.A.; Skobelev, I.Y.; Vodyankina, O.V. Propylene glycol oxidation with tert-butyl hydroperoxide over Cr-containing metal-organic frameworks MIL-101 and MIL-100. Catal. Today 2016, 278, 97-103. [CrossRef]

139. Xue, W.; Feng, Y.; Yin, H.; Liu, S.; Wang, A.; Shen, L. Catalytic Oxidation of 1,2-Propanediol to Lactic Acid with $\mathrm{O}_{2}$ Under Atmospheric Pressure Over Pd-Ag Bimetallic Nanoparticles and Reaction Kinetics. J. Nanosci. Nanotechnol. 2016, 16, 9621-9633. [CrossRef]

140. Feng, Y.; Xue, W.; Yin, H.; Meng, M.; Wang, A.; Liu, S. Selective oxidation of 1,2-propanediol to lactic acid catalyzed by hydroxyapatite-supported Pd and Pd-Ag nanoparticles. RSC Adv. 2015, 5, 106918-106929. [CrossRef]

141. Albuquerque, E.M.; Borges, L.E.P.; Fraga, M.A. Lactic acid production from aqueous-phase selective oxidation of hydroxyacetone. J. Mol. Catal. A Chem. 2015, 400, 64-70. [CrossRef]

142. Song, F. Zh.; Zhu, Q.L.; Yang, X.; Zhan, W.W.; Pachfule, P.; Tsumori, N.; Xu, Q. Metal-Organic Framework Templated Porous Carbon-Metal Oxide/Reduced Graphene Oxide as Superior Support of Bimetallic Nanoparticles for Efficient Hydrogen Generation from Formic Acid. Adv. Energy Mater. 2017, 1701416. [CrossRef]

143. Liu, H.; Liu, X.; Yu, Y.; Yang, W.; Li, J.; Feng, M.; Li, H. Bifunctional Networked Ag/AgPd Core/Shell Nanowires for Highly Efficient Dehydrogenation of Formic Acid and Subsequent Reduction of Nitrate and Nitrite in Water. J. Mater. Chem. A 2018, 6, 4611-4616. [CrossRef]

144. Bozell, J.; Petersen, G.R. Technology development for the production of biobased products from biorefinery carbohydrates-The US department of Energy's "Top 10" revisited. Green Chem. 2010, 12, 539-554. [CrossRef]

145. Crottia, C.; Farnetti, E. Selective oxidation of glycerol catalyzed by iron complexes. J. Mol. Catal. A 2015, 396, 353-359. [CrossRef]

146. Hirasawa, S.; Nakagawa, Y.; Tomishige, K. Selective oxidation of glycerol to dihydroxyacetone over Pd-Ag catalyst. Catal. Sci. Technol. 2012, 2, 1150-1152. [CrossRef]

147. Hirasawa, S.; Watanabe, H.; Tokushi, K.; Nakagawa, Y.; Tomishige, K. Performance, structure and mechanism of Pd-Ag alloy catalyst for selective oxidation of glycerol to dihydroxyacetone. J. Catal. 2013, 300, 205-216. [CrossRef]

148. Skrzyńska, E.; Zaid, S.; Girardon, J.-S.; Capron, M.; Dumeignil, F. Catalytic behavior of four different supported noble metals in the crude glycerol oxidation. Appl. Catal. A 2015, 499, 89-100. [CrossRef]

149. Skrzyńska, E.; Zaid, S.; Addad, A.; Girardon, J.-S.; Capron, M.; Dumeignil, F. Performance of $\mathrm{Ag} / \mathrm{Al}_{2} \mathrm{O}_{3}$ catalysts in the liquid phase oxidation of glycerol-Effect of preparation method and reaction conditions. Catal. Sci. Technol. 2016, 6, 3182-3196. [CrossRef]

150. Skrzyńska, E.; Ftouni, J.; Girardon, J.-S.; Capron, M.; Jalowiecki-Duhamel, L.; Paul, J.-F.; Dumeignil, F. Quasi-homogeneous oxidation of glycerol by unsupported gold nanoparticles in the liquid phase. ChemSusChem 2012, 5, 2065-2078. [CrossRef] [PubMed]

151. Zaid, E.; Skrzyńska, E.; Addad, A.; Nandi, S.; Jalowiecki-Duhamel, L.; Girardon, J.-S.; Capron, M.; Dumeignil, F. Development of Silver Based Catalysts Promoted by Noble Metal M ( $\mathrm{M}=\mathrm{Au}, \mathrm{Pd}$ or Pt) for Glycerol Oxidation in Liquid Phase. Top Catal. 2017, 60, 1072-1081. [CrossRef]

152. Besson, M.; Gallezot, P. Selective oxidation of alcohols and aldehydes on metal catalysts. Catal. Today 2000, 57, 127-141. [CrossRef]

153. Diaz, J.A.; Skrzyńska, E.; Zaid, S.; Girardon, J.-S.; Capron, M.; Dumeignil, F.; Fongarland, P. Kinetic modeling of the glycerol oxidation in the liquid phase: Comparison of $\mathrm{Pt}, \mathrm{Au}$ and $\mathrm{Ag}$ as active phases. J. Chem. Technol. Biotechnol. 2017, 92, 2267-2275. [CrossRef]

154. Zope, B.N.; Hibbitts, D.D.; Neurock, M.; Davis, R.J. Reactivity of the gold/water interface during selective oxidation catalysis. Science 2007, 44, 307-317. [CrossRef] [PubMed]

155. Tao, M.; Zhang, D.; Guan, H.; Huang, G.; Wang, X. Designation of highly efficient catalysts for one pot conversion of glycerol to lactic acid. Sci. Rep. 2016, 6, 29840. [CrossRef] [PubMed]

156. Kaskow, I.; Decyk, P.; Sobczak, I. The effect of copper and silver on the properties of Au-ZnO catalysts and its activity in glycerol oxidation. Appl. Surf. Sci. 2018, 444, 197-207. [CrossRef]

157. Tamiolakis, I.; Lykakis, I.; Armatas, S. Mesoporous CdS-sensitized $\mathrm{TiO}_{2}$ nanoparticle assemblies with enhanced photocatalytic properties: Selective aerobic oxidation of benzyl alcohols. Catal. Today 2015, 250, 180-186. [CrossRef] 


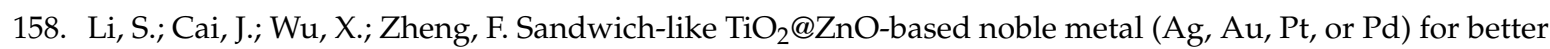
photo-oxidation performance: Synergistic effect between noble metal and metal oxide phases. Appl. Surf. Sci. 2018, 443, 603-612. [CrossRef]

159. Safaei, I.; Mohebbi, S.; Irani, M. Selective aerobic photocatalytic oxidation of benzyl alcohol over spherical structured $\mathrm{WO}_{3} / \mathrm{TiO}_{2}$ nanocomposite under visible light irradiation. J. Sol-Gel. Sci. Technol. 2018, 87, 170-182. [CrossRef]

160. Li, S.; Cai, J.; Wu, X.; Liu, B.; Chen, Q.; Li, Y.; Zheng, F. TiO $\mathrm{O}_{2} @ \mathrm{Pt} @ \mathrm{CeO}_{2}$ nanocomposite as a bifunctional catalyst for enhancing photo-reduction of $\mathrm{Cr}(\mathrm{VI})$ and photo-oxidation of benzyl alcohol. J. Hazard. Mater. 2018, 346, 52-61. [CrossRef] [PubMed]

161. Magdziarz, A.; Colmenares, J.C.; Chernyayeva, O.; Lisovytskiy, D.; Grzonka, J.; Kurzydłowski, K.; Freindl, K.; Korecki, J. Insight into the synthesis procedure of $\mathrm{Fe}^{3+} / \mathrm{TiO}_{2}$-based photocatalyst applied in the selective photo-oxidation of benzyl alcohol under sun-imitating lamp. Ultrason. Sonochem. 2017, 38, 189-196. [CrossRef] [PubMed]

162. Amadelli, R.; Samiolo, L.; Maldotti, A.; Molinari, A.; Gazzoli, D. Selective Photooxidation and Photoreduction Processes at Surface-Modified by Grafted Vanadyl. Int. J. Photoenergy 2011, 1-10. [CrossRef]

163. Yurdakal, S.; Tek, B.S.; Değirmenci, Ç.; Palmisano, G. Selective photocatalytic oxidation of aromatic alcohols in solar-irradiated aqueous suspensions of $\mathrm{Pt}, \mathrm{Au}, \mathrm{Pd}$ and $\mathrm{Ag}$ loaded $\mathrm{TiO}_{2}$ catalysts. Catal. Today 2017, 281, 53-59. [CrossRef]

164. Si, J.; Liu, Y.; Chang, S.; Wu, D.; Tian, B.; Zhang, J. AgBr@TiO 2 /GO ternary composites with enhanced photocatalytic activity for oxidation of benzyl alcohol to benzaldehyde. Res. Chem. Intermed. 2016, 43, 2067-2080. [CrossRef]

165. Zhang, P.; Wu, P.; Bao, S.; Wang, Z.; Tian, B.; Zhang, J. Synthesis of sandwich-structured AgBr@Ag@TiO 2 composite photocatalyst and study of its photocatalytic performance for the oxidation of benzyl alcohols to benzaldehydes. Chem. Eng. J. 2016, 306, 1151-1161. [CrossRef]

166. Chen, Y.; Li, W.; Wang, J.; Yang, Q.; Hou, Q.; Ju, M. Gold nanoparticles-modified $\mathrm{TiO}_{2} / \mathrm{SBA}^{-15}$ nanocomposites as active plasmonic photocatalysts for the selective oxidation of aromatic alcohols. RSC Adv. 2016, 6, 70352-70363. [CrossRef]

167. Feng, W.; Wu, G.; Li, L.; Guan, N. Solvent-free selective photocatalytic oxidation of benzyl alcohol over modified $\mathrm{TiO}_{2}$. Green Chem. 2011, 13, 3265-3272. [CrossRef]

168. Yu, J.; Li, J.; Wei, H.; Zheng, J.; Su, H.; Wang, X. Hydrotalcite-supported gold catalysts for a selective aerobic oxidation of benzyl alcohol driven by visible light. J. Mol. Catal. A 2014, 395, 128-136. [CrossRef]

169. Chassé, M.; Hallett-Tapley, G.L. Gold nanoparticle-functionalized niobium oxide perovskites as photocatalysts for visible light-induced aromatic alcohol oxidations. Can. J. Chem. 2018, 96, 664-671. [CrossRef]

170. Zhang, X.; Ke, X.; Zhu, H. Zeolite-Supported Gold Nanoparticles for Selective Photooxidation of Aromatic Alcohols under Visible-Light Irradiation. Chem. Eur. J. 2012, 18, 8048-8056. [CrossRef] [PubMed]

171. Chen, B.; Li, X.; Zheng, R.; Chen, R.; Sun, X. Bimetallic (Au-Cu core)@(Ceria shell) nanotubes for photocatalytic oxidation of benzyl alcohol: Improved reactivity by Cu. J. Mater. Chem. A 2017, 5, 13382-13391. [CrossRef]

172. Qamar, M.; Elsayed, R.B.; Alhooshani, K.R.; Ahmed, M.I.; Bahnemann, D.W. Highly Efficient and Selective Oxidation of Aromatic Alcohols Photocatalyzed by Nanoporous Hierarchical $\mathrm{Pt} / \mathrm{Bi}_{2} \mathrm{WO}_{6}$ in Organic Solvent-Free Environment. ACS Appl. Mater. Interfaces 2015, 7, 1257-1269. [CrossRef] [PubMed]

173. Moriyama, K.; Takemura, M.; Togo, H. Direct and Selective Benzylic Oxidation of Alkylarenes via C-H Abstraction Using Alkali Metal Bromides. Org. Lett. 2012, 14, 2414-2417. [CrossRef] [PubMed]

174. Gazi, S.; Ananthakrishnan, R. Bromodimethylsulfonium bromide as a potential candidate for photocatalytic selective oxidation of benzylic alcohols using oxygen and visible light. RSC Adv. 2012, 2, 7781-7787. [CrossRef]

175. Qamar, M.; Elsayed, R.B.; Alhooshani, K.R.; Ahmed, M.I.; Bahnemann, D.W. Chemoselective and highly efficient conversion of aromatic alcohols into aldehydes photo-catalyzed by $\mathrm{Ag}_{3} \mathrm{PO}_{4}$ in aqueous suspension under simulated sunlight. Catal. Commun. 2015, 58, 34-39. [CrossRef]

176. DePuccio, D.P.; Landry, C.C. Photocatalytic oxidation of methanol using porous $\mathrm{Au} / \mathrm{WO}_{3}$ and visible light. Catal. Sci. Technol. 2016, 6, 7512-7520. [CrossRef] 
177. Han, C.; Yang, X.; Gao, G.; Wang, J.; Lu, H.; Liu, J.; Tong, M.; Liang, X. Selective oxidation of methanol to methyl formate on catalysts of $\mathrm{Au}-\mathrm{Ag}$ alloy nanoparticles supported on titania under UV irradiation. Green Chem. 2014, 16, 3603-3615. [CrossRef]

178. Yang, X.; Zhang, A.; Gao, G.; Han, D.; Han, C.; Wang, J.; Liu, J.; Tong, M. Photocatalytic oxidation of methanol to methyl formate in liquid phase over supported silver catalysts. Catal. Commun. 2014, 43, $192-196$. [CrossRef]

179. El-Roz, M.; Lakiss, L.; Telegeiev, I.; Lebedev, O.I.; Bazin, P.; Vicente, A.; Fernandez, C.; Valtchev, V. High-Visible-Light Photoactivity of Plasma-Promoted Vanadium Clusters on Nanozeolites for Partial Photooxidation of Methanol. ACS Appl. Mater. Interfaces 2017, 9, 17846-17855. [CrossRef] [PubMed]

180. Lüken, A.; Muhler, M.; Strunk, J. On the role of gold nanoparticles in the selective photooxidation of 2-propanol over $\mathrm{Au} / \mathrm{TiO}_{2}$. Phys. Chem. Chem. Phys. 2015, 17, 10391-10397. [CrossRef] [PubMed]

181. Colmenares, J.C.; Magdziarz, A.; Chernyayeva, O.; Lisovytskiy, D.; Kurzydłowski, K.; Grzonka, J. Sonication-Assisted Low-Temperature Routes for the Synthesis of Supported $\mathrm{Fe}-\mathrm{TiO}_{2}$ Econanomaterials: Partial Photooxidation of Glucose and Phenol Aqueous Degradation. ChemCatChem 2013, 5, 2270-2277. [CrossRef]

182. Colmenares, J.C.; Magdziarz, A.; Bielejewska, A. High-value chemicals obtained from selective photo-oxidation of glucose in the presence of nanostructured titanium photocatalysts. Bioresour. Technol. 2011, 102, 11254-11257. [CrossRef] [PubMed]

183. Lombardi, E. Selective Photo-Oxidation of Cellobiose with $\mathrm{TiO}_{2}$-Supported Metal Nanoparticles. Master's Thesis, Università di Bologna, Bologna, Italy, 2013.

184. Colmenares, J.C.; Aramendía, M.A.; Marinas, A.; Marinas, J.M.; Urbano, F.J. Synthesis, characterization and photocatalytic activity of different metal-doped titania systems. Appl. Catal. A 2006, 306, 120-127. [CrossRef]

185. Gupta, N.; Bansal, P.; Pal, B. Metal ion- $\mathrm{TiO}_{2}$ nanocomposites for the selective photooxidation of benzene to phenol and cycloalkanol to cycloalkanone. J. Exp. Nanosci. 2013, 10, 148-160. [CrossRef]

186. Liu, Y.; Jiang, G.; Li, L.; Chen, H.; Huang, Q.; Du, X.; Tong, Z. Electrospun $\mathrm{CeO}_{2} / \mathrm{Ag} @$ carbon nanofiber hybrids for selective oxidation of alcohols. Powder Technol. 2017, 305, 597-601. [CrossRef]

(C) 2018 by the authors. Licensee MDPI, Basel, Switzerland. This article is an open access article distributed under the terms and conditions of the Creative Commons Attribution (CC BY) license (http:/ / creativecommons.org/licenses/by/4.0/). 